\title{
Chapitre XI - Le trafic
}

\section{Maurice Wolkowitsch}

\section{(2) OpenEdition}

\section{Journals}

Édition électronique

URL : https://journals.openedition.org/rhcf/1331

DOI : $10.4000 /$ rhcf.1331

Éditeur

Rails \& histoire

\section{Édition imprimée}

Date de publication : 10 février 2004

Pagination : 362-421

ISBN : 0996-9403

ISSN : 0996-9403

\section{Référence électronique}

Maurice Wolkowitsch, "Chapitre XI - Le trafic », Revue d'histoire des chemins de fer [En ligne], 30 | 2004, mis en ligne le 16 août 2012, consulté le 22 avril 2022. URL : http://journals.openedition.org/rhcf/1331 ; DOI : https://doi.org/10.4000/rhcf.1331 


\section{Chapitre XI}

\section{Le trafic}

T a connaissance du trafic repose sur les statistiques de

L l'évolution du nombre des déplacements et du volume des échanges. Les lignes secondaires, comme les lignes du plan Freycinet mises en service entre 1880 et 1914, exercent, à une autre échelle, une influence analogue à celle des lignes principales des grands réseaux depuis leur développement. Les chemins de fer secondaires étendent dans l'espace les effets de l'emploi de la nouvelle technique : vecteurs du progrès, ils font reculer l'isolement, source d'archaïsme, d'immobilisme, frein à l'évolution des mentalités. L'analyse du trafic ne saurait être seulement l'occasion de définir l'activité des compagnies à travers les statistiques ; au-delà des chiffres, il convient de saisir les réalités des conditions de vie et de l'activité économique des hommes de l'époque dans la France profonde.

A. de Foville a dressé un tableau des effets de la desserte ferroviaire réalisée par la mise en service des lignes principales ; ce tableau de 1880 mériterait d'être complété, un demi-siècle plus tard, par l'analyse des effets d'une pénétration plus poussée du rail à travers le pays ${ }^{1}$. Nous présentons successivement le transport des voyageurs et des marchandises en examinant dans chaque cas les principales composantes du trafic.

\section{Le trafic des voyageurs}

Le transport des voyageurs est assuré par toutes les catégories des chemins de fer secondaires: CFIL, TVM, TVB, TV. Si les CFIL assurent exceptionnellement des transports urbains, les autres y concourent à des titres divers. De nombreuses compagnies de TV disposent de réseaux plus longs que ceux exploités par des compagnies de CFIL ou de TVM. Il n'existe pas de hiérarchie dans le kilométrage exploité en fonction du régime d'exploitation.

Chaque ligne ou chaque réseau se caractérise par l'intensité du trafic qui l'anime; cette notion permet de dresser une typologie des lignes en cherchant à définir les facteurs expliquant la force des oppositions constatées. Les oppositions règnent aussi entre les compagnies ; des types peuvent être trouvés.

1- A. de Foville, La Transformation des moyens de transport et ses conséquences économiques et sociales, Paris, 1880, 460 p. 
Le souci de l'amélioration des conditions de voyage était limité et ne s'identifiait pas à la politique des grands réseaux : la clientèle, dans sa masse, était peu exigeante, d'autant que les parcours étaient brefs. C'est cependant dans certaines villes, où les parcours étaient souvent plus restreints, que la concentration d'une clientèle socialement différenciée pousse au progrès.

La connaissance des voyageurs doit être appréhendée à travers deux démarches : l'analyse de l'offre et de la demande, puis des composantes sociales et professionnelles de la clientèle qui circule dans les " petits trains ».

\section{. CFIL et TVM}

\section{$>$ L'intensité du trafic}

\section{Vues d'ensemble}

Le trafic progresse entre 1901 et 1911 de 415 à 764 millions de voyageurs $/ \mathrm{km}$, soit une augmentation de $84 \%$ (fig. 20). À part une quasi-stagnation entre 1902 et 1903, le mouvement est continu ; le taux de croissance est de $93 \%$ pour les TVM, $78 \%$ pour les CFIL. La courbe du nombre de voyageurs à toutes distances confirme cette analyse (fig. 21) : le trafic passe de 46 millions en 1901 à 79 en 1911², soit une croissance de $73 \%$ inégalement répartie entre les CFIL (59\%) et les TVM ( $96 \%$ ); ces derniers voient croitre leur part dans le trafic total de 37,5 à $42,3 \%$, pourcentage qui dépasse celui de leur réseau. Les TVM s'affirment comme transporteurs de voyageurs. Le nombre de voyageurs $/ \mathrm{km}$ augmentant davantage que celui des voyageurs à toutes distances indique une croissance du parcours moyen du voyageur.

\section{Mesure de l'intensité du trafic}

L'intensité de trafic est très inégale ; elle peut se mesurer pour chaque ligne ou réseau par cet indice : nombre annuel de voyageurs à toutes distances $/ \mathrm{km}$ exploité. Les moyennes ne sont pas identiques en fonction de l'écartement et du statut (tabl. 69). La comparaison avec la situation du trafic des marchandises confirme la position des lignes les plus anciennes comme étant les plus fréquentées, confirme également la suprématie des voies normales sur les voies étroites avec l'exception des TVM ; en effet, l'intensité du trafic des voyageurs dépasse sur leurs lignes les résultats des CFIL 1880 et même des CFIL 1865 à voie étroite. Cette donnée révèle que les TVM et les CFIL n’ont pas des activités

2- Le volume du trafic du métro parisien, 428865625 voyageurs embarqués à toutes distances, et celui des chemins de fer à crémaillère et funiculaires, 10395390 voyageurs dont $80 \%$ à Lyon, ne sont pas pris en compte. 


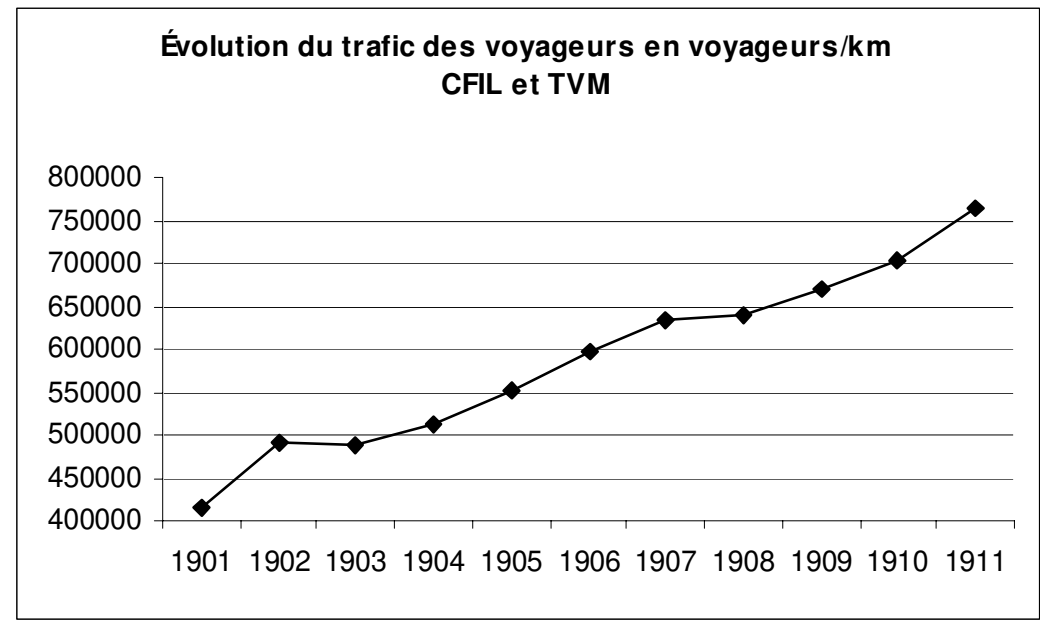

Figure 20. ㅇ M. Wolkowitsch / A.-L. Wolkowitsch, 2003.

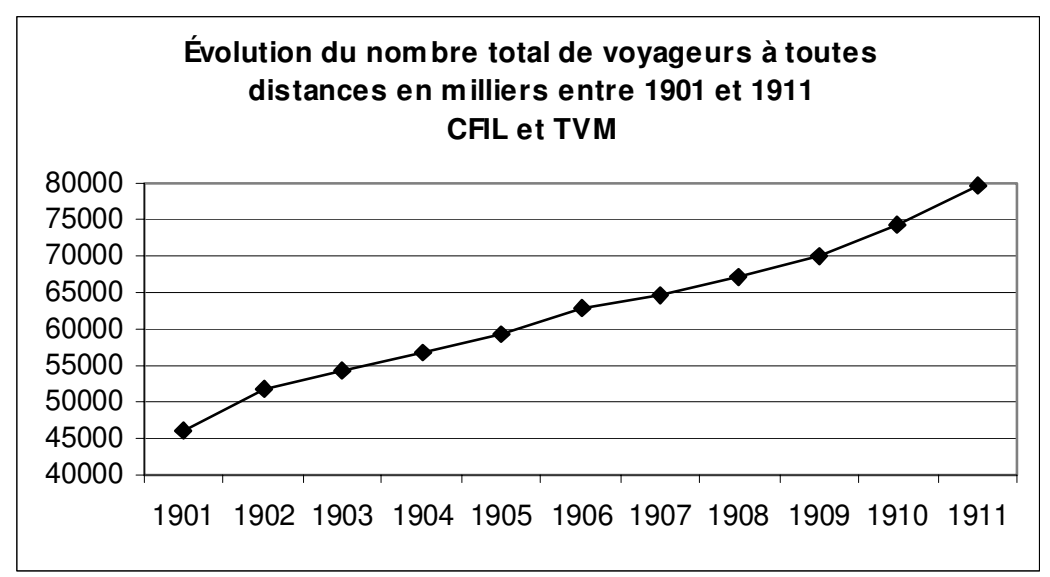

Figure 21. @ M. Wolkowitsch / A.-L. Wolkowitsch, 2003. 
identiques et peut-être même des modes d'exploitation différents. La différence d'intensité du trafic est beaucoup plus marquée pour les marchandises (de 1 à 6) à cause de la faiblesse du tonnage des TVM face aux CFIL 1865 que pour les voyageurs, qui est de l'ordre de 1 à 3 entre les CFIL 1880 à voie étroite et les CFIL 1865 à voie normale.

Tableau 69. Intensité du trafic des voyageurs en fonction du statut et de l'écartement (moyenne)

\begin{tabular}{|c|c|c|c|c|c|}
\hline \multicolumn{2}{|c|}{} & Loi de 1865 & Loi de 1880 & TVB & 260255 \\
\hline \multirow{2}{*}{ CFIL } & N & 7761 & 3505 & TV & $366021^{3}$ \\
\cline { 2 - 6 } & E & 4348 & 2487 & TVM & 5510 \\
\hline
\end{tabular}

Le nombre de lignes ou réseaux dépassant 10000 voyageurs au km exploité est de 31 pour les TVM, de sept pour les CFIL à voie étroite 1880 et quatre pour les CFIL à voie normale 1865. Les pourcentages sont très expressifs (tabl. 70). Plus du tiers des lignes et réseaux de TVM connaissent un trafic de plus de 10000 voyageurs au km exploité contre $11 \%$ aux CFIL à voie étroite 1880 qui ont un même équipement dominant de voie étroite. Trois types de lignes à haute intensité de trafic peuvent être définis : d'abord celles qui circulent en ville et à travers les banlieues, avec des arrêts peu espacés, pour gagner la campagne ( $1^{\text {er }}$ type), puis les lignes reliant une gare à la localité voisine ( $2^{\mathrm{e}}$ type), enfin celles bénéficiant d'une activité touristique ( $3^{\mathrm{e}}$ type) (tabl. 71).

Tableau 70. Pourcentages de ligne ou de réseaux atteignant un nombre donné de voyageurs au kilomètre exploité

\begin{tabular}{|c|c|c|c|c|c|c|c|c|c|c|}
\hline & $<1000$ & $\begin{array}{c}1001 \\
\text { à } \\
2000\end{array}$ & $\begin{array}{c}2001 \\
\stackrel{a}{a} \\
3000\end{array}$ & $\begin{array}{c}3001 \\
\text { à } \\
4000\end{array}$ & $\begin{array}{c}4001 \\
\text { à } \\
5000\end{array}$ & $\begin{array}{c}5001 \\
\text { à } \\
10000\end{array}$ & $\begin{array}{c}10001 \\
\text { à } \\
25000\end{array}$ & $>25001$ \\
\hline \multirow{4}{*}{ CFIL } & $\mathrm{N}$ & \multirow{2}{*}{1865} & 5,3 & 5,3 & 10,6 & 21,2 & 0 & 36,9 & 15,6 & 5,3 \\
\hline & $E$ & & 0 & 0 & 0 & 33,3 & 0 & 66,9 & 0 & 0 \\
\hline & $\mathrm{N}$ & \multirow{2}{*}{1880} & 17,4 & 8,7 & 21,8 & 12,4 & 21,8 & 8,6 & 4,3 & 0 \\
\hline & $E$ & & 4,8 & 19 & 30,6 & 24 & 6,4 & 3,2 & 8 & 3,2 \\
\hline \multicolumn{3}{|c|}{ TVM } & 0 & 12,2 & 24,4 & 6,2 & 10,8 & 9,6 & 20 & 16,8 \\
\hline \multicolumn{3}{|c|}{ Moyenne } & 4,2 & 13,2 & 24,3 & 15,3 & 9,4 & 11 & 13,7 & 8,9 \\
\hline
\end{tabular}

3- Paris et Seine 588 579, province 307815. 
Tableau 71. Nombre total de voyageurs et nombre de voyageurs à toutes distances au kilomètre exploité selon les types de lignes de TVM

\begin{tabular}{|c|c|c|c|c|}
\hline & Ligne & km & Total & $\begin{array}{l}\text { Voyageurs/km } \\
\text { exploité }\end{array}$ \\
\hline \multirow{4}{*}{$1^{\text {er }}$ type $(\mathrm{a})$} & Cherbourg et banlieue & 11 & 1893940 & 171176 \\
\hline & Rodez-gare - hôtel de ville & 2 & 187359 & 92764 \\
\hline & Arpajon à Paris-les-Halles & 40 & 3504946 & 76194 \\
\hline & Réseau de Valenciennes & 66 & 3301735 & 50026 \\
\hline \multirow{3}{*}{$2^{\mathrm{e}}$ type (b) } & $\begin{array}{l}\text { Pont-de-Vaux à Fleurville - } \\
\text { Pont-de-Vaux }\end{array}$ & 5 & 83538 & 16707 \\
\hline & Cassel-ville à Cassel-gare & 4 & 91352 & 22836 \\
\hline & Beaucourt à Beaucourt-Dasle & 4 & 80279 & 20065 \\
\hline \multirow{4}{*}{$3^{e}$ type } & Dinard à Saint-Briac & 9 & 259573 & 28852 \\
\hline & $\begin{array}{l}\text { Avranches au Mont Saint- } \\
\text { Michel }\end{array}$ & 10 & 107540 & 10354 \\
\hline & $\begin{array}{l}\text { TVM de Nice et du littoral } \\
\text { (moyenne) (c) }\end{array}$ & 60 & 1015948 & 16932 \\
\hline & Paramé à Cancale & 17 & 166066 & 9768 \\
\hline \multirow{4}{*}{$\begin{array}{l}\text { Lignes à } \\
\text { faible } \\
\text { fréquentation }\end{array}$} & Levens à Saint-Martin-Vésubie & 34 & 13920 & 1291 \\
\hline & Réseau des Deux-Sèvres & 197 & 278536 & 1413 \\
\hline & Réseau de l'Aude & 327 & 513764 & 1571 \\
\hline & Lons-le-Saunier à Saint-Claude & 142 & 255725 & 1800 \\
\hline
\end{tabular}

(a) Nombreux exemples autour de Bordeaux (14 271 voy.), Tours (38 930), Grenoble (25 053). (b) Avec un trafic moindre, on trouve des liaisons du même type : Saint-Céré à Bretenoux-Biars PO. (c) Moyenne pour les 5 lignes de la compagnie dont le nombre de voyageurs au km exploité varie de 3721 à 31245 .

Aucune ligne de TVM n'enregistre moins de 1000 voyageurs au $\mathrm{km}$ exploité, alors qu'on en compte plusieurs pour l'ensemble des CFIL. Les exploitations qui atteignent seulement entre 1000 et 2000 voyageurs au $\mathrm{km}$ exploité sont souvent des réseaux parcourant des régions rurales centrées sur une modeste préfecture qui n'alimente pas un trafic urbain et périurbain. Pour chacun de ces types, les exemples pourraient être multipliés.

Les CFIL circulent en principe en site propre, même si, au départ d'un terminus, ils n'évitent pas toujours d'utiliser la voirie urbaine sur quelques kilomètres; ils disposent souvent de leur propre gare : les Tramways d'Ille-et-Vilaine en comptent cinq dans Rennes, toutes 
indépendantes de celle de l'État; à Montpellier les chemins de fer de l'Hérault ont leur gare à l'Esplanade : de là, la ligne décrit une large boucle entourant la ville au Sud-Est ; après la bifurcation vers Palavasles-Flots, elle atteint la gare Chaptal et au-delà Rabieux et Béziers ; ce tracé est en grande partie en site propre (fig. 22). Les CFIL, beaucoup moins que les TVM, s'intéressent aux déplacements intra-urbains auxquels répondent dans les deux cas envisagés des réseaux ramifiés de TV.

Un cas exceptionnel de haute fréquentation est fourni par la ligne de Bayonne à Biarritz où se conjuguent un trafic urbain et des mouvements touristiques. À un niveau plus modeste se trouve une ligne dans le Rhône, plusieurs dans les départements de la France septentrionale (Aisne, Pas-de-Calais, Nord). Des lignes traversant des espaces limités animés par une activité industrielle bénéficient de migrations pendulaires : textile et bois dans les Vosges entre Étival et Senones, textile dans les monts du Lyonnais pour des lignes assurant en plus la liaison entre une localité et une gare (Cours ou Thizy et Saint-Victor PLM). Enfin, comme pour les TVM, on constate l'efficacité du fait touristique (tabl. 72).

Tableau 72. Nombre total de voyageurs et nombre de voyageurs à toutes distances au km exploité sur des types de lignes de CFIL

\begin{tabular}{|c|l|c|c|c|}
\hline Statut & \multicolumn{1}{|c|}{ Ligne } & Km & Total & $\begin{array}{c}\text { Voy. km } \\
\text { exploité }\end{array}$ \\
\hline N1865 & Bayonne à Anglet-Biarritz & 8 & 1340617 & 155577 \\
\hline E1880 & Lyon St-Just à Vaugneray et Mornant & 33 & 544434 & 16496 \\
\hline E1880 & Maubeuge à Villers-Sire-Nicole & 12 & 250198 & 20849 \\
\hline E1880 & Chemin de fer du Cambrésis & 85 & 1197772 & 14091 \\
\hline N1865 & Saint-Quentin à Guise & 48 & 578838 & 12059 \\
\hline N1880 & Chemin de fer d'Étival à Senones & 9 & 174907 & 19431 \\
\hline N1865 & Cours à Saint-Victor & 13 & 145120 & 11153 \\
\hline E1880 & $\begin{array}{l}\text { Pierrefitte-Nestalas à Cauterets et Luz- } \\
\text { Saint-Sauveur }\end{array}$ & 26 & 325074 & 12502 \\
\hline E1880 & Toulon à Fréjus (compagnie Sud-France) & 105 & 1046712 & 9968 \\
\hline E1880 & Réseau d'Indre-et-Loire de la CFD & 243 & 460247 & 1894 \\
\hline E1880 & Réseau du Morbihan & 339 & 609322 & 1797 \\
\hline E1880 & Réseau de la Nièvre de la SGCFE & 213 & 352554 & 1655 \\
\hline N1880 & Luxey à Mont-de-Marsan & 48 & 39497 & 817 \\
\hline E1880 & Levier à Andelot & 21 & 17233 & 820 \\
\hline N1865 & La Teste à Cazaux & 13 & 11846 & 911 \\
\hline N1880 & $\begin{array}{l}\text { Société des chemins de fer } \\
\text { économiques des Landes }\end{array}$ & 12 & 8595 & 716 \\
\hline
\end{tabular}




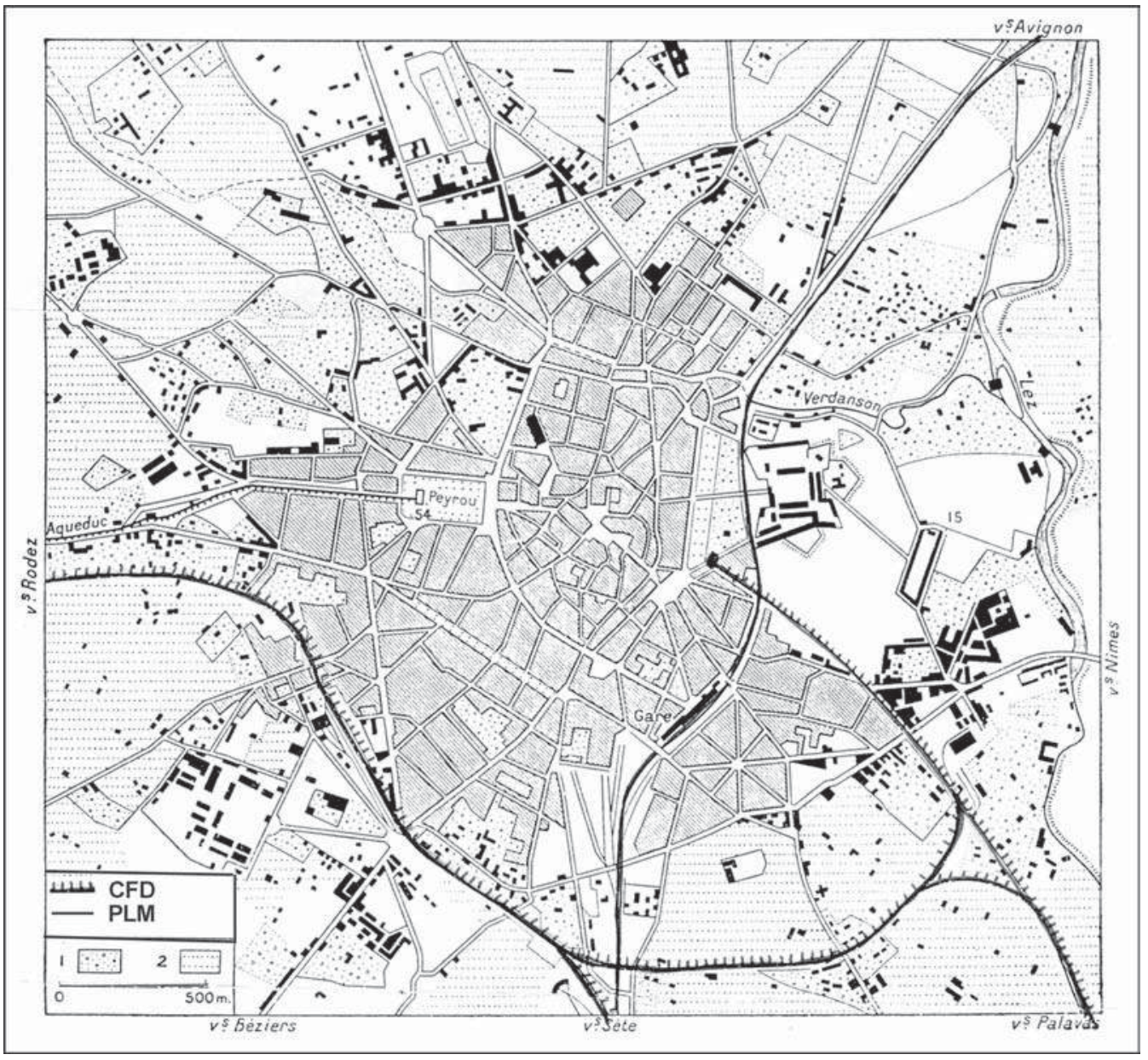

Figure 22. Plan de Montpellier montrant la gare de l'Esplanade des Chemins de fer de l'Hérault et le contournement au Sud et à l'Est en site propre. Albert Demangeon, Géographie universelle, t. 2, fig. 182, Paris, Colin, 1947. 
Les réseaux départementaux ont une fréquentation moyenne (Ardennes, Côtes-du-Nord) ou faibles, il en est de même pour les lignes, en fonction du milieu.

\section{Inégale intensité du trafic et conditions de voyage}

L'intensité du trafic apparaît très variable d'une ligne à l'autre ; le fait est dissimulé pour les longs réseaux départementaux au sein desquels s'opèrent des compensations entre les résultats des lignes. Les meilleurs résultats sont obtenus pour des lignes ne dépassant pas quelques dizaines de kilomètres parcourant un espace favorable : le fait se vérifie au sein de divers éléments de la SGCFE, opposant le réseau de la Nièvre, avec $213 \mathrm{~km}$ et 1655 voyageurs au km exploité, ou la ligne de Valmondois à Marines, avec $22 \mathrm{~km}$ et 9512 voyageurs.

Ces différences dans l'intensité du trafic ne modifient pas sensiblement les conditions dans lesquelles les voyageurs étaient transportés. Les voyages s'effectuaient en majorité dans les trains mixtes marchandises - voyageurs ; la part des trains réservés aux voyageurs était élevée sur les lignes de TVM (56\%), à un moindre degré sur celles des CFIL à voie normale 1865 (43 \%). Sur les bonnes lignes de TVM, les fréquences étaient accrues avec comme corollaire une fréquentation plus faible. Le parcours moyen d'un voyageur s'abaissait en dessous de $9 \mathrm{~km}$ pour les TVM pour atteindre des valeurs plus fortes pour les CFIL (tabl. 73).

Tableau 73. Conditions de transport des voyageurs

\begin{tabular}{|c|c|c|c|c|c|c|}
\hline & \multicolumn{2}{|c|}{$\begin{array}{c}\% \text { Nombre de } \\
\text { trains }\end{array}$} & \multirow{2}{*}{$\begin{array}{c}\% \text { Trains } \\
\text { mixtes sur } \\
\text { total GV }\end{array}$} & \multirow{2}{*}{$\begin{array}{l}\text { Nombre } \\
\text { voyageurs } \\
\text { par train }\end{array}$} & \multirow{2}{*}{$\begin{array}{l}\text { Parcours } \\
\text { moyen d'un } \\
\text { voyageur }\end{array}$} \\
\hline & & $\mathrm{PV}$ & GV & & & \\
\hline \multirow{2}{*}{ CFIL } & N 1865 & 15 & 85 & 57 & 50 & $14,0 \mathrm{~km}$ \\
\hline & E 1865 & 8,6 & 91,4 & 100 & 80 & $10,0 \mathrm{~km}$ \\
\hline \multirow{2}{*}{ CFIL } & N 1880 & 5,3 & 94,7 & 85,5 & 20 & $14,6 \mathrm{~km}$ \\
\hline & E 1880 & 5,9 & 94,1 & 67,3 & 34 & $12,6 \mathrm{~km}$ \\
\hline \multicolumn{2}{|l|}{ TVM } & 5,7 & 94,3 & 43,6 & 27 & $8,9 \mathrm{~km}$ \\
\hline
\end{tabular}

Les grandes compagnies manifestaient un réel souci du confort ; les progrès se transmettaient plus lentement sur les chemins de fer secondaires ; pour le chauffage et l'éclairage les petites compagnies jugeaient que pour de brefs parcours les usagers pouvaient s'accommoder d'équipements surannés. Le pire était sans doute la conception des caisses des voitures, qui imposait une hauteur insuffisante, une place disponible étroite pour chaque voyageur, sans parler de l'espace réduit 
entre les banquettes; pour voyager, mieux valait être petit, mince et doté de courtes jambes, surtout si on était client de la classe inférieure ${ }^{4}$ ! En revanche, les lignes secondaires étaient sûres : en 1911, sur les seules lignes des CFIL, près de $9000 \mathrm{~km}$, on a comptabilisé parmi les voyageurs 11 morts et 41 blessés, dont respectivement 3 et 11 accidents réputés dus à des fautes de l'exploitation, les autres à l'imprudence des voyageurs.

Rappelons que les statistiques sur les accidents signalés sur les derniers services des Messageries à fonctionner sur route vers 1850 donnaient un mort pour 350000 voyageurs, un blessé pour 50000 voyageurs. En 1911, sur les CFIL, le ratio était d'un mort pour quatre millions de voyageurs.

\section{$>$ Trafic quotidien et types de compagnies}

$\mathrm{Si}$ on se place du point de vue des compagnies, et non des lignes ou réseaux, on peut synthétiser les données sur leur trafic en se fondant sur le nombre quotidien de voyageurs à toutes distance qui exprime clairement leur activité.

En dessous de $10 \mathrm{~km}$, le nombre quotidien de voyageurs dépasse rarement 250, il s'abaisse même à 41 pour la Compagnie du chemin de fer d'Aulnoye à Pont-sur-Sambre ; le cas déjà cité de la Société des tramways électriques de Rodez est l'exception. Les compagnies exploitant de 10 à $100 \mathrm{~km}$ transportent en général entre 100 et 350 voyageurs, avec quelques exceptions : 956 voyageurs pour la Compagnie de chemin de fer du Cambrésis, à l'opposé 47 pour le CFIL d'Andelot à Levier. Les compagnies à la tête de réseaux de 100 à $400 \mathrm{~km}$ comptent entre 1000 et 2500 clients quotidiens, mais les TVM des Deux-Sèvres se satisfont apparemment de 763, tandis que la Compagnie des chemins de fer de l'Hérault en achemine 5 057, celle du Finistère 3 475. Le kilométrage exploité n'est pas le seul facteur qui commande le volume du trafic. Sur leurs multiples exploitations, les plus grandes compagnies acheminent quotidiennement un nombre important de voyageurs : 4140 pour les CFD, 11801 pour la SGCFE.

Les voyageurs ne sauraient, pour nous, demeurer des abstractions, des effectifs. Ce sont des êtres vivants qui choisissent leurs conditions de voyage, surtout ils sont le reflet de la société du début du $\mathrm{xx}^{\mathrm{e}}$ siècle, contemporaine de la période où CFIL et TVM ont exercé une réelle influence.

4- Les voitures de $3^{\mathrm{e}}$ classe des grandes compagnies offraient par personne entre 0,45 et $0,50 \mathrm{~m}$ de large, une hauteur de 1,20 $\mathrm{m}$ et une distance entre les cloisons d'un compartiment de $1,75 \mathrm{~m}$. Voir chap IV. 


\section{$>$ Les voyageurs transportés vus à travers la documentation statistique}

En 1911, la mode n'était ni aux sondages, ni aux enquêtes sociologiques. Les motifs de déplacements doivent être saisis d'abord à travers les statistiques et les documents tarifaires produits par l'administration.

La répartition des voyageurs entre les classes doit être analysée en tenant compte de l'offre et de la demande ; la première varie suivant les compagnies en fonction des obligations imposées par des cahiers des charges divers dans leurs exigences.

Dix-huit lignes de CFIL 1865 offrent comme les grands réseaux trois classes, sans distinction d'écartements ; trois d'entre elles, cependant à écartement normal, n'offrent que deux classes (chemin de fer de l'Hérault, liaisons de La Teste à Cazaux et de Bayonne à Anglet). L'offre de deux classes domine sur la voie métrique, mais cela souffre des exceptions : les réseaux du Cambrésis et du Calvados, les lignes de Paramé à Cancale et de Pontorson au Mont Saint-Michel disposent de trois classes. La classe unique rarement employée règne sur le réseau à voie métrique des Côtes-du-Nord. Pour compléter ce tableau, notons que le réseau du Beaujolais et la ligne de Pithiviers à Toury offrent deux classes, la $1^{\text {re }}$ et la $3^{\text {e }}$. Ces subtilités pourraient paraitre sans intérêt, mais les règlements se traduisent en prix de transport et en conditions de confort : une compagnie précisait que les voyageurs de $3^{\text {e }}$ classe ne disposaient pas de places assises! En outre, ces complications rendaient l'établissement de billets directs difficile entre compagnies ; on limitait les liaisons concernées. Les documents tarifaires nécessaires à ces opérations, répertoriant les règles propres à chaque compagnie, avaient un volume impressionnant. Cette diversité correspondait-elle à une demande véritable?

L'étude de la demande fournit quelques indications sur la clientèle. L'immense majorité souhaite le transport le plus économique, elle peuple la $3^{\mathrm{e}}$ classe ou en son absence la $2^{\mathrm{e}}$. Cette dernière, pratiquement en service sur tous les trains, recueille dans les convois à trois classes ceux qui cherchent un confort relatif et surtout qui souhaitent éviter la cohabitation avec les ouvriers et les paysans. Le prix du voyage en $1^{\text {re }}$ classe, souvent un tiers en plus qu'en seconde, limite le nombre des usagers. La répartition des voyageurs pour l'ensemble des chemins de fer secondaires montre la prééminence de la $2^{\mathrm{e}}$ classe ; 59 millions $(74,3 \%)$, face à une $1^{\text {re }}$ peu fréquentée avec 1,8 millions $(2,3 \%)$ et à une $3^{\mathrm{e}}$ et une à classe unique, plus attractives réunissant respectivement 13 millions $(16,5 \%)$ et 5,3 millions $(6,9 \%)$ de voyageurs. 
Les choix imposés aux concessionnaires en matière d'offre n'étaient pas dictés par une connaissance de la demande : trois classes, deux classes correspondent plus à des périodes de construction, à la volonté d'une exploitation plus économique, par exemple en allégeant la composition des trains, car la suppression d'une classe allait dans ce sens.

L'étude de quelques exemples permet d'opposer les lignes touristiques fréquentées par une clientèle voyageant en $1^{\text {te }}$ classe à des réseaux départementaux cheminant en zone rurale où les voyageurs voulaient payer peu (tabl. 74). Le nombre de voyageurs de $1^{\text {re }}$ était encore plus faible qu'en Haute-Vienne sur certaines lignes : deux par jour entre Méru et Labosse, ligne exploitée par un particulier, trente dans l'année sur un total de 24337 entre Roisel et Hargicourt, liaison assurée par la Compagnie de CFIL du Nord de la France. Ces effectifs se partageaient entre les convois, au moins un et souvent quotidiennement deux dans chaque sens, se concentraient sur certains jours ou certaines périodes de l'année, autrement dit la voiture ou les compartiments de

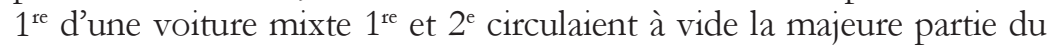
temps.

Les statistiques relatives aux voyageurs ont permis leur répartition par classe. Elles montrent aussi que les concessionnaires des premières lignes CFIL 1865 ont appliqué des règles tarifaires permettant encore à $70 \%$ des usagers de 1911 de voyager à tarif réduit. Les pourcentages s'abaissent à 45,5\% pour les usagers de CFIL 1880, jusqu'à seulement $37 \%$ sur les lignes de TVM ; les concédants ont imposé des modes de gestion de plus en plus stricts, réduisant les possibilités de libéralités de la part des concessionnaires.

Mais les statistiques ne distinguent pas toujours avec rigueur les catégories de voyageurs : ainsi les voyageurs ordinaires munis d'un aller-retour sont classés comme bénéficiaires de tarifs réduits; on ne peut les distinguer des touristes, des hommes d'affaires abonnés, des voyageurs de commerce... jouissant du même privilège ; or le but serait de saisir des motifs de déplacements. Les enfants sont transportés en général à demi-tarif, mais comptabilisés avec les voyageurs des trains de plaisir, dont on aurait aimé connaittre le nombre. Les militaires sont transportés à des tarifs fixés par les compagnies, souvent $50 \%$ du tarif général ; les compagnies subventionnées par l’État, ce qui est le cas de la majorité d'entre elles, doivent des services gratuits : outre la Poste, certains transports de troupes et celui des conscrits allant au chef-lieu de canton pour le conseil de révision. Aussi l'effectif total des militaires acheminés est-il mal connu, d'autant que certaines compagnies seulement en font le décompte, les autres les intègrent au trafic à tarifs réduits ; le chiffre de 538293 hommes cité pour 1911 est inférieur à la réalité. 
Tableau 74. Part de la clientèle de $1^{\text {re }}$ classe sur divers lignes et réseaux

\begin{tabular}{|c|c|c|c|}
\hline \multirow[b]{2}{*}{ Parcours } & \multirow[b]{2}{*}{$\%$} & \multicolumn{2}{|c|}{ Voyageurs } \\
\hline & & $\begin{array}{l}\text { Nombre } \\
\text { année }\end{array}$ & $\begin{array}{c}\text { Moyenne } \\
\text { quotidienne }\end{array}$ \\
\hline \multicolumn{4}{|c|}{ Lignes touristiques (a) } \\
\hline Dinard à Saint-Briac & 15 & 39000 & 106 \\
\hline $\begin{array}{l}\text { Pierrefitte-Nestalas (Midi) à Cauterets et } \\
\text { Luz-Saint-Sauveur }\end{array}$ & 14,7 & 47000 & 128 \\
\hline Cagnes au Cap d'Antibes & 14 & 35000 & 96 \\
\hline Voies ferrées du Dauphiné (b) & 11 & 141800 & 388 \\
\hline Toulon à Saint-Raphaël (c) & 9,6 & 101355 & 278 \\
\hline \multicolumn{4}{|c|}{ Réseaux départementaux } \\
\hline Sarthe & 3,5 & 21826 & 60 \\
\hline Ardennes & 2,7 & 28704 & 78 \\
\hline Indre & 1,2 & 4580 & 13 \\
\hline Finistère & 0,88 & 11280 & 31 \\
\hline Aude & 0,87 & 4496 & 12 \\
\hline Charente & 0,35 & 2734 & 7 \\
\hline Haute-Vienne & 0,15 & 1072 & 3 \\
\hline \multicolumn{4}{|c|}{$\begin{array}{l}\text { (a) Sur } 2 \text { lignes de TVM à } 3 \text { classes, } 1^{\mathrm{re}} \text { et } 2^{\mathrm{e}} \text { réunissent } 93 \% \text { du trafic entre } \\
\text { Paramé et Cancale, } 21 \% \text { entre Pontorson et le Mont-Saint-Michel. } \\
\text { (b) Ce réseau départemental allie au trafic touristique des déplacements autour } \\
\text { de Grenoble. } \\
\text { (c) Ligne desservant les stations littorales des Maures. }\end{array}$} \\
\hline
\end{tabular}

Une approche plus vivante de la réalité doit être tentée. Les conditions d'existence de l'époque étaient si différentes des nôtres que nous évoquons celles qui pèsent sur les déplacements. Les publications passionnées accompagnant tous les projets de voies ferrées évoquent avec réalisme la clientèle; elles sont moins fiables lorsqu'elles abordent des prévisions de trafic. Les monographies récentes sont riches d'informations. Des recherches et des souvenirs personnels ont permis de compléter la documentation.

\section{$>$ Les voyageurs transportés, reflets de la société}

\section{Paysannerie}

La paysannerie se déplaçait peu et rarement loin ; elle formait cependant le tiers environ de la clientèle. Trois motifs de déplacements dominaient. Services militaires et périodes imposées aux réservistes 
étaient les seules occasions de voyages lointains dont les femmes étaient évidemment exclues. La fréquentation des foires et marchés était la source des flux les plus importants ; malgré les circulations supplémentaires, les pointes de trafic s'accompagnaient de trains bondés, ce dont se plaignaient les usagers. Les femmes allant faire des emplettes et apportant au marché œufs, beurre, volailles, fruits étaient particulièrement nombreuses ; les hommes qui ne conduisaient pas de gros bétail étaient de la partie. Les foires et marchés fréquentés se situant dans un rayon de 15 à $20 \mathrm{~km}$, le gros bétail était acheminé à pied : à l'époque, la marche et le départ à trois ou quatre heures du matin n'inquiétaient pas les paysans ; les compagnies ne prévoyaient pas de circulations pour ce trafic diffus ${ }^{5}$. Baptêmes, mariages durant deux ou trois jours, enterrements suivis de libations étaient la troisième cause de voyages, mais dans le même horizon limité que pour les foires. Les recensements de population entre 1876 et 1911 montrent que 70 à $80 \%$ des habitants étaient nés dans leur commune de résidence ou dans les communes limitrophes : on se mariait entre ceux qui se retrouvaient aux mêmes messes, bals, foires et cérémonies familiales et dont les familles s'entraidaient pour les moissons, fauchailles et vendanges. Les paysans utilisant ces chemins de fer passant près de chez eux prolongeaient rarement le voyage sur les voies d'autres compagnies.

Longtemps, la propriété de chevaux était le privilège des grands propriétaires fonciers et des riches fermiers; la diffusion de l'espèce, parallèlement à la mécanisation, au sein de nombreuses exploitations s'est opérée entre 1900 et 1935. Attelé à la carriole, le cheval de trait trottant de 10 à $12 \mathrm{~km}$ à l'heure répond à tous les besoins de déplacements évoqués ; suivant l'aménagement, la voiture transportait un lot de petit bétail à la foire ou six passagers à un mariage. Cheval et carriole ont été avant l'automobile le signe d'une promotion sociale, mais aussi une réelle concurrence aux chemins de fer secondaires ${ }^{6}$.

\section{La clientèle de $1^{\text {re }}$ classe}

Préfets, sous-préfets, inspecteurs de l'administration lorsque leurs missions les conduisaient loin des gares du réseau d'intérêt général circulaient dans la $1^{\text {re }}$ classe des chemins de fer secondaires. Ils y côtoyaient les propriétaires de châteaux et de manoirs ; citadins l'hiver dans leurs hôtels particuliers à Paris ou Versailles pour les plus fortunés, dans les

5- Conduire 2 ou 3 bêtes à une gare, les embarquer, les conduire au champ de foire n'aurait jamais permis d'arriver à l'heure au marché ; la faiblesse des lots aurait d'ailleurs entrainé un prix de transport élevé que les paysans n'auraient pas consenti à payer. 6- M. Wolkowitsch, L’Élevage dans le monde, Paris, Colin, 1966, 224 p., cf. p. 23-25. 
villes plus proches pour les autres, ils venaient à la campagne pour consommer leurs redevances en nature comme au temps de Balzac, pour la chasse, les cérémonies familiales, pour faire les comptes des fermages et métayages à la Saint-Martin ; autant de voyages nécessitant souvent l'emprunt des lignes locales après de laborieuses correspondances avec les trains des grandes compagnies. Ce milieu formait une part appréciable de la clientèle de $1^{\text {re }}$ classe ; les compagnies prévoyaient à leur intention des billets de famille, illustration d'une époque où la «tribu » se déplaçait, domesticité comprise, cette dernière pouvant emprunter une classe inférieure; pouvaient figurer sur le billet mari, femme, grands-parents, beaux-parents, enfants, gendres, belles-filles, beaux-frères, belles-sœurs, oncles, tantes, neveux, nièces, précepteurs, gouvernantes, serviteurs, chauffeur si une auto était acheminée par train. Les dirigeants des entreprises familiales, encore nombreuses, usaient des mêmes billets, mais plus encore de ceux prévus pour gagner les stations balnéaires, climatiques ou thermales où leur famille prolongeait les congés qu'ils s'octroyaient ; ces stations n'étaient souvent desservies que par les voies secondaires (Le Lavandou, Sainte-Maxime, Palavasles-Flots, Lacanau-Océan, Cauterets, Bourbon-l'Archambault... ).

Les compagnies secondaires ne négligeaient pas d'offrir des services appréciés de leur clientèle diverse : horaire variable du dernier train à Reims en fonction de l'heure de la fin de la soirée au théâtre, circulation spéciale à l'occasion du passage d'un cirque ; à l'égal des grandes compagnies, elles mettaient en service des trains de plaisir permettant de découvrir la mer (Compagnie du Médoc entre Bordeaux et Soulac-sur-Mer, par exemple). Mais, marque d'une époque, si nous n'avons trouvé aucune référence à des manifestations sportives de masse, les pèlerinages étaient à l'origine des plus grands rassemblements ; les chemins de fer secondaires mettaient en service jusqu'à cinq ou six trains supplémentaires, ce qui compte tenu des conditions d'exploitation était une prouesse. Habitués aux transhumances touristiques hebdomadaires et annuelles amplifiées sans cesse depuis 1950, les flux auxquels les voies locales faisaient face nous semblent bien modestes.

\section{Les migrations de travail}

Pour le plus grand nombre les loisirs tenaient peu de place dans l'existence. Les filles de la campagne placées en ville, les enfants dans les fermes revenaient exceptionnellement chez eux. Le commun des salariés ne s'éloignait guère de son lieu de résidence confondu avec son lieu de travail. Les vendeuses des grands magasins parisiens, recrutées dans la France profonde, bénéficiaient depuis les premières années du $\mathrm{xx}^{\mathrm{e}}$ siècle d'une semaine de congé tous les sept ans pour regagner leur province ; 
elles étaient une exception; leurs voyages dispersés à travers tout le pays ne représentaient pas un trafic perceptible au niveau de chaque compagnie.

Quel intérêt les compagnies secondaires accordaient-elles à des flux plus soutenus liés aux migrations de travail ou aux déplacements urbains ? Deux sortes de réponses étaient apportées : l'adaptation des services et la tarification, analysée plus loin.

Au milieu du XIX ${ }^{e}$ siècle, les travailleurs saisonniers (manœuvres, maçons, terrassiers, tailleurs de pierres), venaient en ville, essentiellement à Paris ; on comptait 60000 départs du Cantal, 40000 de Haute-Vienne, autant de Creuse... Les migrants cheminaient à pied, employant rarement les pataches par souci d'économie. L'abaissement de 30 à $50 \%$ du prix de transport par le chemin de fer les ont conduits à l'utiliser ; mais ce flux se tarit avant l'essor des réseaux secondaires. La migration définitive a remplacé la migration saisonnière.

Avec le $\mathrm{xx}^{\mathrm{e}}$ siècle, les migrations pendulaires de travail se multiplient; on en constate en province autour d'ateliers ou d'usines en milieu rural, les compagnies secondaires peuvent être concernées, de même autour de certaines villes. Dans la région parisienne où ces flux croissent rapidement, la densité du réseau d'intérêt général est telle que le rôle des chemins de fer secondaires est mineur.

Les déplacements hebdomadaires permettent le retour dans la famille pour la nuit du samedi au dimanche de catégories très diverses, ouvriers, enseignants, jeunes. Ces mouvements réalisés le plus souvent dans le cadre d'un département constituent des flux appréciables auxquels les compagnies secondaires sont en mesure de répondre : ils font souvent se succéder une phase de dispersion au départ des villes, puis de concentration vers elles ; les préfectures retiennent une part appréciable de ce flux.

\section{Les groupes}

Les groupes sont nombreux à voyager ; des scolaires aux touristes, des sportifs aux artistes, les participants n'ont nul autre moyen de se déplacer. Les associations sont déjà nombreuses à organiser des sorties. Hors des troupes de théâtre ou de cirque qui font des tournées longues, utilisant si nécessaire les chemins de fer secondaires, les autres mouvements sont généralement à faible distance et empruntent les voies d'une seule compagnie. 


\section{Les flux liés à l'évolution du commerce}

En milieu rural, bien au-delà de 1850 subsiste un commerce itinérant assuré par les colporteurs et temporaire dans le cadre de foires, principaux lieux des échanges. Le paysan y vend une faible part de sa production, celle qu'il ne consomme pas, et y acquiert l'indispensable à ses modestes besoins. Les foires animent de nombreux villages plusieurs fois par an, les villes aussi où ces manifestations se prolongent, quatre jours à Sancerre, vingt à Bourges. Le commerce devient progressivement sédentaire et permanent : les villes ont déjà des magasins depuis longtemps; jusque vers 1880 les bourgs, souvent chefs-lieu de cantons, en comptent un ou deux, les villages ont le cabaretier pour seul commerçant. Progressivement les magasins se spécialisent et se multiplient dans les bourgs (alimentation, mercerie, chapellerie, modes et nouveautés, droguerie, vaisselle, ameublement, bicyclette, quincaillerie) ; ils s'ouvrent dans les villages sous forme d'une unique boutique offrant une diversité de produits à faire pâlir les supermarchés du XxI ${ }^{\mathrm{e}}$ siècle. Les cabaretiers deviennent aubergistes, hôteliers, les cafés prospèrent partout. Les relations entre ce commerce diffus, les demi-grossistes, installés dans les petites villes souvent sous-préfectures, et les grossistes reposent sur les déplacements incessants des voyageurs et représentants de commerce visitant jusque dans les villages les plus isolés les détaillants et aussi les artisans, dont le nombre augmente. Les VRP relèvent les commandes pour l'épicier, le boulanger, le charron, le tailleur, les modistes, le café ou l'hôtelier ; le commerce de demi-gros a vu naître les métiers de marchands de vin ou de charbon, ceux de maquignons, volaillers qui hantent foires et marchés, négociants en grains. Tout un monde qui se déplace pour ses affaires, notamment les VRP. Ces derniers par leur effectif, l'intensité de leurs déplacements, les conséquences bénéfiques des commandes enregistrées sur le trafic des marchandises méritent l'intérêt des compagnies. Transportant leurs échantillons dans de volumineux bagages, ils bénéficient de fortes réductions des taxes d'enregistrement et du prix des billets, de possibilités de surclassement et, lors de transports d'échantillons précieux, du droit de garder avec eux les bagages correspondants. Chaque compagnie édicte ses propres règles. De même que les VRP sont popularisés dans la littérature comme le type de client des tables d'hôtes, ils mériteraient d'y figurer comme «le voyageur » des chemins de fer secondaires, au moins ceux qui dépassent le cadre strictement local.

La mobilité facilitée par les VFIL a contribué à diversifier les populations rurales dans leur origine géographique et leur activité socioprofessionnelle, elle n'apparait pas comme un facteur déterminant 
de l'évolution psychologique du monde agricole : le paysan restait fidèle à son horizon limité. En 1960, dans la France profonde, on rencontrait encore de vieilles campagnardes qui ne connaissaient pas la préfecture de leur département.

En réplique, une Parisienne vivant à Ménilmontant déclarait, dans les années 1930, borner son horizon à la place de la République et ne rien connaitre des quartiers ouest de la capitale. Cependant, depuis le début du siècle, les transports urbains de voyageurs connaissaient un intense développement, favorisant l'individualisation des quartiers et permettant de faire face à la croissance des villes. S'ils se permettent quelques escapades campagnardes, TV et même TVB ont bien pour fonction première de répondre à la demande de déplacements urbains.

\section{. TVB et TV}

\section{$>$ Les TVB}

TVB et TV méritent des traitements spécifiques. Les TVB associent des lignes qui par leur trafic voyageur volumineux s'apparentent aux TV, tandis que d'autres par leur parcours prolongé à travers des espaces non urbanisés ont un trafic rappelant celui des TVM. Le trafic global des TVB s'élève à 239266537 voyageurs ; il le doit essentiellement à cinq lignes qui assurent près de $90 \%$ du total du trafic. Face à ces lignes dont la fréquentation se chiffre par dizaines de millions de voyageurs, on en compte 20 dont le trafic est inférieur à 500000 voyageurs. L'intensité en voy. $/ \mathrm{km}$ exploité offre une amplitude exceptionnelle, pas très éloignée de 1 à 1000 (tabl. 75).

On peut proposer une typologie fondée sur des exemples, en soulignant qu'on ne peut établir de rapport entre le volume et l'intensité du trafic, puisque le facteur de la distance est très important. Un premier type réunit des lignes à trafic considérable se développant en milieu urbain ou au moins en voie d'urbanisation intense. Un second type rassemble des lignes réunissant deux villes ou une ville à un bourg sur des distances de l'ordre de 5 à $40 \mathrm{~km}$; les trafics y sont différenciés, de 200000 à 900000 voyageurs dans les exemples choisis ; les indices y sont beaucoup plus faibles que dans le cas précédent. Enfin, un troisième type réunit des lignes en zones littorales ou montagneuses, avec une fréquentation variable en cours d'année conduisant à des indices particulièrement faibles. À part des exceptions notables, mais rares (Nice, Lille, Rennes), les TVB n'exploitent pas de réseaux spécifiquement urbains ; parmi les deux réseaux parisiens concernés, l'un s'étend à la Seine-et-Oise. 
Tableau 75. Typologie des lignes de TVB

\begin{tabular}{|c|c|c|c|}
\hline Lignes & Km & $\begin{array}{c}\text { Total des } \\
\text { voyageurs }\end{array}$ & $\begin{array}{l}\text { Voy./km } \\
\text { exploité }\end{array}$ \\
\hline \multicolumn{4}{|l|}{ 1- Milieu urbain ou très urbanisé } \\
\hline Compagnie générale parisienne de tramw ays & 90 & 81658983 & 907299 \\
\hline Réseau urbain de Nice & 30 & 17771000 & 590382 \\
\hline Réseau de l'Est parisien & 184 & 60330000 & 327733 \\
\hline Chemin de fer de Firminy à Rive-de-Gier & 64 & 20248000 & 316380 \\
\hline Réseau urbain et suburbain de Lille & 127 & 33167000 & 261118 \\
\hline \multicolumn{4}{|c|}{ 2- Lignes de liaison entre des localités traversant un milieu rural } \\
\hline Saint-Germain-en-Laye à Poissy & 5 & 258879 & 51775 \\
\hline Versailles à Saint-Cyr-l'Ecole & 6 & 303637 & 50605 \\
\hline Dijon à Gevrey-Chambertin & 10 & 376579 & 37657 \\
\hline Nancy à Dombales et Pont-Saint-Vincent & 29 & 894498 & 30840 \\
\hline Marseille à Aix-en-Provence & 30 & 844208 & 28140 \\
\hline Tours à Vouvray & 11 & 200943 & 18267 \\
\hline \multicolumn{4}{|c|}{$\begin{array}{l}\text { 3- Lignes à fréquentation irrégulière au cours de l'année et indices } \\
\text { faibles }\end{array}$} \\
\hline Société des tramw ays de Savoie & 23 & 188631 & 8201 \\
\hline Gérardmer à La Schlucht & 20 & 151266 & 7563 \\
\hline Fort-Mahon à Monchaux-les-Quend & 5 & 18565 & 3713 \\
\hline Saint-Gervais à l'Aiguille du Goûter & 10 & 21500 & 2150 \\
\hline Quend-Nord gare à Plage de Saint-Quentin & 8 & 10041 & 1255 \\
\hline
\end{tabular}

Sur la moitié des exploitations, une classe unique est offerte aux voyageurs, mais cela ne représente qu'environ $5 \%$ du trafic. La ventilation entre $1^{\text {re }}$ et $2^{\mathrm{e}}$ classes dans les réseaux où elles coexistent ne figure que partiellement dans les statistiques ; les constats suivants peuvent être faits : la part de la $1^{\text {re }}$ classe est de $20 \%$ à Lille, $17 \%$ sur la ligne de Cagnes à Menton, $14 \%$ sur les réseaux urbains de Nice et de l'Est parisien, de $9 \%$ sur le réseau de Cannes et de sa banlieue, de 3,5\% sur la ligne de Firminy à Rive-de-Gier par Saint-Étienne. La faiblesse de ce dernier chiffre traduit bien la place prépondérante prise par les déplacements ouvriers. L'exemple du réseau de Cannes s'explique parce que c'est la périphérie qui est desservie et non le centre, or c'est le lot commun à beaucoup de réseaux de TVB de répondre à une clientèle de banlieue lointaine qui, en majorité, n’appartient pas aux classes aisées ; par ailleurs ces dernières fréquentaient inégalement les transports publics. 


\section{$>$ Les TV}

Le trafic total des TV s'établit en 1911 à 820985971 voyageurs dont $71 \%$ en province (530 millions) et $29 \%$ à Paris et dans la Seine (292 millions). Comme dans le cas des TVB, une grande part du trafic est assurée par un nombre restreint de compagnies exploitant les réseaux des villes principales (tabl. 76) .

Tableau 76. Les principales entreprises de tramways

\begin{tabular}{|l|c|c|c|}
\hline \multicolumn{1}{|c|}{ Com pagnie } & Km & Trafic total & $\begin{array}{l}\text { Voy./km } \\
\text { exploité }\end{array}$ \\
\hline Compagnie générale des omnibus de Paris & 175 & 150948000 & 862560 \\
\hline Réseau de Bordeaux & 101 & 68006000 & 673267 \\
\hline Réseau de Marseille & 166 & 104159000 & 627463 \\
\hline Compagnie des chemins de fer nogentais & 55 & 28734000 & 522436 \\
\hline $\begin{array}{l}\text { Compagnie des omnibus et tramw ays de } \\
\text { Lyon }\end{array}$ & 238 & 107780000 & 452857 \\
\hline $\begin{array}{l}\text { Réseaux urbain et suburbain de Roubaix et } \\
\text { Tourcoing }\end{array}$ & 54 & 21078000 & 383236 \\
\hline $\begin{array}{l}\text { Compagnie des tramw ays de Paris et de la } \\
\text { Seine }\end{array}$ & 217 & 78087000 & 359847 \\
\hline Compagnie des tramw ays de Rouen & 69 & 24078000 & 348956 \\
\hline Réseau de Toulouse & 91 & 25434000 & 279494 \\
\hline
\end{tabular}

\section{Typologie}

Neuf entreprises acheminent 608 millions de voyageurs, soit près des trois quarts du trafic national, sur les $1166 \mathrm{~km}$ de lignes qu'elles contrôlent et qui ne représentent que 56 \% du réseau. Sauf dans un cas, le nombre de voyageurs $/ \mathrm{km}$ exploité ne s'abaisse pas en dessous de 340000 et il peut dépasser 800000 .

À un niveau inférieur à un seuil de 20 millions, on trouve encore douze compagnies traitant au moins cinq millions de voyageurs : les réseaux ont entre $18 \mathrm{~km}$ à Limoges et 62 au $\mathrm{Havre}^{7}$, on compte entre cinq millions à Dunkerque, Tours et Calais et près de 19 millions de voyageurs au Havre ; l'intensité du trafic se situe entre 175766 voy. $/ \mathrm{km}$ et 450117 à des niveaux nettement moins élevés que dans le cas précédent, ce qui s'explique par un volume plus faible de clientèle potentielle, compte tenu de la démographie urbaine. Les autres villes relevant de ce type sont Toulon, Reims, Nantes et Amiens, il faut y inclure le réseau de

7- On soulignera que les quatre réseaux de la Compagnie générale française de tramways (Marseille, Le Havre, Nancy et Orléans) figurent parmi les deux types de réseaux aux plus forts trafics. 
la société «L'électrique Lille à Roubaix et Tourcoing ». Le trafic total réalisé par toutes ces entreprises est de l'ordre de 110 millions de voyageurs transportés sur les $381 \mathrm{~km}$ exploités, cela représente $13 \%$ du trafic total et $17 \%$ du réseau. Le nombre moyen de voyageurs $/ \mathrm{km}$ exploité est de 288713 contre 521440 pour le premier groupe.

Des réseaux dont le trafic n'atteint pas quatre millions de voyageurs peuvent dans certaines conditions bénéficier d'une grande intensité de trafic. Il varie dans une fourchette comprise entre 3961000 voyageurs au Mans, 657000 à Armentières. L'intensité du trafic est très élevée au Mans (360 090), plus encore à Roanne grâce à la conjonction d'un fort trafic sur un faible kilométrage : 3109800 voyageurs et $7 \mathrm{~km}$, soit une intensité de 444152 voyageurs/ $\mathrm{km}$ exploité. Certaines villes ouvrières sont susceptibles de donner des résultats de ce type ; tel est le cas d'une autre ville de la Loire, Saint-Chamond, sur une ligne de $2 \mathrm{~km}$, transportant 671518 voyageurs, donnant une intensité de trafic de 335500 voy. $/ \mathrm{km}$ exploité. Les indices relevés le plus fréquemment se situent entre 100000 et 300000 voy./ km exploité ; outre les trois villes citées, seulement cinq comptent plus de 300000 voy. $/ \mathrm{km}$ exploité : Brest, Dijon, Nîmes, Montpellier et Versailles.

Il reste à évoquer le cas de quelques lignes longues de 2 à $15 \mathrm{~km}$ avec une fréquentation comprise entre 36000 voyageurs (Wimereux à l'hippodrome d'Aubenque ) et 780000 pour la liaison de $4 \mathrm{~km}$ entre Vichy et Cusset. Le nombre de voy./km exploité est de 195000 pour cette relation, mais il s'abaisse à 3743 sur la ligne de Clermont-Ferrand au sommet du Puy de Dôme. Dans cette catégorie, citons encore les lignes du Tréport à Eu, d'Aubenas à Vals et de La Grande-Côte à Saint-Georges-de-Didonne ; toutes ces lignes sont influencées par l'activité touristique, elles ont en tout un peu plus de $50 \mathrm{~km}$ et transportent, réunies, un peu plus de 2000000 de voyageurs, nettement moins de $1 \%$ du trafic national : une goutte d'eau pour cette activité, mais, par leur situation géographique, elles méritaient d'être citées.

\section{Les flux}

Attachons-nous maintenant à définir les flux qui animaient ces réseaux ; il est d'abord indispensable de se projeter un siècle en arrière.

La population, l'extension des villes et les déplacements en leur sein n'ont rien à voir en 1900 avec la situation de l'an 2000 : les villes ont conquis en cent ans des centaines, parfois des milliers d'hectares avec les communes voisines, les déplacements se sont multipliés en volume comme en distance. 
La population des villes dont les réseaux véhiculent entre 5 et 20 millions de voyageurs se situe entre 90 et 135000 habitants (Amiens, Toulon, Reims, Nantes et Le Havre) avec l'exception de Tours, seulement 65000 habitants. Pour les réseaux dont le trafic est inférieur à cinq millions de voyageurs, la population est comprise entre vingt-cinq et quatrevingt cinq mille habitants ${ }^{8}$. Le volume de la population est un des facteurs du nombre de déplacements; un autre est l'extension des villes. Beaucoup de villes citées ont moins de la moitié de la population qu'elles comptent aujourd'hui ; il en va de même pour l'étendue ; l'obstacle des lignes des grands réseaux a rarement été franchi en 1900, ou seulement en quelques endroits ; l'examen des plans de villes présentés pour les années 1920 ou 1930 par A. Demangeon est suggestif ; la situation est alors plus proche de 1900 que de 2000. Des espaces disponibles pour l'urbanisation subsistaient encore entre les installations ferroviaires des grands réseaux et les quartiers qui progressaient vers elles?.

Les déplacements des citadins n'étaient pas l'objet de l'attention qui leur est accordée aujourd'hui ; ils sont analysés, segmentés, modélisés, prédits, même si l'avenir ne cadre pas toujours avec les vues des augures. Les flux observés dans la majeure partie des villes, fiacres et essentiellement des déplacements à pied, étaient considérés comme l'expression d'une demande qui pouvait justifier la construction d'une ligne de tramway. Flux permanent, important à satisfaire, était la liaison entre la gare de la grande compagnie et le centre de la ville. Ce centre symbolisé par une place ou par une artère était le lieu de toutes les convergences. La ville était en 1900 un organisme plus simple qu'aujourd'hui ; il y avait rarement des quartiers très excentrés. Le centre rassemblait dans un rayon plus ou moins restreint la préfecture, le palais de justice, le lycée de garçons, le théâtre, l'hôpital, mais aussi le marché couvert avec ses prolongements en plein air, les cabinets des professions libérales, la cathédrale si elle n'était pas au cœur d'un quartier médiéval qui n'était pas devenu le cœur de la ville ; on y trouvait encore les hôtels et restaurants et cafés peu nombreux mais bien fréquentés, les commerces de l'habillement, de la chaussure, de la joaillerie... Administration, santé, loisirs, enseignement, achat, tout concourait à faire converger vers le centre des flux venus des divers horizons, souvent tout proches du centre lui-même. Hors le centre, les quartiers offraient des petits commerces d'alimentation, les écoles primaires. Aujourd'hui, les installations

8- Exemples de villes de ce type et population en milliers: Brest 85, Nîmes 80, Montpellier 76, Dijon 71, Besançon et Versailles 55, Troyes 53, Caen 44, Poitiers 39, Pau 34, Épinal 28, Châlons-sur-Marne 26...

9- Cf. ci-dessus fig. 22. 
sportives, universitaires, les zones commerciales et industrielles sont des pôles d'attraction vers l'extérieur, sources d'intenses migrations ; ce sont des réalisations du dernier demi-siècle que rien ne laissait même entrevoir avant 1950.

Les usines étant généralement en ville, le flux des ouvriers allant au travail a conduit parfois à construire des lignes au départ d'une commune de banlieue, pour draîner vers les usines la main-d'œuvre ; cela n'excluait pas pour ces lignes de contribuer à la convergence vers le centre; des villes comme Elbeuf, Roanne, Sedan, Armentières pour n'en citer que quelques-unes offraient ce type d'équipement.

Chaque ville est un cas, mais l'organisation des flux est plus complexe dans les métropoles : ces dernières disposent de centres secondaires d'attraction parallèlement au centre principal (place Bellecour à Lyon). L'activité portuaire le long d'un estuaire à Bordeaux ou d'un front de mer à Marseille induit des flux ; dockers, douaniers, représentants des compagnies, passagers se côtoient.

\section{La clientèle}

Les citadins de toutes conditions utilisent le tramway. Les propriétaires d'équipages et d'automobiles ne sont pas très nombreux ; l'automobile reste un luxe. Les statistiques ne ventilent pas, pour toutes les compagnies, le nombre des voyageurs de chaque classe. Il faut se satisfaire d'exemples et admettre la difficulté d'une interprétation qui exige une connaissance parfaite du milieu social desservi par un réseau. Soulignons que $70 \%$ des exploitations sont à classe unique, particulièrement en province. À Paris, seule la liaison entre Belleville et la place de la République à travers les quartiers populaires est dans ce cas, les six autres entreprises offrent deux classes à leur clientèle avec un inégal succès : $43 \%$ de voyageurs en $1^{\text {re }}$ classe pour la Compagnie générale des omnibus de Paris, $3 \%$ pour la ligne de Neuilly à Suresnes. En province, $2 \%$ des voyageurs choisissent la $1^{\text {re }}$ à Maubeuge, ville ouvrière, $15 \%$ à Melun, sur l'unique ligne de $2 \mathrm{~km}$ reliant la gare aux nouvelles casernes ; sans doute les officiers ne concevaient-ils pas de se mêler à la troupe? Dans bien des cas, on peut s'interroger sur les critères qui ont conduit les rédacteurs des cahiers des charges à opter pour une ou deux classes. Pourquoi la classe unique à Marseille, Bordeaux, Toulouse, Nancy, Calais, Dijon, Angers... ? Pourquoi deux classes à Lyon (8,7 \% de voyageurs en $1^{\text {re }}$ classe), au Havre (34\%), à Caen (13\%), à Reims $(6 \%)$, ou à Paris $(3,4 \%) \ldots$ ? Il serait intéressant de connaître les arguments utilisés au cours des débats en faveur de chacune des solutions. 
Mixité sociale ou non, le tramway obtient l'adhésion des citadins. La rétrospective décennale (1901-1911) sur le trafic ne permet pas d'isoler les résultats des TV de ceux des TVB (fig. 23). Le trafic total s'élève de près de 700 millions de voyageurs à toutes distances à nettement plus de 1 milliard de voyageurs-kilomètre.

Le déplacement des personnes en ville comme en campagne est un reflet de l'évolution sociale et économique, mais aussi un facteur de ces transformations. En zone rurale, CFIL et TVM jouent aussi un rôle important dans le transport des marchandises. L'analyse du trafic des marchandises doit permettre de mieux appréhender l'influence des CFIL et des TVM sur l'évolution du monde rural.

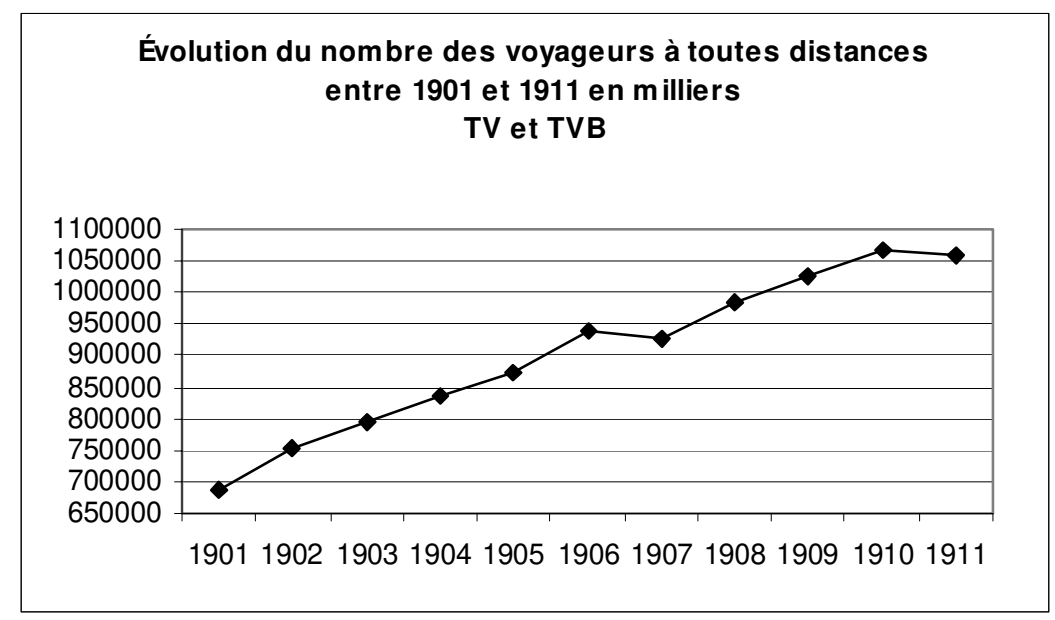

Figure 23. @ M. Wolkowitsch / A.-L. Wolkowitsch, 2003.

\section{Le trafic des marchandises}

. Statistiques et tonnage total (fig. 24-25)

Les statistiques relatives au trafic des marchandises souffrent de quelque faiblesses. Les « accessoires de la PV» (voiture et matériel roulant, animaux) sont comptés à l'unité ; pour pouvoir les convertir en tonnes, suivant les compagnies, ils sont, soit soumis à une pesée, soit à une évaluation basée sur des coefficients de conversion définis : voiture $2 \mathrm{t}$, équidé $400 \mathrm{~kg}$, gros, moyen, et petit bétails, respectivement 600 , 90 et $30 \mathrm{~kg}$. Plus grave est l'insuffisante définition des marchandises répertoriées dans les neuf classes de la PV. La situation est claire pour 


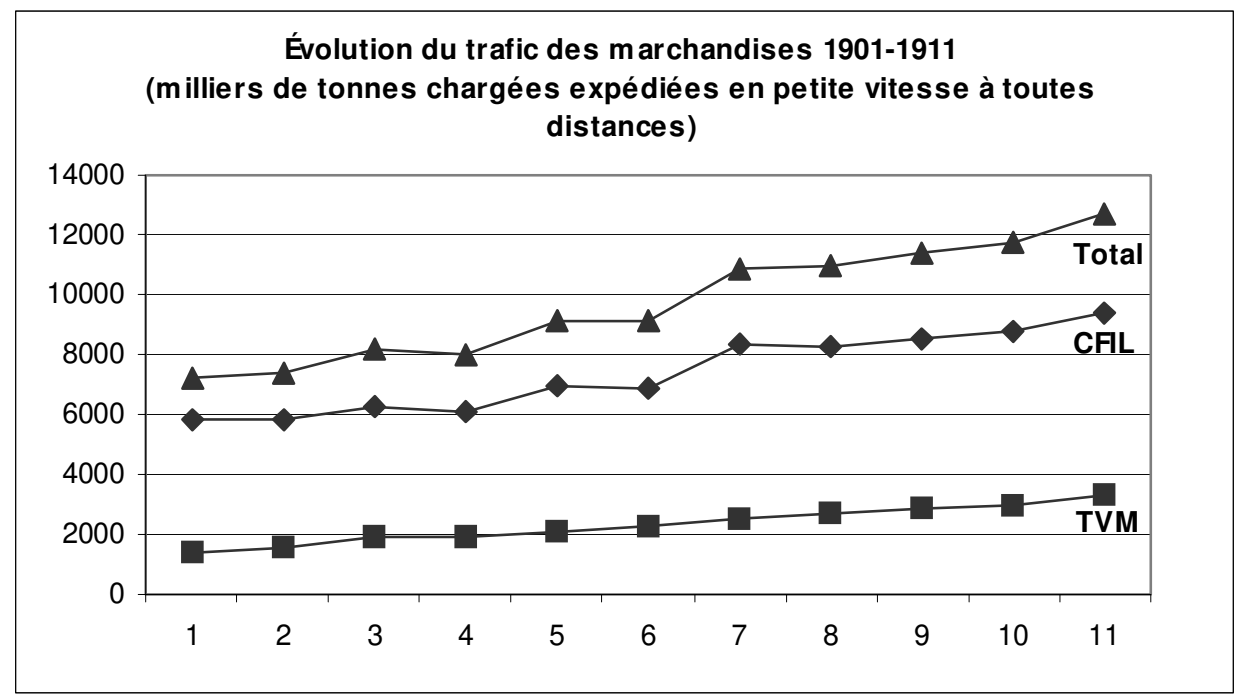

Figure 24. @ M. Wolkowitsch / A.-L. Wolkowitsch, 2003.

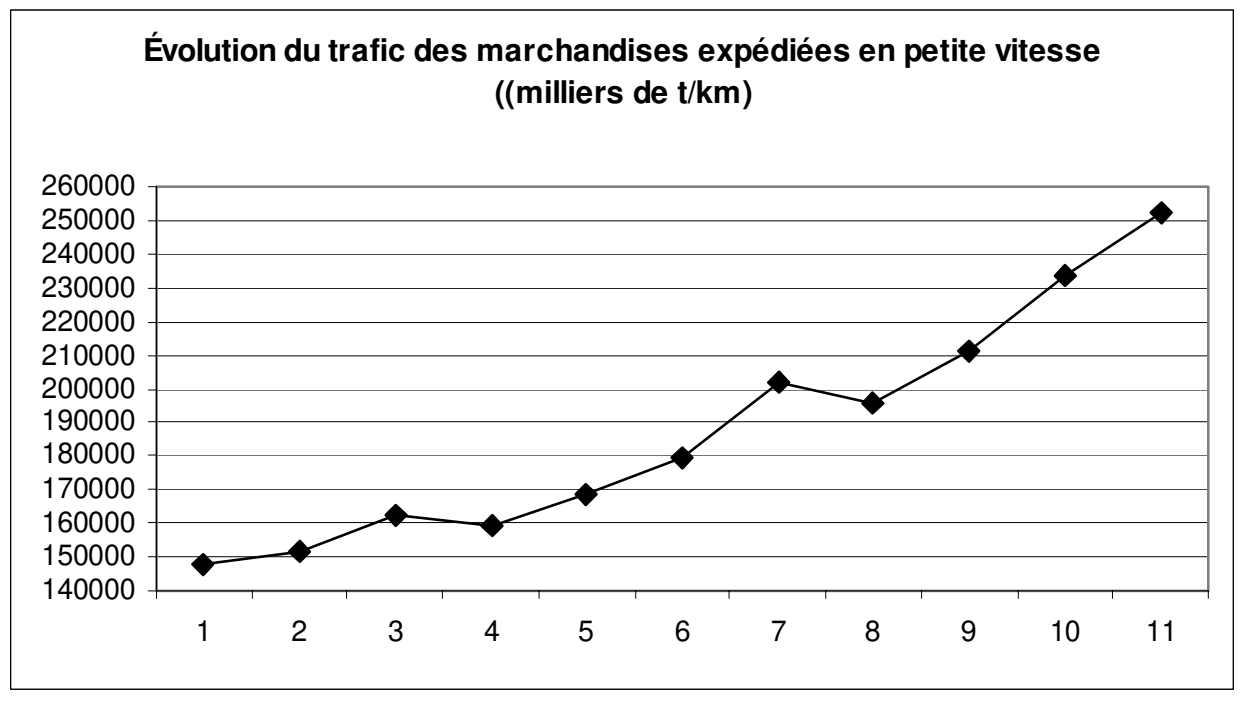

Figure 25. @ M. Wolkowitsch / A.-L. Wolkowitsch, 2003. 
les combustibles ou les matériaux de construction. Le regroupement des produits manufacturés avec les matières premières laisse insatisfait. L'important trafic du bois n'est pas individualisé. La part des marchandises diverses dans le tonnage total transporté varie entre $0,2 \%$ et $80 \%$ suivant les compagnies. En fait, le contenu de cette classe de marchandises est imprécis : chaque compagnie établit une liste des marchandises qu'elle achemine sous cette dénomination. Enfin, quelques entreprises se satisfont de fournir le chiffre global du tonnage chargé sans distinguer les classes de marchandises reconnues par ailleurs ; c'est avant tout le cas de concessionnaires exploitant moins de $10 \mathrm{~km}$.

Les statistiques ne distinguent pas les marchandises circulant seulement sur une ligne secondaire de celles qui l'utilisent pour un parcours initial ou terminal. Les grandes compagnies imposaient la gare de transit de leur choix, qui minimisait les acheminements sur les réseaux secondaires ; cela contribuait à y limiter le parcours moyen à une vingtaine de kilomètres.

Malgré ces restrictions, le trafic total en 1911 peut être correctement apprécié ; il s’élève à 13237478 t chargées, accomplissant $250463980 \mathrm{t} / \mathrm{km}$; les messageries interviennent pour très peu (tabl. 77).

Tableau 77. Trafic des chemins de fer secondaires (tous statuts) en PV et en GV en 1911

\begin{tabular}{|l|c|c|c|c|c|}
\hline & \multicolumn{2}{|c|}{ Petite vitesse } & \multicolumn{3}{c|}{ Grande vitesse } \\
\hline Marchandises & $12664139 \mathrm{t}$ & $95,4 \%$ & Messageries & $249946 \mathrm{t}$ & $1,80 \%$ \\
\hline Accessoires & $188044 \mathrm{t}$ & $1,4 \%$ & Bagages & $155578 \mathrm{t}$ & $1,30 \%$ \\
\hline
\end{tabular}

Le trafic PV était en 1901 de 7,2 millions de tonnes et 146 millions de tonnes-kilomètres, ce qui signifie en 1911 une progression de $75 \%$ particulièrement pour les TVM grâce à l'allongement de leur réseau. Les courbes (fig. 24 et 25) traduisent deux fléchissements de l'ordre de $4 \%$ en 1904 et 1908 effacés par une nouvelle progression dès 1905 et $1909 .$. La part du TVM se renforce, 25,8 contre 19,5\%, mais ne correspond pas au réseau correspondant qui dépasse $40 \%$ du total des lignes secondaires ; cela souligne l'infériorité du TVM pour le transport des marchandises.

\section{$>$ L'intensité du trafic}

Les lignes et les réseaux acheminent des parts très inégales du trafic, sans qu'on reconnaisse une proportion avec le kilométrage exploité. L'intensité peut être définie par le rapport entre le tonnage chargé 
à toutes distances et le kilométrage exploité. Ce rapport, calculé pour chaque exploitation, conduit à des comparaisons et à une typologie. Cette analyse établie, l'étude des échanges propres à chaque classe de marchandises peut être entreprise.

\section{$>$ Typologie des lignes en fonction de l'intensité du trafic}

L'intensité du trafic est la plus forte, si on examine les tonnages moyens, pour les lignes anciennes à écartement normal que pour les lignes à voie étroite, la moyenne la plus faible étant celle du TVM. Les moyennes cachent une réalité complexe (tabl. 78). Le cas de la SGCFE illustre ce propos (annexe 1)

Tableau 78. Intensité du trafic en fonction du statut et de l'écartement des voies (t) en 1911

\begin{tabular}{|l|c|c|c|}
\hline \multicolumn{2}{|l|}{} & Loi de 1865 & Loi de $\mathbf{1 8 8 0}$ \\
\hline \multirow{2}{*}{ CFIL } & N & $3363 \mathrm{t}$ & $1858 \mathrm{t}$ \\
\cline { 2 - 4 } & $\mathbf{E}$ & $857 \mathrm{t}$ & $607 \mathrm{t}$ \\
\hline TVM & - & $529 \mathrm{t}(\mathrm{a})$ \\
\hline
\end{tabular}

Dans l'ensemble les meilleurs résultats apparaissent lorsque les trafics industriels sont étoffés (combustibles, matières premières et produits manufacturés, fer, fonte, acier) ; la situation est fréquente dans le Nord (Aulnoye à Pont-sur-Sambre). La viticulture de l'Hérault avec un important trafic de vins, mais aussi d'engrais, conduit à un taux élevé. Le réseau de la Somme bénéficie de la conjonction d'une agriculture évoluée consommatrice d'engrais, d'une industrie sucrière fondée sur la production de betteraves, sa matière première, et consommatrice de charbon. Lorsque les marchandises diverses retiennent une part énorme du trafic avec de forts tonnages au kilomètre (Vallée de Celles, Luxey à Mont-de-Marsan), si le milieu géographique est favorable, on a toutes chances d'être en présence d'un acheminement de bois. Le trafic portuaire peut alimenter les réseaux secondaires comme le montre le cas de Bordeaux, assurant un résultat favorable au réseau girondin (exportations de bois et de vins notamment).

Dans certains cas, l'extraction minière était à la source d'un trafic important soutenant l'activité d'un réseau : dans l'Indre, le tiers du trafic de la Compagnie des tramways de l'Indre était lié à la production du 
gisement de fer de $\mathrm{Chaillac}^{10}$; même ainsi, le résultat global était à peine supérieur à la moyenne obtenue sur les réseaux de TVM (tabl. 79). Les résultats obtenus sur les différents réseaux et lignes de la SGCFE ne se différencient pas de ceux des autres compagnies (annexe 1).

Tableau 79. Tonnage total, tonnage au km exploité (à toutes distances) et part des principaux trafics de marchandises dans le tonnage total

\begin{tabular}{|c|c|c|c|c|c|}
\hline Statut & $\mathrm{Km}$ & Lignes & $\begin{array}{l}\text { Tonnage } \\
\text { total }\end{array}$ & $\begin{array}{l}\text { Tonnage } \\
\text { au km }\end{array}$ & $\begin{array}{l}\text { Principaux trafics/ } \\
\text { trafic total (en \%) }\end{array}$ \\
\hline $1880 \mathrm{~N}$ & 5 & $\begin{array}{l}\text { Aulnoye à Pont-sur- } \\
\text { Sambre }\end{array}$ & 28426 & 5685 & $\begin{array}{l}\text { Fer, fonte, acier } 39 \\
\text { Combustibles } 33\end{array}$ \\
\hline $1880 \mathrm{~N}$ & 24 & $\begin{array}{l}\text { Chemins de fer de la } \\
\text { Vallée de Celles }\end{array}$ & 32603 & 1358 & Divers 76 \\
\hline $1880 \mathrm{~N}$ & 45 & $\begin{array}{l}\text { Luxey à Mont-de- } \\
\text { Marsan }\end{array}$ & 53934 & 1198 & Divers 68 \\
\hline $1865 \mathrm{~N}$ & 207 & Réseau de l'Hérault & 392558 & 1896 & $\begin{array}{l}\text { Vin } 36 \\
\text { Engrais } 15\end{array}$ \\
\hline $1880 \mathrm{E}$ & 369 & $\begin{array}{l}\text { Réseau de la Somme } \\
\text { (SGCFE) }\end{array}$ & 462545 & 1253 & $\begin{array}{l}\text { Matières premières } 38 \\
\text { Engrais } 30 \\
\text { Houille } 12\end{array}$ \\
\hline $1880 \mathrm{~N}$ & 316 & $\begin{array}{l}\text { Réseau de la Gironde } \\
\text { (SGCFE) }\end{array}$ & 517959 & 1322 & $\begin{array}{l}\text { Matières premières } 53 \\
\text { Matériau de } \\
\text { construction } 18\end{array}$ \\
\hline $1880 \mathrm{E}$ & 288 & $\begin{array}{l}\text { Réseau de l'Allier } \\
\text { (SGCFE) }\end{array}$ & 293577 & 1019 & $\begin{array}{l}\text { Combustibles } 29 \\
\text { Céréales } 20\end{array}$ \\
\hline TVM & 182 & Tramw ays de l'Indre & 110258 & 605 & $\begin{array}{l}\text { Matières premières } 33 \\
\text { Céréales } 22 \\
\text { Engrais } 12\end{array}$ \\
\hline
\end{tabular}

\section{$>$ Répartition des exploitations en fonction de l'intensité du trafic}

La répartition des exploitations atteignant un niveau de trafic donné en fonction des statuts et des écartements est riche d'enseignements (tabl. 80). Des pourcentages voisins s'appliquent aux lignes dépassant $1000 \mathrm{t}$ à toutes distances par km exploité $(37 \%)$ et à celles se satisfaisant de moins de $500 \mathrm{t}(38,8 \%)^{11}$; un grand nombre de ces dernières n'atteignent même pas 300 t ou, pour être plus explicite, moins

10- Type de gisement superficiel dans les dépôts du sidérolithique dont la production annuelle est toujours restée faible, plusieurs cas aussi en Périgord avec également une desserte par une compagnie secondaire.

11- Ces pourcentages concernent l'ensemble des lignes sans distinction de statuts et d'écartements : dernière colonne du tableau en bas. 
de $892 \mathrm{~kg}$ par jour au km exploité. Le trafic marchandises sur ces lignes n'aidait guère à obtenir des résultats d'exploitation satisfaisants. Seconde constatation, la forte opposition induite par l'écartement; l'exemple des CFIL 1880 est probant : $80 \%$ des lignes à voie normale écoulent un tonnage au $\mathrm{km}$ exploité supérieur à $1000 \mathrm{t}$ contre 21,7 pour les lignes à voie étroite. Enfin, plus de la moitié des lignes de TVM se contente d'un tonnage inférieur à $500 \mathrm{t}$.

Tableau 80. Pourcentages de lignes ou réseaux atteignant un tonnage chargé au km exploité donné, en fonction des statuts et des écartements (1911)

\begin{tabular}{|c|c|c|c|c|c|c|c|c|c|}
\hline & & $<300 t$ & $\begin{array}{l}301 \text { à } \\
500 t\end{array}$ & $\begin{array}{l}501 \text { à } \\
700 t\end{array}$ & $\begin{array}{c}701 \text { à } \\
1000 \mathrm{t}\end{array}$ & $\begin{array}{l}1001 \text { à } \\
1500 \mathrm{t}\end{array}$ & $\begin{array}{l}1501 \text { à } \\
2000 \mathrm{t}\end{array}$ & $\begin{array}{l}2001 \text { à } \\
5000 \mathrm{t}\end{array}$ & $>5000 t$ \\
\hline & N 1865 & 0 & 0 & 5,5 & 0 & 5,5 & 16,6 & 27,9 & 44,5 \\
\hline & E 1865 & 0 & 0 & 66,6 & 0 & 0 & 33,4 & 0 & 0 \\
\hline & N 1880 & 4 & 0 & 4 & 12 & 40 & 8 & 16 & 16 \\
\hline & E 1880 & 16,6 & 28,4 & 18,3 & 15 & 16,6 & 3,4 & 1,7 & 0 \\
\hline TVM & & 34,4 & 20,5 & 11,9 & 9,6 & 4,3 & 6,5 & 10,7 & 2,1 \\
\hline Ense & mble & 21,1 & 17,7 & 13,8 & 10,4 & 12,3 & 6,9 & 9,9 & 7,9 \\
\hline
\end{tabular}

Les situations où on enregistre de forts tonnages au $\mathrm{km}$ exploité correspondent à de courtes lignes où les trafics de produits sidérurgiques et combustibles dépassent $70 \%$. On constate de faibles tonnages au $\mathrm{km}$ exploité, également sur des lignes courtes où les matériaux de construction assurent entre 28 et $60 \%$ des mouvements (tabl. 81).

Une autre remarque concerne, dans le temps, le parcours moyen accompli par une marchandise. Il s'abaisse de 23,7 à 19,8 km au cours de la première décennie du $\mathrm{xx}^{\mathrm{e}}$ siècle. L'allongement du réseau est plus rapide que le développement du trafic entre 1901 et 1911 : cette situation indique que les nouvelles lignes doivent une partie de leur activité à un détournement de trafic au détriment de celles déjà en service. La volonté de minimiser le prix de transport conduisait à l'emploi d'une ligne nouvelle, si cela réduisait le parcours sur voie ferrée. Par ailleurs, le passage d'une ligne à proximité d'une carrière, d'un lieu de foire, d'un bourg commerçant pouvait favoriser l'appel au transport ferroviaire pour des mouvements locaux auxquels le roulage répondait auparavant. 
Tableau 81. Valeurs extrêmes du tonnage à toutes distances par km exploité

\begin{tabular}{|c|c|c|c|c|c|}
\hline Statut & $\mathrm{Km}$ & ligne & $\begin{array}{c}\text { Tonnage } \\
\text { total }\end{array}$ & \begin{tabular}{|} 
Tonnage \\
$\mathrm{Km}$ \\
exploité
\end{tabular} & Principaux flux \\
\hline N 1865 & 15 & Chemin de fer de l'Est (a) & 188878 & 12589 & $\begin{array}{l}\text { Fer, fonte acier } \\
\text { Houille }\end{array}$ \\
\hline E 1865 & 11 & $\begin{array}{l}\text { Chemin de fer de } \\
\text { Marlieux à Châtillon-sous- } \\
\text { Chalaronne }\end{array}$ & 6082 & 552 & $\begin{array}{l}\text { Matériaux de } \\
\text { construction } \\
\text { Céréales }\end{array}$ \\
\hline N 1880 & 5 & $\begin{array}{l}\text { Aulnoye à Pont-sur- } \\
\text { Sambre }\end{array}$ & 28426 & 5685 & $\begin{array}{ll}\text { Fer, fonte, acier } & 3 \\
\text { Combustible } & 3\end{array}$ \\
\hline E 1880 & 7 & Roisel à Hargicourt (b) & 104250 & 14852 & $\begin{array}{l}\text { Engrais } \\
\text { Combustibles }\end{array}$ \\
\hline E 1880 & 59 & $\begin{array}{l}\text { Monsols à Cluny et La } \\
\text { Clayette (c) }\end{array}$ & 4273 & 72 & $\begin{array}{l}\text { Matériaux de } \\
\text { construction }\end{array}$ \\
\hline TVM & 2 & $\begin{array}{l}\text { Beaucourt à Beaucourt- } \\
\text { Dasle }\end{array}$ & 15962 & 7981 & $\begin{array}{l}\text { Combustible } \\
\text { Fer, fonte, acier } \\
\text { Matières premières } \\
\text { produits } \\
\text { manufacturés } \\
\end{array}$ \\
\hline TVM & 5 & $\begin{array}{l}\text { Pont-de-Vaux à Fleurville- } \\
\text { Pont-de-Vaux }\end{array}$ & 365 & 73 & $\begin{array}{l}\text { Matériaux de } \\
\text { construction } \\
\text { Divers }\end{array}$ \\
\hline TVM & 16 & $\begin{array}{l}\text { Nice à Contes } \\
\text { (Tramw ays de Nice et du } \\
\text { littoral) }\end{array}$ & 157164 & 9822 & $\begin{array}{l}\text { Matériaux de } \\
\text { construction } \\
\text { Houille }\end{array}$ \\
\hline
\end{tabular}

(a) Ligne de Carignan à Messempré, Monthermé-gare à Monthermé-ville, de VrigneMeuse à Vrigne-aux-Bois administrées par l'Est pour le compte du département des Ardennes.

(b) CFIL du Nord de la France.

(c) Chemin de fer départementaux du Rhône et Saône-et-Loire.

\section{. Les éléments du trafic de la petite vitesse}

Nous étudions maintenant les volumes des diverses classes de marchandises $^{12}$ (fig. 26 et 27 ) ; nous tenterons d'élargir le sujet en replaçant la statistique dans le cadre socio-économique qu'elle traduit (annexe 2).

$>$ Céréales et farines (fig. 26)

Cette classe regroupe des marchandises différentes n'alimentant pas des flux identiques par leur volume et leur circulation. Le seigle, le sarrazin occupent de vastes territoires dans les terres acides des massifs

12- L'ordre de présentation des classes de marchandises correspond à celui des statistiques et non à l'importance des flux. 
anciens et leur culture s'accompagne de transports à une échelle locale qui en font en Vendée, en Bretagne, en Limousin quelquefois des usagers des compagnies secondaires. L'orge, comme l'avoine, sert à l'alimentation animale dans les exploitations où elle est produite; dans la France de l'Est et du Nord, la France de la bière, on fait usage des voies secondaires pour l'acheminer jusqu'aux malteries. Le blé fait l'objet des trafics les plus volumineux et les plus lointains.

Il y a cent ans, la spécialisation en agriculture s'amorçait lentement ; les rendements céréaliers étaient à peine le quart de ce qu'ils sont devenus ; récolte faite, le paysan prélevait ses semences et le nécessaire à sa consommation, puis commercialisait le surplus, variable suivant les années. Des milliers et des milliers de tonnes de céréales panifiables faisaient l'aller-retour de la ferme au moulin, revenant sous forme de farine, et n'empruntaient aucun chemin de fer mais la voiture tirée par les bœufs, les chevaux ou les ânes. Rappelons que le boulanger a été un des derniers artisans à s'installer dans les villages, faute de clientèle suffisante : il lui fallait un bourg où vivait une population diversifiée ; il s'approvisionnait beaucoup auprès des meuniers voisins et, lui non plus, ne faisait pas appel au transport ferroviaire. Rappelons qu'à l'automne 1940, lorsque le spectre du rationnement est devenu réalité, la pratique ancestrale de faire son pain a été retrouvée rapidement, parce qu'il n'y avait dans la France profonde que peu d'années qu'elle avait été abandonnée.

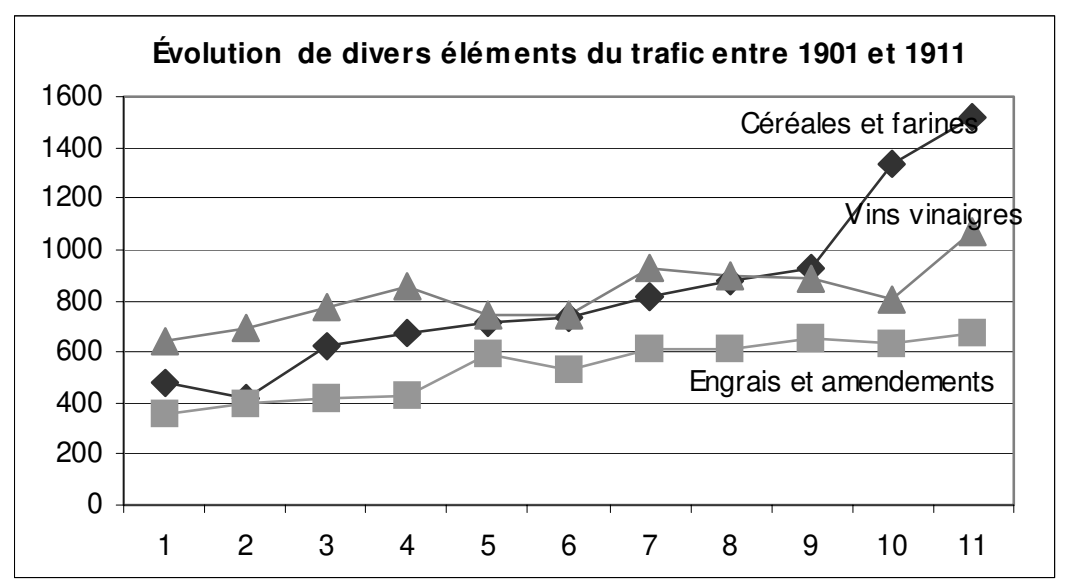

Figure 26. @ M. Wolkowitsch / A.-L. Wolkowitsch, 2003. 
Les céréales panifiables et essentiellement le blé entrainaient des courants de trafic appréciables puisqu'il fallait nourrir les populations urbaines. Selon leur importance, les villes faisaient appel à une zone plus ou moins étendue, mais en limitant au mieux le transport. Les mercuriales signalent l'ampleur des écarts entre les prix des blés sur les marchés urbains ; entre 1859 et 1878, cet écart se réduit des deux tiers entre Albi et Bourges par exemple, grâce au chemin de fer, mais c'est avant l'essor des réseaux secondaires ${ }^{13}$. L'uniformisation des cours encourage l'appel à des régions de plus en plus lointaines ; les compagnies secondaires bénéficient d'un trafic diffus de ramassage des grains acheminés vers les villes proches, mais de plus en plus vers les gares de transit avec les grandes compagnies.

Autre réalité de l'époque, la France n'est pas dans les premiers rangs des pays exportateurs de céréales comme aujourd'hui, mais importatrice pour alimenter ses citadins. De Rouen à Paris par la Seine, de Bordeaux ou Marseille pour la région toulousaine ou le Languedoc, les blés étrangers inondent les marchés. Le marché parisien est perdu par les régions du sud du Bassin parisien ou de ses confins ; le PO crée un tarif spécial dégressif pour ouvrir aux producteurs de ces régions les marchés du Languedoc et de l'Aquitaine pour concurrencer les grains étrangers. Les réseaux secondaires de la Vienne, de l'Indre-et-Loire, du Loir-et-Cher, de l'Indre, du Cher étaient mis à contribution si nécessaire pour un transport initial ; pour autant, le PO n'avait pas jugé nécessaire d'établir un tarif commun avec les compagnies intéressées.

Entre le meunier immortalisé par Daudet en $1866^{14}$ et la fondation de la Société des grands moulins de Paris en 1919 se situe un demi-siècle d'évolution d'une profession. De telles transformations ne pouvaient qu'engendrer un bouleversement des circuits de la farine. Ne pouvant distinguer dans les statistiques ceux de la farine de ceux des grains, nous ne pouvons que suggérer des interprétations et le rôle des lignes secondaires. La meunerie artisanale, encore vivante dans l'entredeux-guerres, ne disparait pas avant 1914 avec la création des minoteries ; ces dernières sont créées près de grandes villes, Bordeaux, Nancy, Lille, Paris pour produire des milliers de quintaux par jour. L'approvisionnement en farine, même dans des villes modestes, est de plus en plus le fait de ces minoteries; cette diffusion fait appel aux réseaux secondaires, dans les villes ou les bourgs non desservis par les grandes compagnies.

13- Foville, ouvr. cité, fournit pour d'autres denrées des exemples de ces mécanismes conduisant à la formation d'un marché national.

14- A. Daudet, Les Contes de mon moulin. 
Les ports contribuent à l'approvisionnement des minoteries, mais les chemins de fer secondaires, ne disposant pas de voies de quai, n'en profitent pas. Les chemins de fer départementaux des Bouches-duRhône transportent 121000 t de céréales et farines, soit $49 \%$ de leur activité marchandises, en combinant la collecte de blé dans les campagnes et quelques acheminements terminaux vers des usines (pâtes et semoulerie).

Entre le ramassage des grains et la distribution de la farine, presque toutes les compagnies acheminent cette classe de marchandises. Les réseaux des zones de production enregistrent des tonnages élevés : Seineet-Marne : 78000 t; Allier : 59000 t ; Loir-et-Cher et Indre : plus de $25000 \mathrm{t}$. Avec un plus faible tonnage, $12000 \mathrm{t}$, ce trafic représente $30 \%$ sur la ligne de Maringues à Gerzat en Limagne.

Le tonnage total est passé de 480000 à 1520000 t, soit plus $214 \%$, en dix ans, la plus forte progression pour l'ensemble des lignes secondaires ; aussi la part de ces marchandises s'est-elle considérablement accrue (fig. 27a, 27b). La courbe du trafic est ascendante, à part un fléchissement en 1902, peut-être lié à une mauvaise récolte ; la progression du trafic est spectaculaire entre 1909 et 1911.

\section{$>$ Vin, vinaigre, esprit de vin (fig. 26)}

Le vin domine totalement les échanges dans cette classe de marchandises. La consommation est généralisée, la production est localisée, même si des vignobles médiocres produisant des «piquettes » de 7 à $9^{\circ}$ ne font qu'amorcer leur déclin; pour leur producteur, le véritable vin est, suivant le parler populaire, « le gros rouge qui tache », originaire du Languedoc et coupé d'importation algérienne.

Des zones de production, le vin est transporté vers les marchés de consommation en wagon-réservoir ou en fûts, suivant les volumes à acheminer. Les grands marchés de consommation sont la région parisienne, les régions industrielles du Nord, de l'Est, de la Loire... mais aussi les campagnes, notamment la Bretagne et la Normandie.

La principale zone de production est le Languedoc avec des extensions vers le Roussillon et, en Bas-Languedoc, le Minervois : ainsi la Compagnie des chemins de fer de l'Hérault transporte $142300 \mathrm{t}$ de vins (36 \% de son trafic), les Tramways de l'Aude 48000 t (57\%), les chemins de fer des Pyrénées-Orientales 28000 t (47\%), les chemins de fer départementaux des Bouches-du-Rhône 25600 t (15\%), ceux des Charentes 21429 t (12\%), pour citer les principaux ; d'autres directement desservis par les grands réseaux n'apparaissent pas. 


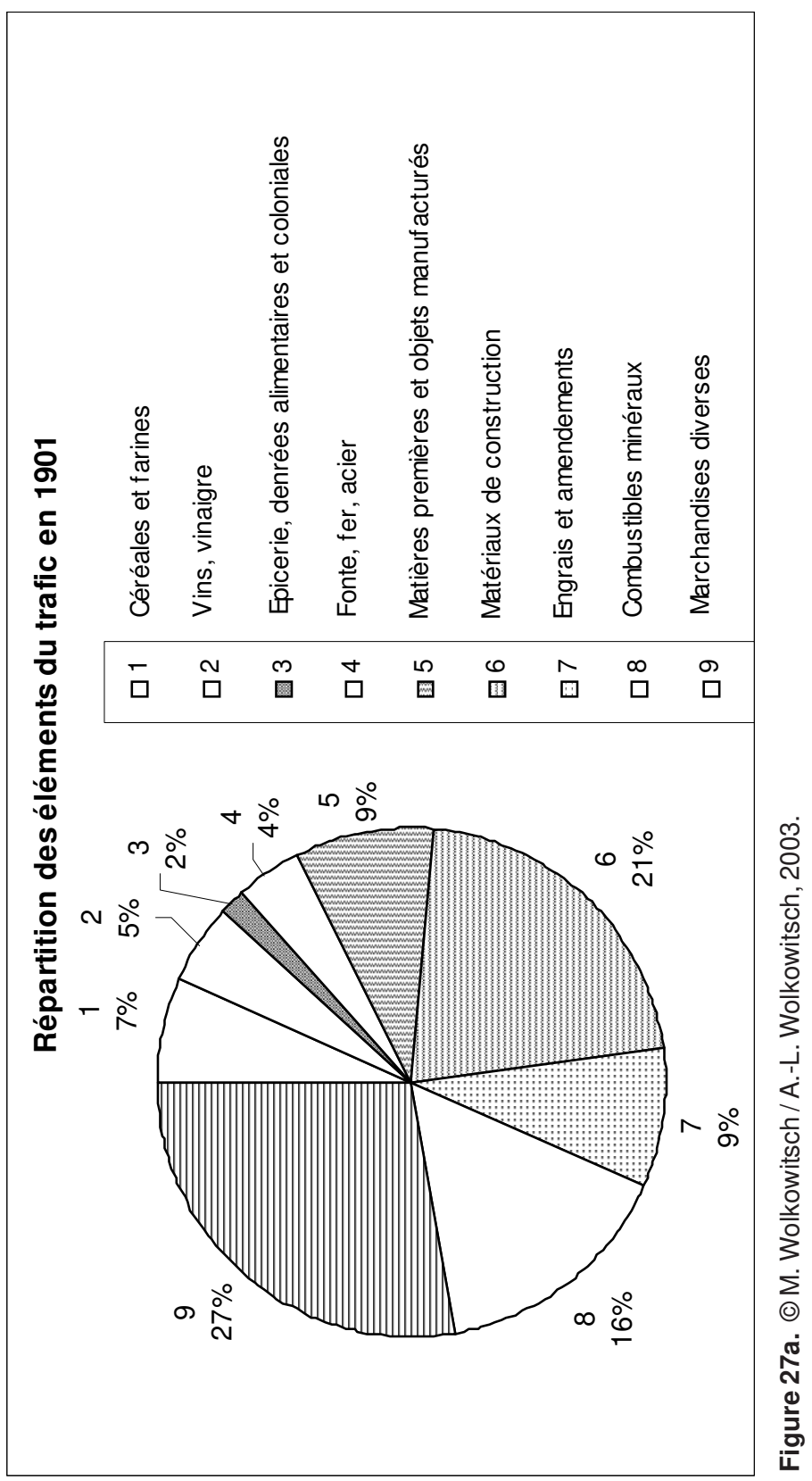




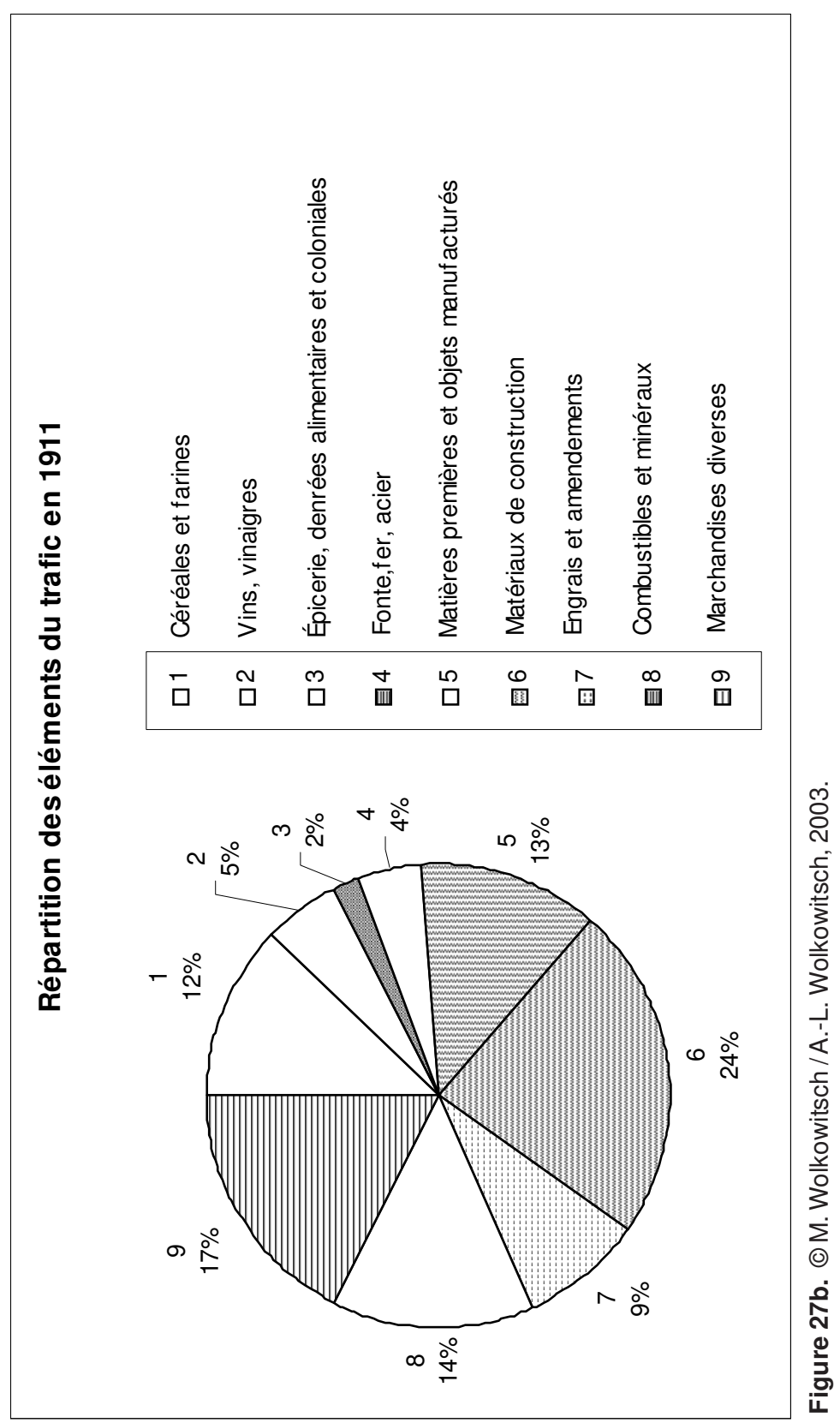


Ce trafic du vin a été facilité par l'établissement de tarifs communs associant grands réseaux et compagnies secondaires concernées. Lorsque ces dernières étaient équipées de voies normales, comme dans l'Hérault et les Pyrénées-Orientales, l'envoi des wagons-réservoirs sans manutention était possible. Les expéditions se faisaient par ailleurs en fûts, notamment pour les vins de qualité ; les expéditions aux grossistes des villes moyennes, à des commerçants des bourgs, même à des particuliers supposaient parfois pour un parcours terminal l'appel à une compagnie secondaire : contrairement au rôle de collecteur dans les zones de production, les compagnies secondaires pour la distribution diffuse n'offraient pas de tarifs communs avec les grands réseaux ; l'expéditeur ne bénéficiait même pas toujours d’un tarif spécial. Cela n'empêche pas la présence d'un trafic de vin sur la majorité de ces compagnies. Les wagons-réservoirs n'étaient utilisés que pour les envois vers Paris-Bercy; ils appartenaient à des propriétaires privés, grands négociants en vin ou entreprises de location (voir chapitre XII).

Les expéditions ne progressent pas régulièrement; elles dépendent des vendanges plus ou moins favorables, des méventes qui s'accompagnent de crises sociales graves. Le tonnage passe de 351 à 673 mille tonnes en dix ans, soit une croissance de $91 \%$. La part de cette classe de marchandises dans le total du trafic oscille autour de $5 \%$ (fig. 27).

\section{> L'épicerie, denrées alimentaires et coloniales (fig. 28)}

L'épicerie comprend les produits comestibles et les produits ménagers. Les épiceries des villages, des bourgs ou des toutes petites villes desservies par les seuls chemins de fer secondaires offraient à leur clientèle un choix plus varié (outillage simple, vêtement de travail...); quels critères les compagnies adoptaient-elles pour établir le tonnage correspondant à cette classe de marchandises ? Ces épiceries rurales avaient en face d'elles une part de population disposant de moyens limités, faisant d'abord appel à ses propres productions : fromages, produits laitiers, orge grillé en substitut du café... mais achetant le sel, le sucre, l'huile éventuellement, le chocolat, quelques produits d'entretien de base, savon noir, savon de Marseille. Ces marchandises n'ont jamais tenu une grande place, $2 \%$ du trafic total en 1901 comme en 1911 (128 000 et 259000 tonnes), soit néanmoins une croissance en volume de $103 \%$; la progression du trafic est particulièrement marquée après 1908 ; cela traduit sans doute une évolution vers une consommation se détachant lentement d'une satisfaction des besoins par ses propres 
productions ; c'est à mettre à l'actif des chemins de fer comme moyen d'ouverture des régions rurales vers les marchés régionaux et nationaux (fig. 27) ${ }^{15}$.

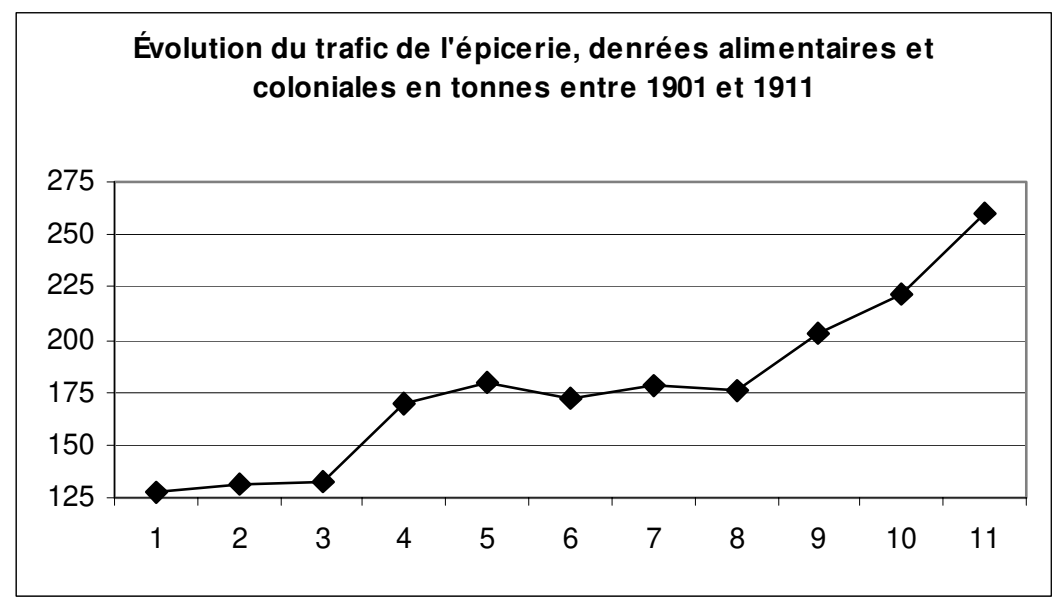

Figure 28. (c) M. Wolkowitsch / A.-L. Wolkowitsch, 2003.

\section{$>$ Fer, fonte, métaux (fig. 29)}

Les centres métallurgiques les plus actifs étant desservis par les grandes compagnies, ce trafic a de l'importance pour un nombre restreint de compagnies secondaires. Des tonnages appréciables représentant un pourcentage élevé du trafic s'enregistrent sur quelques exploitations : la ligne de Gudmont à Rimaucourt de la SGCFE (47 300 t, 44 \%), le réseau de Saône-et-Loire des CFD (51 324 t, 47 \%), diverses lignes secondaires exploitées par l'Est $(80000$ t, $61 \%$ ) et par d'autres compagnies ${ }^{16}$. Une seule ligne de TVM, dans la région de Montbéliard, peut être retenue (18000 t, $25 \%$ ), face à une dizaine de lignes de CFIL dont plusieurs à voie normale. Sur le reste du réseau circulent des tonnages allant de quelques dizaines à quelques centaines de tonnes, souvent moins de $5 \%$ et même de $1 \%$ du trafic ; ce sont les approvisionnements en fer ou en acier nécessaires aux ateliers et aux

15- Rappelons que dans les années trente, dans bien des campagnes, des "produits coloniaux » comme les bananes et les oranges étaient encore mis dans les sabots de Noël des enfants. Cela souligne leur rareté. On imagine la situation avant 1914.

16- Pour les premières, voir tabl. 79, note a. Autres compagnies : Tramways de la Sarthe $38600 \mathrm{t}$ (35\% du trafic), Chemin de fer à voie étroite des Ardennes $29000 \mathrm{t}$ (12\%), Aulnoye à Pont-sur-Sambre 11140 t (39\%). 
artisans ruraux, charron, chaudronnier, maréchal-ferrant, d'où des mouvements diffus. Les tonnages expédiés sont passés de 304000 à 539000 tonnes, soit une progression de $77 \%$. La part dans le trafic total est restée de l'ordre de $4 \%$ (fig. 27). Entre 1903 et 1908, on note des phases de régression et stagnation suivies d'une reprise très sensible.

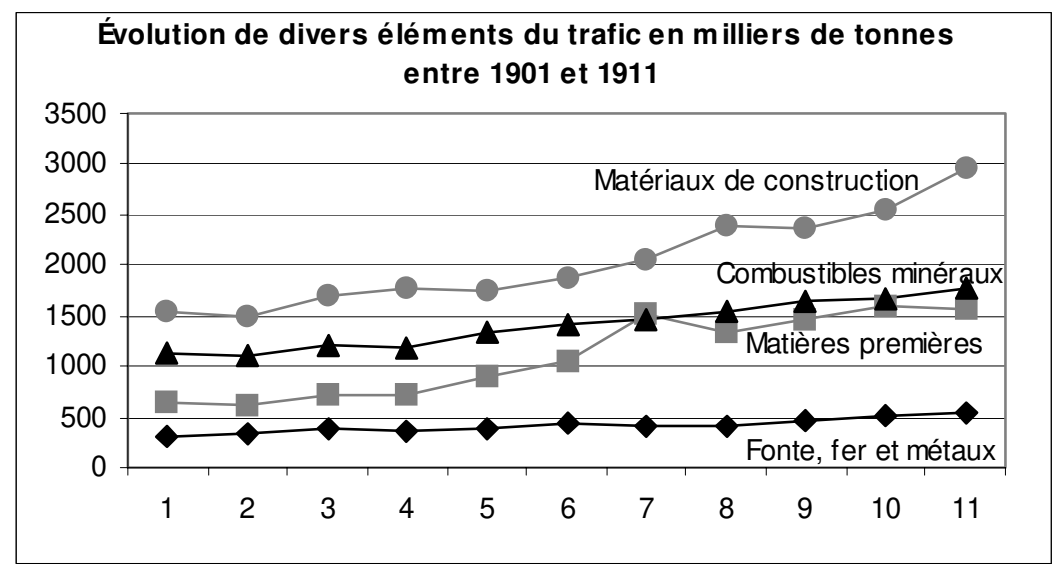

Figure 29. @ M. Wolkowitsch / A.-L. Wolkowitsch, 2003.

\section{> Matières premières, produits manufacturés (fig. 29)}

Nous sommes encore en présence d'un regroupement statistique qui laisse dubitatif. Par exemple, dans l'entre-deux-guerres et, bien plus, avant 1914, subsistent des biscuiteries dans des bourgs desservis par les seules compagnies secondaires : la farine et le sucre sont les matières premières ; les biscuits sont vendus dans le cadre régional ; la farine estelle comptée en matière première ou dans la première classe «céréales et farine ", les biscuits comme produits manufacturés ou mieux dans l'épicerie ? Les tonnages en question dans chaque cas sont faibles, mais ils peuvent peser lourd dans l'activité d'une compagnie. Les industries textiles reçoivent leur matière première par les grandes compagnies qui les acheminent du Havre pour le coton, de Rouen ou de Dunkerque pour la laine directement vers les usines. Le fer et l'acier sortis de la sidérurgie du Nord ou de Lorraine sont de même acheminés vers les usines de métallurgie de transformation. Hors les mines de fer de Lorraine, la production est limitée. C'est au niveau de la distribution des produits manufacturés que les chemins de fer secondaires jouent un rôle. 
Le tonnage transporté passe de 635000 à 1,570 million de tonnes, soit une croissance de $147 \%$, la plus importante après celle des céréales (fig. 27). La part dans le trafic total augmente de façon sensible, atteignant $13 \%$. Comme pour la classe précédente, on remarque une croissance accentuée à partir de 1908.

Plus du tiers du trafic est concentré sur les réseaux de la Gironde (275 000 t) et de la Somme (174000 t) de la SGCFE, de la Société des voies ferrées du Dauphiné $(58000$ t) et du Réseau de la Camargue (54 000 t) ; sur ces réseaux, ces marchandises interviennent respectivement pour $53 \%, 33 \%, 29 \%$ et $33 \%$ du trafic. Pour 21 compagnies, la part des matières premières et produits manufacturés dépasse $25 \%$ : l'activité portuaire en Gironde, le sel en Camargue, les betteraves dans la Somme expliquent cette situation qui se traduit par des tarifications adaptées (chapitre xiI). On relève un trafic important sur la ligne de Caen à la mer lié à la métallurgie normande, sur les lignes vosgiennes et des monts du Lyonnais probablement grâce aux industries textiles. Les 35000 t des Chemins de fer du Born et du Maremsin sont peut-être du bois des Landes. Force est de constater que des études approfondies sur le trafic des compagnies permettraient seules d'accéder à des connaissances satisfaisantes.

\section{$>$ Matériaux de construction (fig. 29)}

La demande de matériaux de construction est importante : la construction ferroviaire suppose l'établissement de la plate-forme, le ballast, les bâtiments, les ouvrages d'art ; ils sont nécessaires aussi pour les routes, dont on se soucie pour les principales d'améliorer la chaussée. L'urbanisation s'accompagne de la construction de maisons d'immeubles ; la construction d'entreprises industrielles, d'entrepôts se développe ; à côté des matériaux de carrière, le bois intervient dans la charpente. La production des forêts et des carrières se trouve souvent à proximité de lignes secondaires, les utiliser même pour des trajets restreints et malgré une double manutention est économique.

Le trafic des matériaux de construction est le premier en tonnage en 1911 (fig. 27) où il a supplanté les marchandises diverses; il passe de 1540000 à $2946000 \mathrm{t}$; la progression est continue à partir de 1905 et s'accélère à partir de 1909 ; en dix ans, le gain est de 91 \%.

Rares sont les compagnies sans trafic de cette classe ; 38 compagnies lui doivent plus de $30 \%$, dont 16 plus de $50 \%$ de leur activité ; la demande dans les villes explique les pourcentages sur les lignes de Veurey à Grenoble (62\%), de Camarsac à Bordeaux (64\%), de Lyon à Vaugneray et Mornant (53\%) et sur le réseau de l'Est de Lyon (51 \%), des Tramways de Cherbourg (100\%). Des lignes bien situées vis-à-vis 
de l'exploitation des carrières ou des forêts ont aussi un trafic de matériaux de construction dominant: Riom à Volvic (94\%), Gué à Ménaucourt (81\%), Voiron à Saint-Béron (66 \%).

Même s'il existe une réelle permanence dans l'exploitation des carrières, ce type de trafic est aussi dépendant de la demande qui peut se déplacer en fonction des grands travaux en cours et des aménagements urbains prévus. Trafic traditionnel où, lorsqu'elle le pouvait, la voie d'eau concurrençait le chemin de fer, tandis que celui-ci, pour un trafic souvent de proximité, a subi une forte concurrence des camions ${ }^{17}$. Les chemins de fer secondaires avant 1914 ont vu les matériaux de construction occuper une part croissante des marchandises transportées.

\section{$>$ Engrais et amendements (fig. 26)}

Parcourant les espaces ruraux, les compagnies secondaires devaient jouer un rôle décisif dans la diffusion des engrais et amendements. Les engrais étaient d'abord destinés aux zones d'agriculture en évolution rapide vers la spécialisation, vers l'intensification, vers une commercialisation systématique de la production : ceintures maraîchères des villes et, notamment, de Paris, production betteravière picarde, viticulture. Les tonnages acheminés et le pourcentage des engrais sur le trafic total ne relèvent pas du hasard : réseau de la Somme de la SGCFE : 140000 t (30\%); ligne de Roisel à Hargicourt ${ }^{18}$ : 91000 t (87\%); Chemin de fer de l'Hérault : 57000 t $(15 \%)$; ligne d'Arpajon aux Halles : 35000 t (60\%).

Les amendements avaient un double rôle à jouer ; ils devaient permettre d'améliorer le système de culture et de conquérir de nouvelles terres sur la friche. Le problème était celui des terres acides du Massif central, du Massif armoricain ; les fours à chaux installés nombreux sur leurs bordures calcaires expédiaient leur production dans le rayon permis par les prix du roulage pour un produit pondéreux de faible valeur. La pénétration n'excédait pas une zone de 25 à $30 \mathrm{~km}$. Le chemin de fer modifie la situation : dans le Massif armoricain comme dans le Massif central et dans leurs confins, les expéditions sur les grands réseaux à plus de $100 \mathrm{~km}$ représentent rapidement près de $50 \%$; une bonne partie de ce trafic s'achève sur les lignes secondaires; sans parler du réseau breton géré par la SGCFE, on trouve sur les réseaux de Vendée, du Morbihan, du Finistère... des données assez proches, environ

17- Paris qui consommait un tonnage considérable recevait ses matériaux en grande partie par voie fluviale. Le TVM d'Arpajon à Paris en transportait tout de même $12000 \mathrm{t}$.

18- Roisel abrite une fabrique d'engrais. 
20000 t et $20 \%$ du trafic en 1911. Si on examine les effets de l'utilisation des amendements, on peut retenir deux résultats : entre 1831 et 1903, les brandes dans la Vienne ont reculé de 90000 à 29000 ha $^{19}$; l'évolution des cultures céréalières dans le département de la Haute-Vienne est marquée par un double recul du sarrazin (31 000 à 5000 ha), du seigle (77 000 à $15000 \mathrm{ha}$ ) face aux progrès du blé (16 000 à $50000 \mathrm{ha}$ ) entre 1840 et $1930^{20}$. Ces exemples sont représentatifs de transformations qui ont touché les régions marquées par un même retard à cause de leurs sols. Si la mode aujourd'hui est de consommer des crêpes au sarrazin et du pain de seigle, accéder à la consommation de pain blanc, à la farine de blé, apparaissait au début du siècle précédent comme un véritable progrès social.

Le tonnage total des engrais et amendements a progressé de 1901 à 1911 seulement de $66 \%$ (646 700 t à 1072000 t), leur part dans l'activité des compagnies secondaires a peu varié. Rares sont les compagnies qui ne transportent pas du tout ces marchandises, ne serait-ce que quelques milliers de tonnes; très nombreuses sont celles où elles représentent au moins $20 \%$ de l'activité de l'exploitation (fig. 27). Les progrès enregistrés dans l'agriculture, grâce au développement de la consommation d'engrais et amendements transportés à bas prix, ont favorisé une diversification de la production (pommes de terre, autres légumes, fruits...) dont l’acheminement vers les marchés à prix élevés a bénéficié à toutes les compagnies de chemins de fer, VFIL incluses.

\section{> Les combustibles minéraux : houille, coke (fig. 29)}

Un regard vers le passé est nécessaire pour comprendre la fonction assurée par les chemins de fer secondaires pour le transport des combustibles. Au moment où ces lignes se multiplient, la houille a triomphé du bois et son utilisation semble garantir le développement industriel. Un mémoire de 1859 souligne que l'équipement des départements en « forces en chevaux fournis par les machines à vapeur » dépend du prix de la houille : 1481 chevaux avec la houille à 7,80 F la tonne dans l'Allier disposant de treize houillères, 107 chevaux en Indre-et-Loire avec un prix de la tonne à 47,22 $\mathrm{F}^{21}$. Seul le chemin de fer pouvait éliminer cette inégalité ; encore en 1867 un contemporain estimait que, avec la même somme, on transporterait la houille à $30 \mathrm{~km}$ par roulage et à $300 \mathrm{~km}$ par chemin de fer ${ }^{22}$.

19- C. Passerat, Les Plaines du Poitou, Paris, 1909, 232 p.

20- Office national interprofessionnel des céréales (ONIC), Services techniques, monographies céréalières départementales, 1940.

21- Mémoire Mauguin, Archives nationales, $F^{14}$ 8939. Ligne Tours-Gannat 1859.

22- A. d. de l'Allier, S j m 1 1-2. Ligne Tours à Montluçon 1855-1878. 
Les espérances d'un trafic houiller apparaissent comme la justification de construire une ligne dont la nécessité serait indispensable et la rentabilité assurée ; aussi tous les concessionnaires recherchent-ils, si possible, dans le tracé de leurs lignes, des bassins houillers à desservir.

Les petits bassins de l'Allier, du Puy-de-Dôme, de la Creuse, du sud du Massif central sont souvent à l'écart des lignes d'intérêt général concédées : Montluçon à Moulins, Gannat à Limoges, Brive-la-Gaillarde à Rodez, Alès à La Grand-Combe ; les concessionnaires ont aussitôt créé les courts embranchements nécessaires à voie normale pour que le trafic houiller ne leur échappe pas ${ }^{23}$. Lorsque des compagnies houillères ont manifesté l'intention de construire des lignes pour acheminer leur production jusqu'à une gare d'une compagnie de chemin de fer, elles se sont heurtées à une opposition résolue des grandes compagnies, même dans le cas d'un projet de ligne à voie étroite (Société des houillères de Champagnac-les-Mines ou des houillères de Saint-Éloy-les-Mines) ${ }^{24}$. Seules les puissantes compagnies minières du bassin du Nord - Pas-deCalais ont pu créer un véritable réseau de chemins de fer industriels relié aux lignes du Nord.

Dans tous ces cas de figures, il reste peu ou pas de place pour permettre aux lignes secondaires d'aller chercher le charbon sur le carreau des mines. Le trafic des combustibles n'est pas pour autant négligeable ; il s'élève de 1123000 t à 1772600 t, soit une augmentation de $57 \%$ de 1901 à 1911 ; il reste le troisième par le tonnage, même si sa part enregistre un léger déclin (fig. 27). Après quatre années de flux et reflux, à partir de 1904, la progression ne s'arrête plus.

L'indispensable distribution de la houille à travers le pays se traduit par sa présence dans le trafic de la quasi-totalité des compagnies; les quantités varient beaucoup en fonction de l'espace desservi. De rares compagnies acheminent de volumineux tonnages : dépôts pour constituer des stocks, près des villes : réseau de l'Est de Lyon $107000 \mathrm{t}$ et $23 \%$ du trafic, ligne de Nice à Contes 68000 t et $43 \%$; réseau du

23- Mine de Montvicq (Doyet-la-Presle à Bézenet), mine de Lavaveix (Busseau-surCreuse à Lavaveix, prolongement vers Ussel, mine de Decazeville-Fontvergne (Vivier à Decazeville), mines de Saint-Ambroix et Bessèges (Alès à Saint-Ambroix et Bessèges).

24- La société houillère de Champagnac demandait la concession de $111 \mathrm{~km}$ à voie métrique pour transporter sa production, mais aussi tous trafics, voyageurs compris, jusqu’à Saint-Denis-près-Martel. La Compagnie du chemin de fer d'intérêt général de Tulle à Clermont-Ferrand a rappelé qu'un embranchement vers Champagnac était prévu et qu'elle comptait sur le trafic houiller pour assurer la rentabilité de la ligne. Même cas de figure pour la desserte des mines de Saint-Éloy ; un embranchement a été construit depuis Lapeyrouse, prolongé ultérieurement jusqu’à Volvic, bifurcation avec la ligne Clermont-Ferrand à Tulle. 
département de la Somme de la SGCFE pour faire face aux besoins industriels des sucreries, 59000 t et $12 \%$. La même entreprise, dans l'Allier, conduisait aux usines et ateliers $85000 \mathrm{t}$ de houille $(29 \% \mathrm{du}$ trafic), que les grands réseaux acheminaient depuis les petites houillères jusqu'à des gares de transit. Dans les régions industrielles de l'Est, du Nord, mais surtout des confins du Rhône et de la Loire, on trouve d'innombrables exemples de lignes courtes acheminant des tonnages modestes représentant une proportion appréciable du trafic : ligne de Cambrai à Catillon (15000 t, $35 \%$ ), ligne de Maubeuge à Villers-SireNicole (13 000 t, $38 \%$ ), réseau du Valenciennois (5 000 t, $11 \%$ ), ligne de Saint-Amand à Hellemmes $(4000 \text { t, } 80 \%)^{25}$. Cette diffusion de la houille comme celle de l'acier et du fer permettent le développement d'une multitude d'ateliers ruraux où charrons, chaudronniers, maréchauxferrants deviennent de plus en plus indispensables à la vie agricole ; les chemins de fer secondaires répondent bien à la volonté de desserte de proximité voulue par ceux qui les ont créés.

\section{$>$ Marchandises diverses (fig. 30)}

La classe des marchandises diverses connait une croissance faible par rapport aux autres, seulement $10 \%$; sa part régresse fortement ; le trafic est de 1991000 t en 1901, 2190000 t en 1911. La courbe d'évolution du trafic est en dents de scie (fig. 27) ; le trafic maximum est atteint en 1909 (2590000 t), suivie de deux années de déclin (2 190000 t), soit un recul de $15 \%$. Le trafic de 1911 est à peine supérieur à celui de 1903. Aucune des courbes déjà observées ne montrait un tel profil, elles signalaient notamment un relèvement du trafic dans les dernières années; elles traduisent une consommation accrue de matières premières, matériaux de construction etc. ; quelles sont donc ces marchandises diverses dont la consommation diminuerait ? Il y a là un constat qui mérite réflexion.

Observons d'abord la disparition des industries locales face aux productions de masse qui se sont imposées : en 1900, il y a longtemps qu'on a cessé de filer la laine et tisser du drap dans les fermes, les ateliers du textile ont pour beaucoup disparu dans les années 1875-1885, il en va de même de la petite métallurgie dans le Poitou, par exemple ; les derniers hauts-fourneaux du Berry s'éteignent en 1870 et 1908. Les industries produisant pour un marché restreint disparaissent devant la concurrence des produits venus de l'extérieur.

25- Exemples dans la région Rhône-Loire : Amplepuis à Saint-Vincent-de-Reins : 4000 t, $33 \%$; Saint-Victor à Thizy : 9000 t, $41 \%$. 
Seconde observation : le commerce sédentaire et permanent se substitue au commerce temporaire et itinérant. Les magasins se multiplient ; le choix de leur localisation ne pouvait être indifférent à la présence d'une desserte ferroviaire proche ${ }^{26}$; de vieilles enseignes, des inscriptions laissées par le temps sur de vieux murs sont les témoignages de la vitalité de cette activité commerciale au cœur des bourgs et parfois des villages. Les marchandises arrivaient depuis les régions de grande production industrielle jusqu'aux gares de contact avec les réseaux secondaires ; ces derniers se chargeaient de la phase ultime de distribution, suivant des flux qui copiaient ceux accomplis par les commis-voyageurs, lors de leurs visites à leurs clients ${ }^{27}$.

Il nous paraît vraisemblable que les compagnies ont progressivement eu le souci de mieux connaitre la composition de leur trafic et ont ventilé une partie des marchandises diverses entre l'épicerie, les produits manufacturés, peut être d'autres classes. Cela semble la seule explication à la faible progression du tonnage acheminé sous cette appellation. L'imprécision sur la nature des marchandises diverses explique que les pourcentages sur le trafic total et leur tonnage par compagnie ne peuvent faire l'objet de commentaires valables.

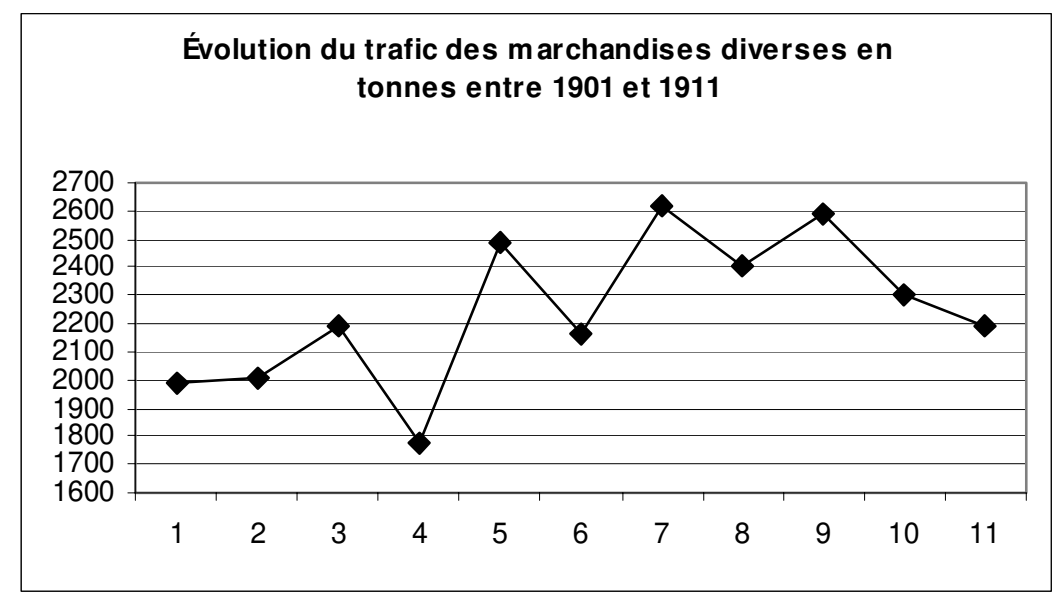

Figure 30. () M. Wolkowitsch / A.-L. Wolkowitsch, 2003.

26- Brian-Berry, Géographie des marchés et du commerce de détail, Ur, Paris, Colin, 1971, 254 p., traduit de l'anglais par B. Marchand.

27- Cf. ci-dessus p. 377. 


\section{. Les accessoires de la petite vitesse (fig. 31)}

Voitures et matériel roulant, animaux figurent sous ce vocable. Les statistiques fournissent d'une part le nombre de voitures et d'espèces animales par tête, d'autre part l'équivalent en tonnes suivant une méthode de conversion dont nous avons signalé les limites (tabl. 82).

\begin{tabular}{|c|c|c|c|c|c|}
\hline & Véhicules & Équidés & Gros bétail & Moyen bétail & Petit bétail \\
\hline $\mathbf{1 9 0 1}$ & 1211 & 14831 & 99604 & 248269 & 131644 \\
\hline $\mathbf{1 9 1 0}$ & 1855 & 31681 & 233660 & 444564 & 212785 \\
\hline $\mathbf{1 9 1 1}$ & 2032 & 31185 & 230063 & 374745 & 207648 \\
\hline $\mathbf{1 9 0 1 / 1 9 1 1}(\%)$ & 67 & 110 & 131 & +51 & 57 \\
\hline
\end{tabular}

Tableau 82. Les "accessoires de la petite vitesse", nombre de véhicules et de têtes de bétail sur les chemins de fer secondaires, 1901-1911

Le tonnage est faible : 88000 t en 1901, 188000 t en 1911, soit une croissance de $113 \%$. La courbe traduit une montée constante jusqu'en 1910, suivie d'une chute de $20 \%$ en un an. L'étude des mouvements par l'autre méthode éclaire cette évolution : le nombre de têtes embarquées du moyen bétail baisse de $15 \%$, tandis qu'on observe un léger tassement pour les gros et petits bétails comme pour les équidés. Le nombre de voitures et matériel roulant est seul en progrès : cette formule ne permet pas de connaitre les parts des automobiles, dont le transport apparaît dans la tarification, des voitures à chevaux et du matériel roulant, désignant sans doute des machines agricoles simples et du matériel militaire.

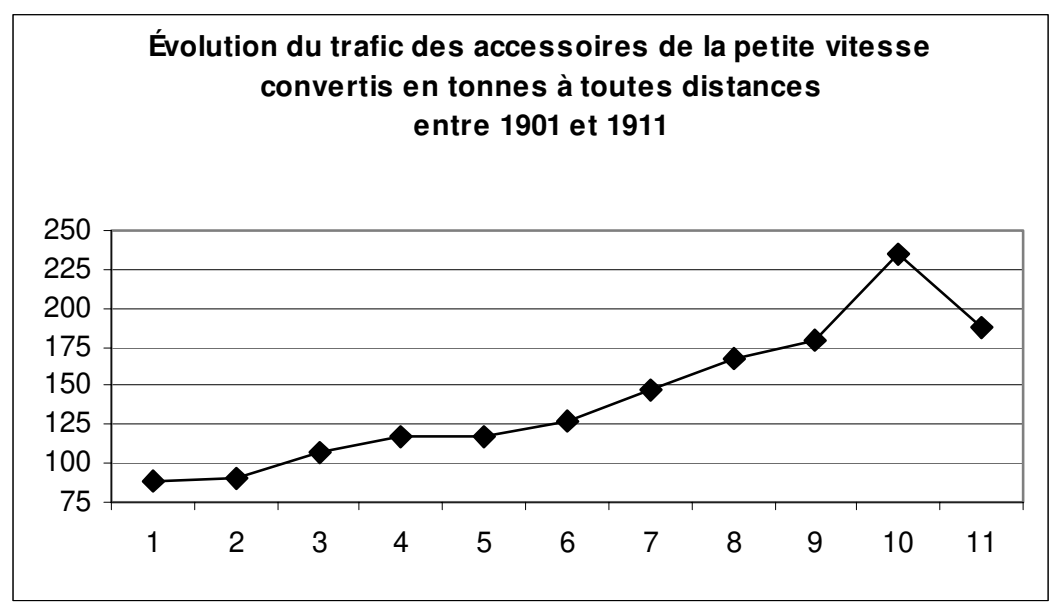

Figure 31. @ M. Wolkowitsch / A.-L. Wolkowitsch, 2003. 


\section{$>$ Voitures et équidés}

Le très petit nombre de véhicules transportés ne surprend pas; des ateliers fabriquaient des voitures à chevaux pour la promenade ou le travail livrées dans un rayon proche. La production automobile était réduite; les rares véhicules qui circulaient accompagnaient plutôt un voyageur qu'ils ne faisaient l'objet d'une livraison à un acheteur. Nous manquons de précisions sur ces données. Les effectifs du bétail transporté par les chemins de fer secondaires sont réduits ; le problème du transfert des animaux dans les gares de transit devait limiter leur rôle à l'acheminement direct des bêtes vers un marché local de consommation; les expéditeurs devaient rechercher les gares d'où l'envoi était possible sans transbordement jusqu'aux grands marchés de consommation comme Paris ou Lyon.

Toutes les compagnies ne concourent pas également à ces trafics ; beaucoup ignorent totalement tel ou tel élément; on le vérifie pour les voitures comme pour les animaux, ce qui s'explique par l'absence de telle ou telle espèce dans la zone desservie.

Six compagnies, transportant plus de cent voitures chacune, se partagent plus de $40 \%$ des mouvements. Si la ligne de Vélu à SaintQuentin transporte 233 voitures, quatre entreprises de la France méridionale en acheminent 468, soit $23 \%$; hors l'Ille-et-Vilaine (103), les chiffres sont de l'ordre de quelques dizaines ${ }^{28}$. Toutes les autres compagnies transportent très peu ou pas du tout de voitures. Absence de demande, absence d'équipement adapté, qu'il s'agisse de wagons plats ou de systèmes d'embarquement? Une analyse permettant de connaitre la réponse au cas par cas serait intéressante ; cela dépasse le problème de ce type de trafic ; des obstacles techniques, matériels, ont souvent limité l'activité de certaines entreprises, notamment de TVM ; l'exemple de gares dotées d'appareils de levage de faible puissance seulement n'est pas exceptionnel.

Même constat pour les équidés, 50 \% des acheminements se font sur six lignes ou réseaux (Mamers à Saint-Calais, Angoulême à Matha, Sarthe, Ille-et-Vilaine, Loir-et-Cher et Eure-et-Loir) ; entre 1500 et 4500 bêtes sont transportées. Beaucoup d'autres compagnies participent à ce trafic pour de faibles effectifs. La tarification prévoit des conditions spéciales à l'occasion des concours hippiques. La présence de haras et d'élevage de chevaux de course semble favoriser le commerce des

28- Chemin de fer du Centre, de Côte-d'Or, de la Nièvre (SGCFE), de Haute-Saône $(\mathrm{CFV})$, du Loir-et-Cher et de Bordeaux à Cadillac. 
chevaux. Les chevaux de trait étaient issus de races locales pour l'agriculture ; ils n'étaient expédiés au loin que pour l'utilisation en ville, pour tirer les fiacres et les voitures de livraison des marchandises.

\section{$>$ Gros moyen et petit bétail}

Les autres animaux sont conduits vers les marchés de consommation des villes voisines; les réseaux bien structurés autour d'une préfecture sont avantagés pour jouer ce rôle ; le bétail peut aussi, après transit, être expédié à La Villette. L'élevage bovin d'embouche existe, mais il ne repose pas encore sur la recherche lointaine dans un pays naisseur de jeunes bêtes à engraisser; la spécialisation n'est pas arrivée à ce stade ; les flux qui naitront de cette activité sont à venir. Pour le petit bétail, sans que nous puissions les distinguer, coexistent des circuits de distribution orientés particulièrement vers les villes du Midi grosses consommatrices de viande ovine et des mouvements liés à la transhumance ; l'opération est facilitée pour deux réseaux qui sont à voie normale (Chemins de fer de l'Hérault, Chemins de fer départementaux des Bouches-du-Rhône), elle exige un transbordement pour la Compagnie des chemins de fer de la Camargue, à voie étroite ; ensemble ces entreprises acheminent 39000 ovins et caprins.

$\mathrm{Si}$ on examine le trafic pour les gros, petit et moyen bétail, on note que moins de $10 \%$ des entreprises assurent une part énorme des expéditions (tabl. 83). Pour le gros bétail, les principales expéditions se font au départ d'un vaste ensemble allant de l'Ille-et-Vilaine à la Vendée, englobant les pays de la Loire, se prolongeant jusqu'à la Nièvre et à l'Allier. Pour le moyen bétail, on retrouve beaucoup de compagnies exploitant des lignes ou des réseaux dans la zone précédente (expédition de veaux), mais aussi la Compagnie de Calais à Anvin, celle exploitant des liaisons autour de Bapaume, également la Compagnie des chemins de fer du Sud-Ouest, toutes régions d'élevage du porc. Pour le petit bétail, pour compléter les indications déjà données, signalons les départements du Loir-et-Cher, de l'Allier, et de la Seine-et-Marne où les ovins bénéficient encore des chaumes.

Un frein à un plus grand essor du trafic du bétail tient, outre l'inconvénient matériel dans les gares de transit, aux frais de manutention appliqués à ce trafic, pouvant atteindre $1 \mathrm{~F}$ par tête pour le gros bétail. 


\begin{tabular}{|l|c|c|c|}
\hline & Gros bétail & Moyen bétail & Petit bétail \\
\hline $\begin{array}{l}\text { Nombre d'entreprises participant } \\
\text { au trafic }\end{array}$ & 11 & 12 & 13 \\
\hline $\begin{array}{l}\text { Nombre de têtes expédiées par } \\
\text { l'entreprise assurant le plus grand } \\
\text { trafic }\end{array}$ & 19000 & 30000 & 22000 \\
\hline $\begin{array}{l}\text { Nombre de têtes expédiées par } \\
\text { l'entreprise assurant le plus petit } \\
\text { trafic }\end{array}$ & 5000 & 11000 & 7000 \\
\hline $\begin{array}{l}\text { Total des expéditions des } \\
\text { entreprises concernées }\end{array}$ & 113000 & 207000 & 145000 \\
\hline Part des expéditions / trafic total & $49 \%$ & $55 \%$ & $70 \%$ \\
\hline
\end{tabular}

Tableau 83. La concentration dans le trafic du bétail sur les chemins de fer secondaires (1911)

\section{. Les accessoires de la grande vitesse : bagages et messageries}

\section{$>$ Les bagages (fig. 32)}

Le transport des bagages progresse de $136 \%$ entre 1901 et 1911, passant de 59 à $140000 \mathrm{t}$; ce taux dépasse celui du trafic des voyageurs. Hors les VRP, ce sont les classes aisées qui, lors de leurs longs déplacements hors de leur domicile, ne peuvent se passer de leurs affaires; le poids des bagages et les inévitables correspondances sont suffisamment dissuasifs pour faire de l'enregistrement une habitude. La courbe est ascendante, sauf en 1906, année d'une légère régression de moins de $2 \%$, dont l'effet est plus que corrigé l'année suivante.

En données brutes, la plupart des réseaux départementaux étendus expédient entre 1000 et $2000 \mathrm{t}$; sur certaines lignes, on compte moins de 100 t. Six réseaux dépassent 3000 t, dont la Compagnie des chemins de fer économiques des Charentes qui achemine $4514 \mathrm{t}$.

La notion d'intensité du trafic permet de proposer une classification des lignes. L'indice moyen pour l'ensemble des CFIL et de TVM se situe autour de 9 t par km exploité. Les réseaux de 100 à $400 \mathrm{~km}$ intégrés à une grande compagnie (Allier, 11,4 ; Somme, 9,5) et certains réseaux départementaux (Ille-et-Vilaine : 8,7) sont proches de la moyenne; d'autres présentent de faibles indices (Morbihan : 5,4; Aude : 5), cas fréquent pour des lignes (Monsols à Cluny : 5,1; Grignan à Taulignan : 4,5; Andelot à Levier: 3,7). Les taux les plus élevés s'enregistrent sur les courtes lignes unissant une localité à une gare proche : Cassel (49), Beaucourt (40), Saint-Céré (38) ou desservant des lieux 
touristiques : Toulon à Saint-Raphaël : 22,7; Pierrefitte à Cauterets : 17,5. Soulignons l'indice de 30 enregistré sur la ligne d'Arpajon à Paris : à certaines saisons, les Parisiens se rendaient dans leur propriété de banlieue et grande banlieue ; les auteurs dramatiques des années 1880 à 1910 y situaient souvent l'action où se mouvaient leurs personnages ${ }^{29}$.

L'intérêt de ce trafic ne réside pas dans le tonnage transporté, mais dans les faits de société qu'il induit : connaittre les gares de départ et d'arrivée, analyser les relations entre ces mouvements et le calendrier de la fréquentation des lieux touristiques, des résidences secondaires de l'époque, manoirs et châteaux, éclaireraient utilement les indications déjà fournies par les données générales sur le trafic des voyageurs.

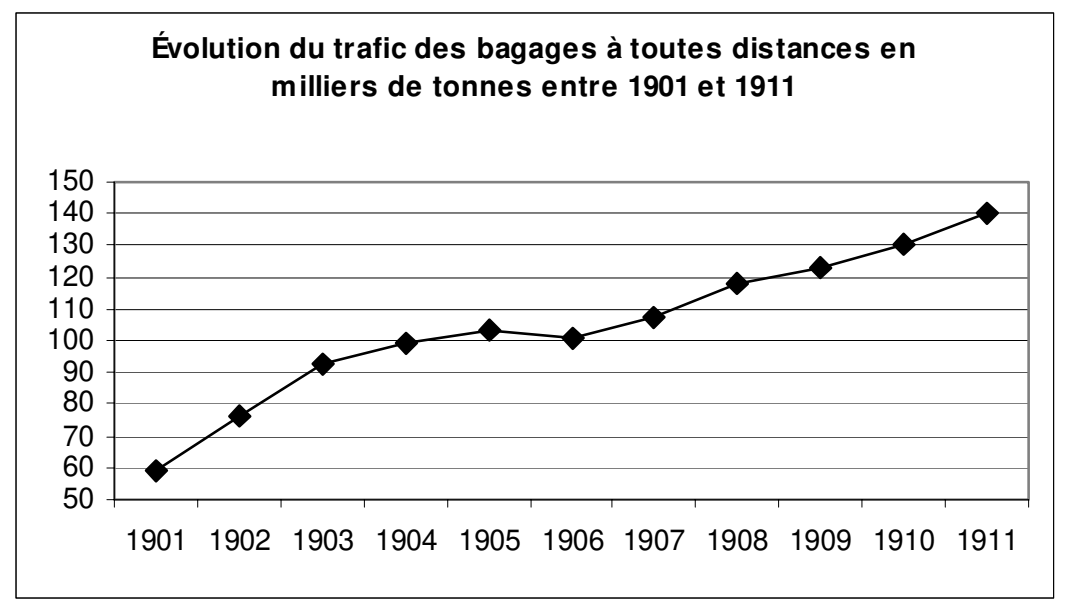

Figure 32. @ M. Wolkowitsch / A.-L. Wolkowitsch, 2003.

\section{$>$ Les messageries (fig. 33)}

\section{TVM et CFIL}

TVM et CFIL ont transporté 117000 t de messageries en 1901, 249000 t en 1911, la croissance est de $113 \%$. Entre 1901 et 1904, la progression annuelle est faible, 2,3\%, puis s'accélère, atteignant $18 \%$ en 1905 ; le développement sera constant à part une mauvaise année en 1910. Vingt-deux exploitations de CFIL et 17 de TVM acheminaient plus de $2000 \mathrm{t}$, dont onze et trois plus de $4000 \mathrm{t}$. Trois d'entre elles se distinguent par la puissance de leur trafic : le TVM de Paris-les-Halles à

29- E. Pailleron dans Le Monde où l'on s'ennuie, Feydeau dans de multiples comédies, également de Flers et Caillavet. 
Arpajon avec 17601 t et deux compagnies de CFIL 1880 à voie étroite, (la Compagnie française des chemins de fer à voie étroite, $13900 \mathrm{t}^{30}$ et la Compagnie du chemin de fer d'Estrées-Saint-Denis à Froissy et Crèvecoeur dans la Somme, 12569 t) ; ensemble elles représentent $14 \%$ des expéditions; si on y ajoute les 21000 t de la SGCFE et les 10000 t des CFD, on constate que ces cinq entreprises monopolisent près de $30 \%$ du trafic.

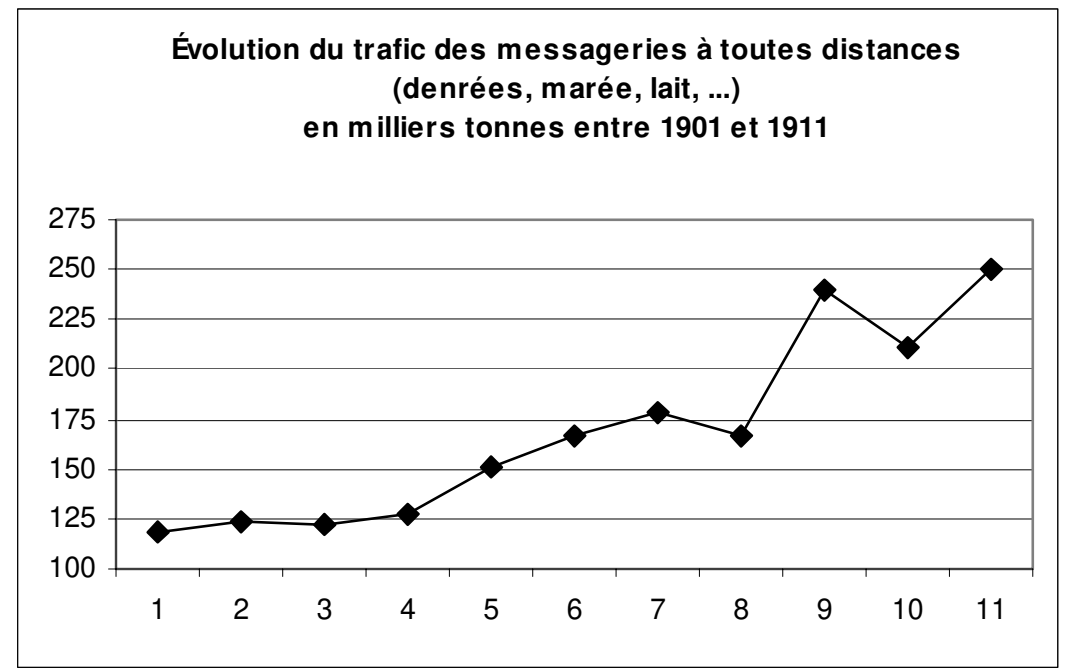

Figure 33. @ M. Wolkowitsch / A.-L. Wolkowitsch, 2003.

L'intensité moyenne du trafic s'établit à 16,1 t/ km exploité pour les CFIL et 15,4 pour les TVM. Des indices très élevés caractérisent les entreprises précédentes : Compagnie du chemin de fer d'Arpajon : 440 ; Chemin de fer d'Estrées-Saint-Denis : 256 ; Chemin de fer à voie étroite : 161. D’autres compagnies offrent aussi des indices très élevés : la Compagnie genevoise de tramways électriques, avec $269^{31}$, ou la ligne de Cours à Saint-Victor : $157^{32}$. À un niveau inférieur, mais encore très au-dessus des indices moyens, on relève les chiffres suivants : 75 pour la ligne de Bordeaux à Cadillac, 73 pour celle de Lyon à Mornant, 60 pour

30- Cette compagnie exploite les lignes de Nantes à Legé, Les Sablonnières à Vieillevigne et Rocheservière.

31- Réseau de 16 km exploités, en France, au départ de Genève desservant les petites zones franches et transportant des matériaux de construction et produits maraîchers vers la ville.

32- Le trafic des messageries est alimenté par les ateliers du textile. 
la ligne de l'Est de Lyon, 40 pour le réseau du Dauphiné, 31 pour la ligne de Toulon à Saint-Raphaël, 26 pour les lignes de Cormiers et de Verzy à Reims... Ces lignes ont en commun d'avoir un de leur terminus dans une grande ville; elles apportent des campagnes environnantes les produits frais nécessaires à la consommation des citadins et des touristes de la côte des Maures.

De nombreux réseaux départementaux ont des indices compris dans une fourchette de 13 à $18 \mathrm{t}$ au $\mathrm{km}$ exploité : Ardennes : 17,4; Indre-et-Loire (réseau des CFD) : 17,4 ; Drôme : 16,7; trois réseaux de la SGCFE, Gironde : 16,7 ; Allier : 16,3 ; Somme : 16,2 ; Sarthe : 14 ; Chemin de fer économiques des Charentes : 13,3 ; Vendée : 13,2. Enfin toute une série d'autres départements ont des indices inférieurs à la moyenne : Cher : 12,3 (SGCFE) ; Calvados : 11,2 ; Côte-d'Or : 10,8 ; Sud-France : 9,6 ; Loir-et-Cher : 7,6 ; Haute-Saône : 7,4 (CFV) ; Anjou : 6,6 ; Ille-et-Vilaine : 5,5 .

Ces listes n'ont rien d'exhaustif, elles fournissent des points de comparaisons. Les longs réseaux exploités aussi bien par des compagnies indépendantes que par les trois grandes compagnies ont des indices soit proches de la moyenne, soit inférieurs à celle-ci. Les grandes compagnies secondaires obtiennent des résultats différents suivant les départements ; elles peuvent obtenir des résultats très supérieurs sur de courtes lignes, comme la SGCFE entre Valmondois et Marines (52). Une interprétation de ces données supposerait une connaissance des divers éléments du trafic des messageries pour les réseaux étudiés.

Les marchandises habituellement soumises au régime des messageries sont tous les produits frais : denrées, lait et produits laitiers, la marée, mais aussi les produits fragiles et précieux : les dentelles, les bijoux, les métaux précieux... les cercueils, les produits financiers et même les espèces. Chaque société génère ses formes de délinquance : il y a cent ans, dans les campagnes traversées par les lignes secondaires, il s'agissait de vol de poules, de lapins, de pommes de terre arrachées dans les champs, voire des draps dans une armoire ou sur un fil. À l'époque du braquage des fourgons bancaires au fusil mitrailleur, il faut une bonne dose d'imagination pour penser au préposé des postes dans son petit espace réservé dans le fourgon convoyant paisiblement les fonds destinés à tous les bureaux de poste desservis. Les métaux précieux et bijoux pouvaient être sous la garde d'un voyageur à qui on réservait un compartiment. 
Ces trafics avaient leur importance. Les grands réseaux avaient commencé à mobiliser la production agricole au service des citadins : pour la première fois, en 1865, des fruits et légumes du Comtat étaient vendus sur les marchés de Lyon et Saint-Étienne ; en 1890, les premières expéditions de fraises de Carpentras arrivent à Paris ${ }^{33}$. Les compagnies secondaires étendent l'aire de ramassage des produits, dont la consommation croît avec l'urbanisation. Le problème de l'approvisionnement des villes en lait a été difficile à satisfaire ; le bassin laitier d'une ville était calqué sur la desserte ferroviaire, associant tous les types de compagnies si nécessaire. En 1895, le bassin laitier de Paris ne dépassait pas une centaine de kilomètres ; en 1910, cette zone fournit $60 \%$ de la consommation, $40 \%$ viennent de distances comprises entre 100 et $150 \mathrm{~km}$, progressivement le ramassage s'étend et $20 \%$ viennent d'une zone distante de 150 à $400 \mathrm{~km}$; ainsi la participation de multiples compagnies secondaires était indispensable, dans les zones définies ${ }^{34}$.

Ces compagnies étaient peu adaptées à ces trafics. Elles ne mettaient pas en mouvement des trains spécialisés de messageries ; ce trafic était confié aux trains de voyageurs, dont un pourcentage élevé était des trains mixtes ; leur vitesse commerciale était abaissée par les manutentions et manœuvres dans les gares. La fréquence sur beaucoup de lignes était seulement bi-quotidienne, ce qui allongeait tous les délais de l'expédition à la livraison (tabl. 84).

Ces compagnies pouvaient difficilement se conformer aux règles que les grands réseaux avaient établies. Cela entravait par exemple la participation de certaines compagnies au transport du lait. L'établissement de tarifs communs avec les grands réseaux se faisait difficilement et sous condition d'un partage de responsabilité en cas de retard et d'avaries et, bien entendu, d'un partage des frais d'indemnisation.

33- M. Wolkowitsch, «Les compagnies de chemins de fer et le monde agricole », in «Les transports par fer et leur clientèle », actes du colloque de l'AHICF, 10-11 octobre 1990, Revue d'histoire des chemins de fer hors série $\mathrm{n}^{\circ} 3$ (1992), p. 27-40

34- M. Wolkowitsch, L'Économie régionale des transports dans le Centre et le Centre Ouest de la France, Paris, SEDES, 1960, 528 p. 


\begin{tabular}{|c|c|c|c|}
\hline \multicolumn{2}{|c|}{ Délais } & Grande vitesse & Petite vitesse \\
\hline \multicolumn{2}{|l|}{ D’expédition } & $\begin{array}{l}3 \text { heures après le dépôt, par le } \\
\text { premier train de voyageurs } \\
\text { comportant } 3 \text { classes ou par } \\
\text { train de messagerie spécialisé } \\
\text { (a) }\end{array}$ & $\begin{array}{l}\text { Lendemain de la remise } \\
\text { de la marchandise }\end{array}$ \\
\hline \multicolumn{2}{|l|}{ D'acheminement } & $\begin{array}{l}\text { Temps de parcours des trains } \\
\text { empruntés }\end{array}$ & $\begin{array}{l}24 \text { heures par tranche } \\
\text { de } 125 \mathrm{~km}, 200 \mathrm{~km} \text { en } \\
\text { cas d'utilisation des } \\
\text { lignes principales }\end{array}$ \\
\hline \multirow{3}{*}{ De transmission } & $\begin{array}{l}\text { entre deux } \\
\text { réseaux }\end{array}$ & $\begin{array}{l}\text { dans une même gare } \\
1 \text { heure (sauf trains directs) }\end{array}$ & 1 jour \\
\hline & $\begin{array}{l}\text { gares distinctes } \\
\text { reliées par rail }\end{array}$ & 3 heures & 2 jours \\
\hline & gares parisiennes & 6 heures & 3 jours \\
\hline \multicolumn{2}{|l|}{ De livraison } & $\begin{array}{l}2 \text { heures après l'arrivée ou } \\
\text { après l'ouverture de la gare } \\
\text { Réduction du prix de transport } \\
\text { en cas de retard } \\
3 \text { à } 4 \mathrm{~h}:-33 \% \\
4 \text { à } 6 \mathrm{~h}:-66 \% \\
\text { plus de } 6 \mathrm{~h}: 100 \% \\
\text { Engagement de la } \\
\text { responsabilité de la compagnie } \\
\text { en cas de perte de la } \\
\text { marchandise à partir de } 12 \mathrm{~h} \\
\text { de retard }\end{array}$ & 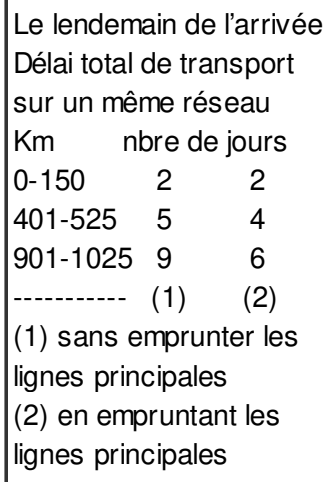 \\
\hline
\end{tabular}

(a) Pour les compagnies secondaires, la règle est de 3 heures après le dépôt par le $1^{\text {er }}$ train desservant le point d'arrêt.

Tableau 84. Délais d'acheminement et de livraison des marchandises dans la première décennie $\mathrm{du} \mathrm{xx}^{\mathrm{e}}$ siècle.

\section{$T V B$}

Les TVB participent au trafic des messageries ; en 1911, ils transportent 27359 t, soit $11 \%$ du trafic total acheminé par les CFIL et TVM auquel il s'ajoute. Nous avons isolé ces échanges parce que les statistiques les concernant ne permettent pas de suivre une évolution décennale, surtout parce qu'elles ne distinguent pas les bagages des messageries, ce qui leur enlève beaucoup d'intérêt. On soulignera l'extrême concentration de ce trafic assuré par cinq compagnies sur 
37 monopolisant $73 \%$ des échanges. Deux ont une vocation d'approvisionnement urbain : ligne d'Aix à Marseille, $1560 \mathrm{t}$ avec $52 \mathrm{t} / \mathrm{km}$ exploité et réseau urbain et périurbain de Lille, 4864 t et $38 \mathrm{t} / \mathrm{km}$ exploité. Deux sont des lignes de la Compagnie des tramways de Nice et du littoral, relayant le PLM pour une desserte au plus près des stations et accumulant bagages et approvisionnement: Cagnes à Menton 8631 t et $191 \mathrm{t} / \mathrm{km}$ exploité et le réseau de $2 \mathrm{~km}$ de Saint-Jean-CapFerrat 491 t et $245 \mathrm{t} / \mathrm{km}$ exploité. Enfin la ligne de Boulogne-sur-Mer à Hardelot (4 991 t et $453 \mathrm{t} / \mathrm{km}$ exploité) a aussi un trafic important.

Le trafic des marchandises est en expansion jusqu'en 1914 et se poursuit même dans les années 1920. On constate, au début du siècle, pour chaque classe de marchandises, un ou deux fléchissements bien vite effacés, n’altérant pas la tendance générale à la hausse. L'absence de concomitance entre ces fluctuations ne permet pas de les rattacher à une évolution générale de la conjoncture économique.

L'espace desservi par une compagnie secondaire se limitait à une zone étroite de part et d'autre d'une ligne, au mieux à l'étendue d'un département ; l'accès à un marché restreint entraînait des transformations limitées de l'agriculture. Une voie ferrée exerçait une triple fonction : satisfaire les échanges locaux, collecter les produits de l'agriculture et de l'industrie des zones traversées pour les expédier au loin, distribuer les produits industriels venus d'autres régions. Des recherches sur les lignes du plan Freycinet ont montré que la fonction de distribution l'emportait dans les années suivant la mise en service ; le rôle de collecteur de produits agricoles apparaissait ultérieurement. L’hypothèse d'un schéma identique pour les lignes secondaires est concevable, mais serait à vérifier. Il fallait un accès assuré à des marchés lointains, pour amener des négociants, ramasseurs de produits agricoles, à peser sur les exploitants pour qu'ils abandonnent le modèle dominant de l'agriculture d'autoconsommation et s'adaptent à l'agriculture commercialisée.

\section{Conclusion}

Les multiples publications consacrées aux VFIL réservent peu d'attention à l'histoire des trafics. Cependant les statistiques annuelles donnent une connaissance précise du trafic total et par classes de marchandises et par catégories de voyageurs ; une rétrospective sur dix ans permet de suivre l'évolution. Les données relatives à chaque réseau ou chaque ligne sont énoncées pour l'année en cours, sans référence au passé. 
La consultation des annuaires année par année permet de suivre l'évolution des activités d'une entreprise et des mouvements le long d'une ligne ; analyser les trafics en déclin et en progrès, saisir de nouveaux échanges ouvrent des perspectives sur l'évolution du milieu.

L'analyse devrait conduire à distinguer les trafics intérieurs à une ligne ou un réseau de ceux qui exigent l'emprunt des lignes de plusieurs compagnies. Peut-on trouver des informations sur l'activité des gares de transit? Cela serait d'un réel intérêt.

Le trafic est un reflet de l'activité économique et de la société ; il traduit les évolutions qui les touchent. Les progrès enregistrés dans les échanges au début du $\mathrm{Xx}^{\mathrm{e}}$ siècle, stimulés ou non par des tarifications appropriées, doivent permettre de mesurer les changements intervenus dans la consommation. Le rôle du chemin de fer comme distributeur de produits de l'industrie ou comme collecteur de biens agricoles ou miniers doit être précisé, parallèlement, son influence sur l'organisation du commerce doit être recherchée. 


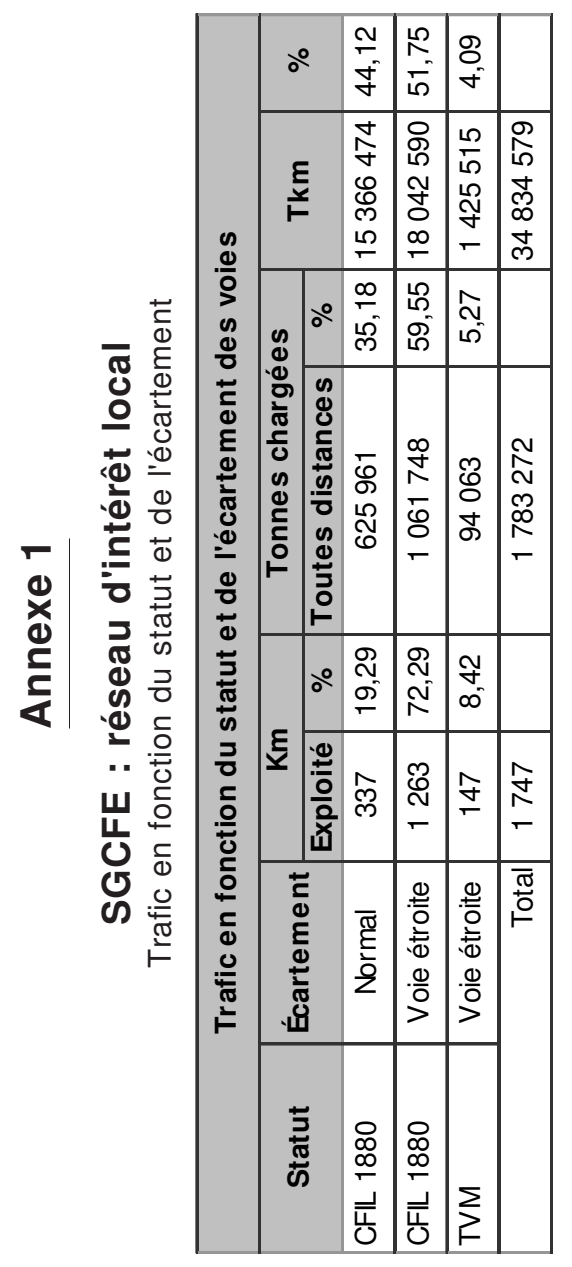

\begin{tabular}{|c|c|c|c|c|c|c|c|c|}
\hline ๙ょ & 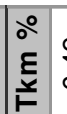 & \begin{tabular}{c|c}
$\stackrel{g}{g}$ \\
\hdashline \\
\hdashline
\end{tabular} & 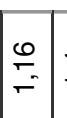 & $\stackrel{+}{=}$ & $\Sigma_{0}$ & $\hat{0}$ & 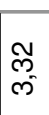 & \\
\hline 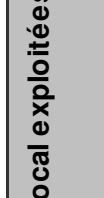 & 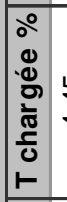 & & $\begin{array}{l} \pm \\
\square \\
=\end{array}$ & 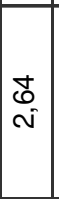 & $\begin{array}{l}\bar{m} \\
\text { o. }\end{array}$ & - & 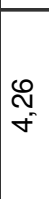 & \\
\hline 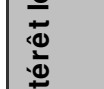 & $\begin{array}{l}\circ \\
\text { కิ } \\
\text { క్ }\end{array}$ & $\stackrel{0}{\stackrel{0}{N}}$ & 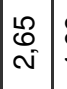 & \begin{tabular}{l}
8 \\
\hdashline \\
$\forall$
\end{tabular} & $\begin{array}{l}0 \\
0 \\
0 \\
0\end{array}$ & $\begin{array}{l}\bar{\sigma} \\
0\end{array}$ & 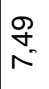 & \\
\hline $\begin{array}{l}\frac{5}{-5} \\
0 \\
0 \\
0\end{array}$ & & & \begin{tabular}{|l|} 
\\
$\infty$ \\
$\mathbb{\Psi}$ \\
$\bar{\Psi}$
\end{tabular} & \begin{tabular}{|l|} 
\\
$\infty$ \\
$\infty$ \\
$\bar{\omega}$ \\
\end{tabular} & $\begin{array}{l}\infty \\
\infty \\
\varpi \\
\amalg \\
\end{array}$ & $\sum$ & $\sum$ & \\
\hline 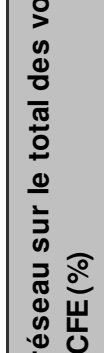 & & $\stackrel{0}{\frac{2}{2}}$ & 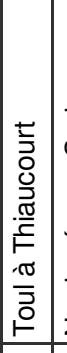 & 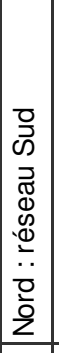 & 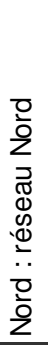 & 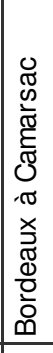 & 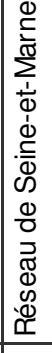 & \\
\hline 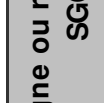 & $\mid$ & $\begin{array}{l}m \\
\bar{f}\end{array}$ & $\mid$ & $\left|\begin{array}{|l|}\bar{\sigma} \\
0 \\
0\end{array}\right|$ & $\begin{array}{l}\tilde{N} \\
\sim \\
\sigma\end{array}$ & $\begin{array}{l}\stackrel{L}{\Omega} \\
\sigma \\
\sigma\end{array}$ & $\stackrel{0}{\hat{r}_{-}}$ & $\begin{array}{l}m \\
0\end{array}$ \\
\hline 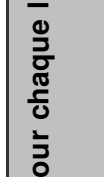 & $\begin{array}{l}0 \\
0 \\
0 \\
0 \\
0 \\
\frac{0}{0} \\
0 \\
1 \\
1\end{array}$ & 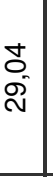 & $\mid$ & $\left|\begin{array}{l}0 \\
\dot{g} \\
\underline{6}\end{array}\right|$ & \begin{tabular}{|l}
$\hat{N}$ \\
$m$
\end{tabular} & $\hat{\curvearrowright}$ & $\stackrel{\substack{\infty \\
\sim \\
\sim}}{ }$ & 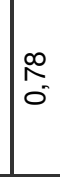 \\
\hline $\begin{array}{l}\stackrel{\Omega}{\xi} \\
\stackrel{F}{F}\end{array}$ & 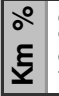 & $\begin{array}{l}\infty \\
0 \\
\infty \\
\stackrel{0}{-}\end{array}$ & $\stackrel{\simeq}{=}$ & $\mid \begin{array}{l}\infty \\
o \\
0 \\
0 \\
0\end{array}$ & $\begin{array}{l}\stackrel{8}{B} \\
\stackrel{B}{*} \\
\end{array}$ & $\frac{N}{\bar{N}}$ & 竞 & 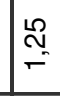 \\
\hline $\begin{array}{l}0 \\
\stackrel{0}{0} \\
. \\
0\end{array}$ & & $\begin{array}{l}\infty \\
\infty \\
\Sigma \\
\Sigma \\
\end{array}$ & $\begin{array}{l}8 \\
\infty \\
\infty \\
\Sigma \\
\Sigma\end{array}$ & $\begin{array}{l}\infty \\
\infty \\
\infty \\
\bar{w} \\
\end{array}$ & $\begin{array}{l}\stackrel{\bigcirc}{\infty} \\
\infty \\
\amalg \\
\end{array}$ & 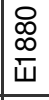 & $\begin{array}{l}\infty \\
\infty \\
\infty \\
\bar{\omega} \\
\end{array}$ & $\begin{array}{l}\infty \\
\infty \\
\infty \\
\bar{\Psi}\end{array}$ \\
\hline 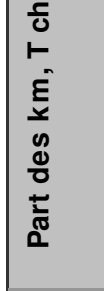 & & 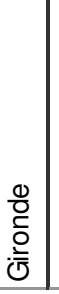 & 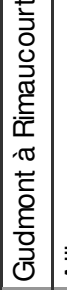 & 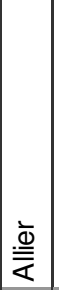 & \begin{tabular}{|l|}
$\bar{\Phi}$ \\
\end{tabular} & 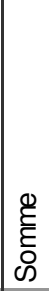 & 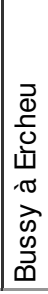 & 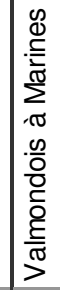 \\
\hline
\end{tabular}




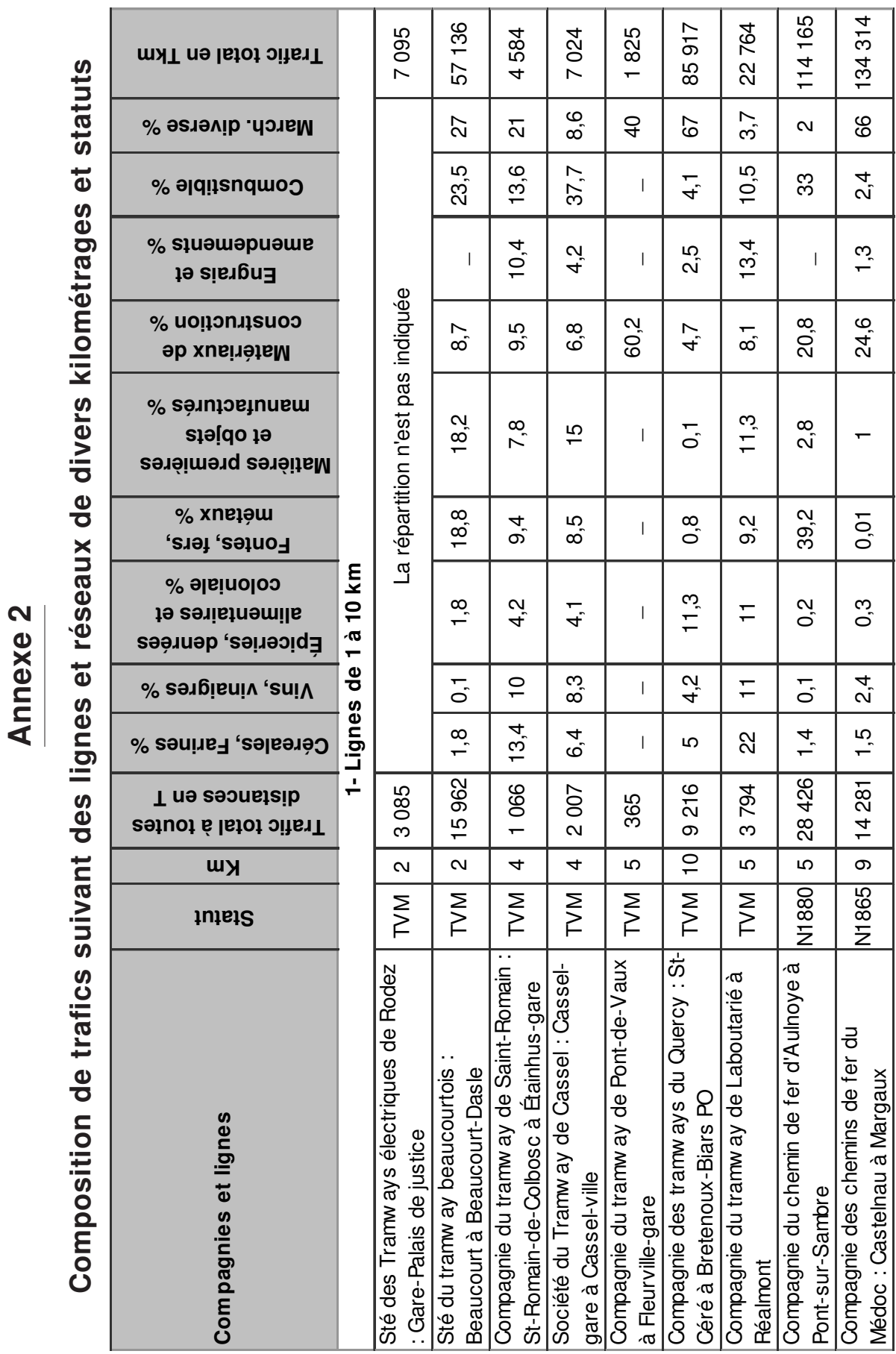




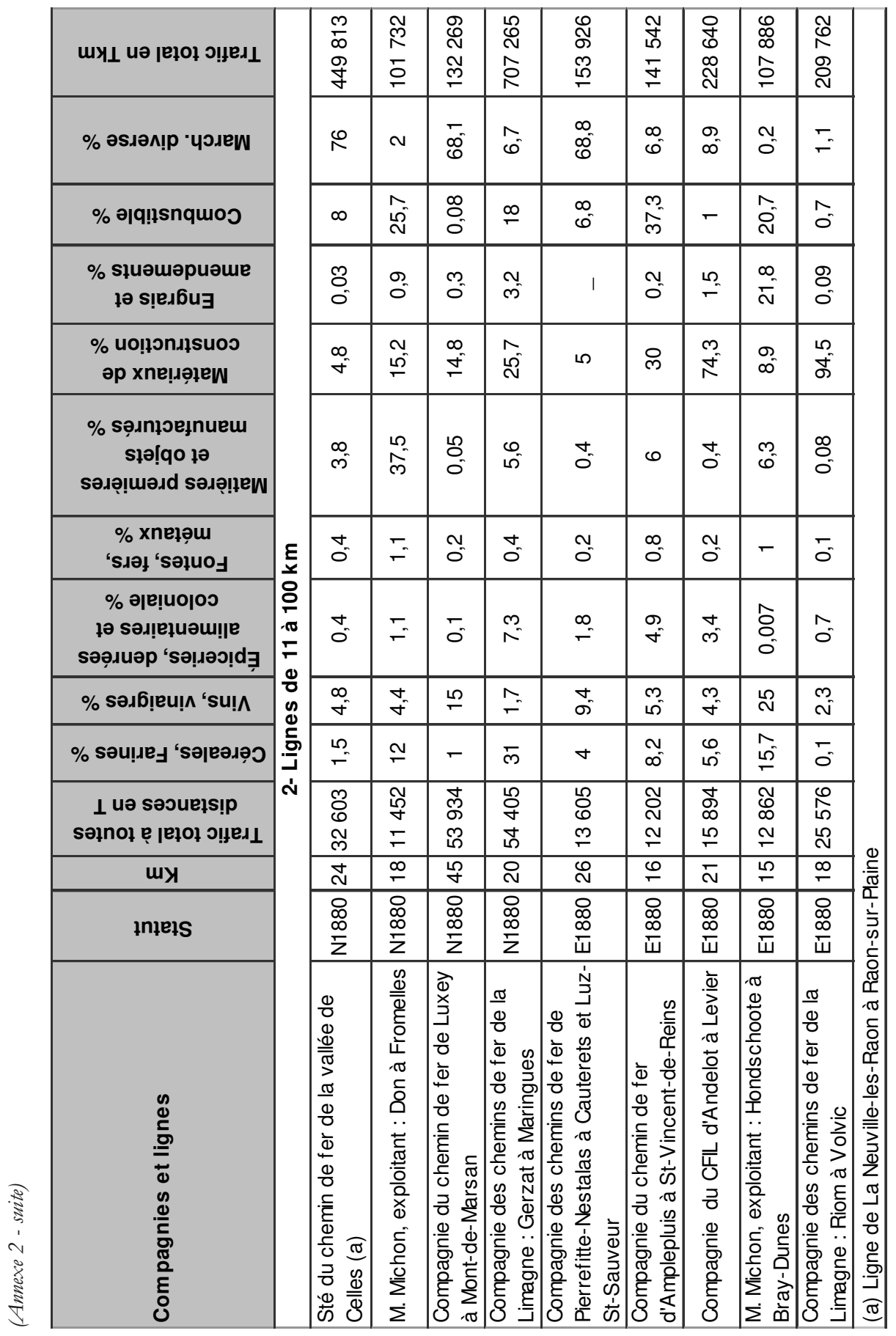




\begin{tabular}{|c|c|c|c|c|c|c|c|c|c|c|c|c|}
\hline 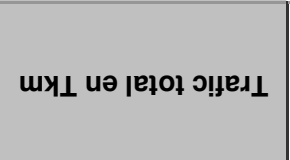 & & 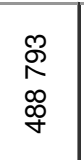 & $\begin{array}{l}\text { f } \\
\text { ర } \\
\text { ల్రి }\end{array}$ & $\frac{\mathscr{m}}{\stackrel{\infty}{\infty}}$ & $\begin{array}{l}\infty \\
\stackrel{1}{N} \\
o \\
\infty \\
\infty\end{array}$ & 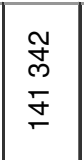 & & 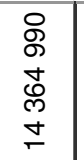 & 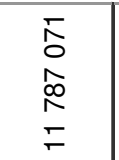 & 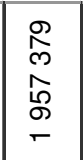 & 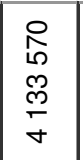 & $\frac{. c}{\frac{\mathbb{T}}{\mathbb{N}}}$ \\
\hline 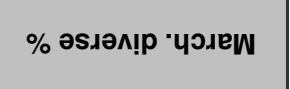 & & 感 & 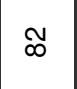 & סू & $\stackrel{+}{N}$ & $\begin{array}{c}\cong \\
O\end{array}$ & & న్లి & $\stackrel{m}{\stackrel{m}{N}}$ & $\stackrel{m}{m}$ & مْ & $\frac{\grave{\omega}}{\frac{\Phi}{\sigma}}$ \\
\hline \% әશ!!snquoว & & $\begin{array}{l}N \\
0 \\
0\end{array}$ & $\stackrel{0}{r}$ & $\sim$ & $\stackrel{n}{\sim}$ & $\begin{array}{l}n \\
0 \\
0\end{array}$ & & $\forall$ & $\hat{\mathrm{N}}$ & $\stackrel{\circ}{0^{\circ}}$ & 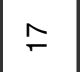 & త্ \\
\hline $\begin{array}{c}\text { \% słuəuәрuәше } \\
\text { †ә s!eıбuヨ }\end{array}$ & & $\stackrel{\Delta}{=}$ & $\forall$ & $\overline{0}$ & $\frac{n}{\frac{d}{4}}$ & $\stackrel{m}{N}$ & & $\stackrel{\bullet}{\mathbb{f}}$ & 1 & $\stackrel{\infty}{0^{-}}$ & $\stackrel{\sim}{\sim}$ & $\begin{array}{l}\overleftarrow{\Phi} \\
\infty \\
\stackrel{\Phi}{\leftrightarrows}\end{array}$ \\
\hline 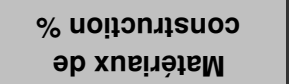 & & $\begin{array}{l}n \\
\infty \\
\infty\end{array}$ & $\begin{array}{l}\text { m } \\
\text { N }\end{array}$ & $\stackrel{\oplus}{\oplus}$ & । & $\stackrel{m}{\sim}$ & & $\stackrel{\infty}{\sim}$ & । & $\frac{\sigma_{n}}{E}$ & $\frac{0}{N}$ & 3 \\
\hline 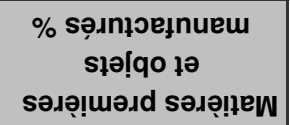 & & $\underset{O}{O}$ & $\stackrel{\infty}{0}$ & $\hat{0}$ & ॄ & $\begin{array}{l}\infty \\
\omega^{-}\end{array}$ & & । & I & - & $\stackrel{\mathscr{N}}{N}$ & 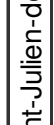 \\
\hline 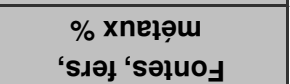 & 紊 & $\stackrel{+}{\sigma_{-}}$ & $\begin{array}{l}n \\
0 \\
0\end{array}$ & $\stackrel{\infty}{+}$ & । & $\stackrel{\bullet}{\varphi^{-}}$ & $\frac{\varepsilon}{2}$ & $\bar{\sigma}$ & 1 & ले & $\stackrel{\simeq}{\simeq}$ & $\begin{array}{l}\text { 言 } \\
\infty \\
-\infty\end{array}$ \\
\hline 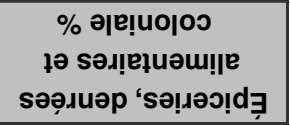 & 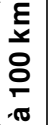 & $\stackrel{\sigma}{0}$ & $\begin{array}{l}\infty \\
0 \\
0\end{array}$ & $\infty$ & । & $\begin{array}{l}\text { m } \\
\infty^{\circ}\end{array}$ & $\begin{array}{l}5 \\
\frac{1}{0} \\
0 \\
\frac{1}{0}\end{array}$ & $\stackrel{\sim}{=}$ & $\begin{array}{l}\infty \\
\infty\end{array}$ & $\stackrel{\sim}{N}$ & $\bar{m}$ & 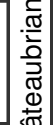 \\
\hline \% səג6!̣eu!n ‘su!^ & 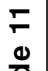 & $\overline{0}$ & 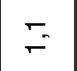 & $\begin{array}{l}\sim \\
\sigma\end{array}$ & 1 & $\wedge$ & $\stackrel{0}{0}$ & $\begin{array}{l}N \\
0 \\
\tilde{m}\end{array}$ & $\stackrel{n}{\mathbb{R}}$ & $\stackrel{0}{0}$ & $\stackrel{N}{=}$ & $\begin{array}{l}\mathcal{U} \\
0 \\
0\end{array}$ \\
\hline 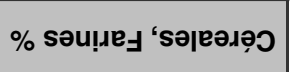 & on & $\stackrel{0}{=}$ & $\stackrel{\infty}{\sim}$ & $\begin{array}{l}\infty \\
0^{-}\end{array}$ & । & $\hat{\circ}$ & 宽 & $\stackrel{\sim}{\sim}$ & $\begin{array}{l}\text { L } \\
\text { क }\end{array}$ & $\stackrel{\text { m }}{\stackrel{N}{\sim}}$ & $\stackrel{\infty}{\text { N }}$ & $\stackrel{\mathscr{\infty}}{\Phi}$ \\
\hline 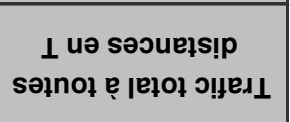 & ה̀ & 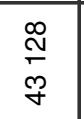 & $\begin{array}{l}\mathscr{0} \\
\stackrel{p}{ } \\
\infty \\
\infty\end{array}$ & $\begin{array}{l}\overline{\mathfrak{g}} \\
\stackrel{+}{\sim}\end{array}$ & 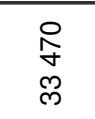 & $\underset{\infty}{\stackrel{\infty}{\%}}$ & व் & $\begin{array}{l}\infty \\
\text { in } \\
\sim \\
\text { Oे }\end{array}$ & 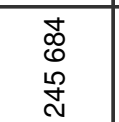 & 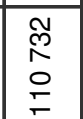 & 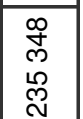 & 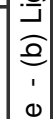 \\
\hline шب्र & & $\stackrel{\infty}{\infty}$ & $\bar{m}$ & 이 & $\stackrel{\circ}{\circ}$ & $\stackrel{\llcorner}{\sim}$ & & i̊ & $\stackrel{m}{\sim}$ & 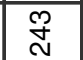 & 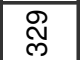 & $\frac{\frac{5}{\pi}}{\frac{\pi}{\pi}}$ \\
\hline ınıeıs & & $\sum$ & $\sum$ & $\sum$ & $\sum$ & $\sum$ & & $\begin{array}{l}10 \\
\infty \\
\sum \\
\sum\end{array}$ & $\begin{array}{l}8 \\
\infty \\
\infty \\
\Sigma\end{array}$ & $\begin{array}{l}\circ \\
\infty \\
\infty \\
\dot{w}\end{array}$ & $\begin{array}{l}\stackrel{8}{1} \\
\infty \\
\bar{\uplus}\end{array}$ & 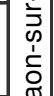 \\
\hline 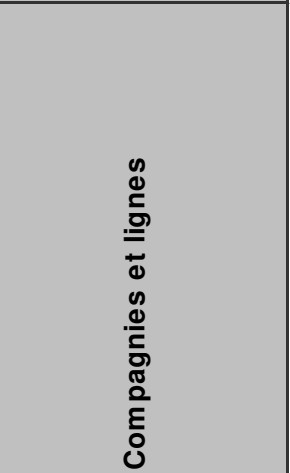 & & 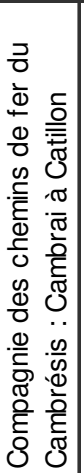 & 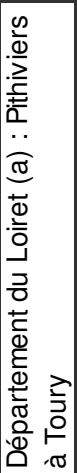 & 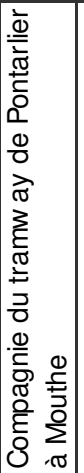 & 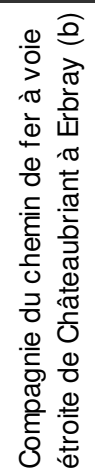 & 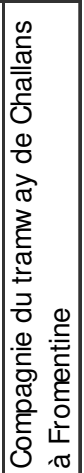 & & 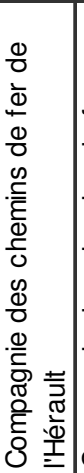 & 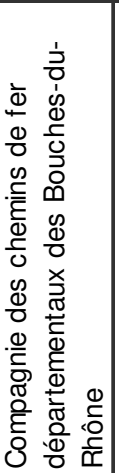 & 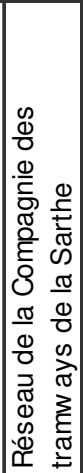 & 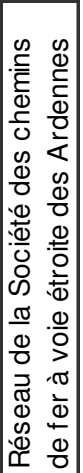 & 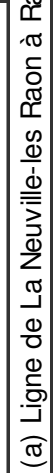 \\
\hline
\end{tabular}




\begin{tabular}{|c|c|c|c|c|c|c|c|c|c|c|c|}
\hline 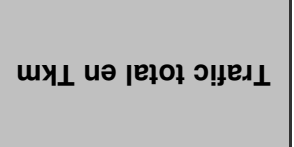 & & $\begin{array}{l}0 \\
\stackrel{O}{+} \\
\sim \\
\infty \\
\infty \\
\sim\end{array}$ & $\mid \begin{array}{l}\bar{\delta} \\
\infty \\
\dot{⿰} \\
\bar{w} \\
\bar{\sigma} \\
\end{array}$ & 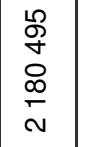 & 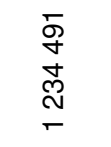 & 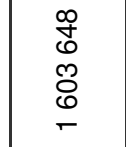 & $\begin{array}{l}\text { g } \\
\text { g } \\
\stackrel{g}{g} \\
\text { m } \\
m\end{array}$ & $\mid \begin{array}{l}\bar{N} \\
\tilde{S} \\
\bar{N} \\
\bar{n} \\
\bar{m}\end{array}$ & $\begin{array}{l}\text { J } \\
\text { ర్ } \\
\mathbb{N} \\
\infty \\
\infty \\
10\end{array}$ & 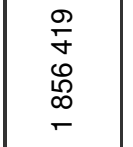 & $\begin{array}{l}8 \\
8 \\
8 \\
\frac{8}{2} \\
\sim\end{array}$ \\
\hline \% әьıәл!р 'чગлеW & & $\bar{N}$ & 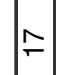 & $\stackrel{m}{F}$ & $\begin{array}{l}0 \\
\stackrel{\omega}{\sim}\end{array}$ & $\stackrel{\circ}{*}$ & $\stackrel{2}{\circ}$ & $\stackrel{N}{N}$ & $\stackrel{0}{\circ}$ & $\stackrel{9}{0}$ & $\stackrel{2}{r}$ \\
\hline \% ә әવ!!snquoว & & 5 & 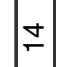 & $\stackrel{\sim}{\infty}$ & $\bar{N}$ & $\stackrel{m}{\stackrel{m}{p}}$ & $\stackrel{m}{\infty}$ & $\left|\begin{array}{l}0 \\
0 \\
0\end{array}\right|$ & $\stackrel{2}{\infty}$ & $\hat{F}$ & $\Sigma$ \\
\hline 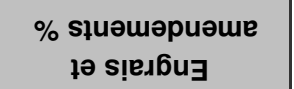 & & $\stackrel{N}{\stackrel{N}{N}}$ & $\simeq$ & $\stackrel{N}{\infty}$ & 음 & $\hat{f}$ & $\ddot{\infty}$ & $\left|\begin{array}{l}n \\
\\
\end{array}\right|$ & $\stackrel{F}{=}$ & $\stackrel{\stackrel{N}{N}}{\stackrel{2}{L}}$ & $\stackrel{9}{r}$ \\
\hline 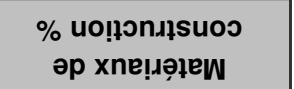 & & $\begin{array}{c}m \\
\stackrel{m}{\omega^{\prime}}\end{array}$ & $\mathbb{N}$ & $\frac{n}{n-1}$ & ले & $\stackrel{\infty}{\stackrel{\sim}{y}}$ & $\begin{array}{l}\infty \\
\mathbb{\infty}^{\infty} \\
\end{array}$ & $\left|\begin{array}{l}m \\
F \\
F\end{array}\right|$ & $\frac{m}{i n}$ & $\stackrel{N}{\stackrel{N}{N}}$ & $\stackrel{m}{\sim}$ \\
\hline 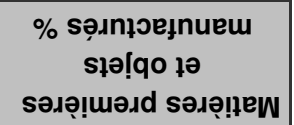 & $\stackrel{\Phi}{=}$ & $\stackrel{+}{0}$ & $m$ & $\begin{array}{l}\mathscr{\theta} \\
\stackrel{+}{\sim}\end{array}$ & $\hat{o}$ & $\overline{0}$ & $\cong$ & $\ddot{m}$ & $\stackrel{9}{i}$ & $\stackrel{0}{r}$ & $\hat{\curvearrowright}$ \\
\hline 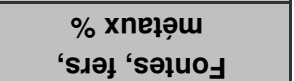 & $\frac{\vec{b}}{\varepsilon}$ & $\stackrel{+}{\mathrm{N}}$ & $\vec{F}_{-}$ & $\stackrel{\sim}{\sim}$ & $\stackrel{n}{-}$ & $\stackrel{0}{0}$ & $\hat{N}$ & 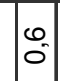 & $\overline{0}$ & $\stackrel{n}{=}$ & $\hat{o}$ \\
\hline 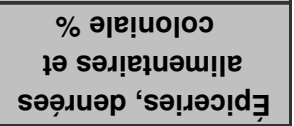 & $\frac{8}{0}$ & 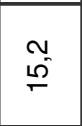 & $\stackrel{\sim}{\sim}$ & $\stackrel{\llcorner}{N}$ & $\stackrel{\oplus}{\infty}$ & $\stackrel{\infty}{\infty}$ & $\stackrel{\oplus}{\infty}$ & $\stackrel{n}{\sim}$ & $=$ & $\tilde{N}$ & $\hat{o}$ \\
\hline \% səגб!̣eu!n 'su!n & $\frac{9}{2}$ & $\begin{array}{c}\infty \\
0 \\
0\end{array}$ & $F_{-}$ & $\stackrel{0}{6}$ & $\stackrel{0}{\infty}$ & $\stackrel{\mathscr{O}}{=}$ & 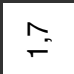 & $\mid \begin{array}{r}* \\
+\end{array}$ & $\theta$ & $\stackrel{+}{\infty}$ & $\begin{array}{l}0 \\
0 \\
0 \\
0\end{array}$ \\
\hline \% səu!̣eg 'sә|еәдә̣ว & $\underset{0}{x}$ & ㄱ. & $\mid$ & $\begin{array}{l}m \\
\stackrel{M}{\sim}\end{array}$ & $\stackrel{\text { N }}{ }$ & $\stackrel{m}{\stackrel{m}{\sim}}$ & $\begin{array}{l}\infty \\
\stackrel{\infty}{N}^{\infty} \\
N^{\prime}\end{array}$ & $\mid \hat{N}$ & $\stackrel{2}{N}$ & $\stackrel{\substack{N \\
\tilde{N}}}{\sim}$ & $\stackrel{\omega}{\infty}$ \\
\hline 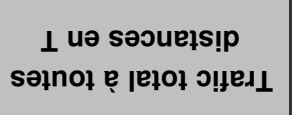 & 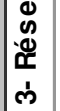 & $\begin{array}{l}\infty \\
\stackrel{\infty}{+} \\
\stackrel{8}{\circ}\end{array}$ & $\left|\begin{array}{l}0 \\
0 \\
0 \\
\\
\end{array}\right|$ & $\begin{array}{l}\stackrel{8}{0} \\
\stackrel{0}{\infty} \\
\infty\end{array}$ & 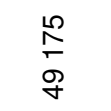 & $\begin{array}{l}\underset{\Gamma}{c} \\
\stackrel{\infty}{\infty} \\
\stackrel{\infty}{c}\end{array}$ & 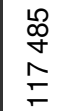 & 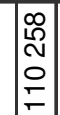 & 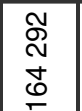 & $\begin{array}{l}\overline{0} \\
\infty \\
\infty\end{array}$ & $\begin{array}{l}\infty \\
\infty \\
\infty \\
\infty\end{array}$ \\
\hline шત્ર & & నิ & $\frac{0}{m}$ & ì & $\frac{O}{N}$ & $\stackrel{\substack{0 \\
m}}{2}$ & $\begin{array}{l}\mathscr{\infty} \\
\infty \\
\infty\end{array}$ & 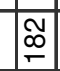 & 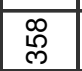 & 今े & స్ల \\
\hline fnłełs & & $\begin{array}{l}\infty \\
\infty \\
\stackrel{\infty}{\Psi} \\
\end{array}$ & $\begin{array}{l}8 \\
0 \\
\infty \\
\bar{\varpi} \\
\end{array}$ & $\sum$ & $\sum$ & $\sum_{i}$ & $\sum$ & $\sum$ & $\sum_{i}$ & $\sum_{i}$ & $\sum$ \\
\hline 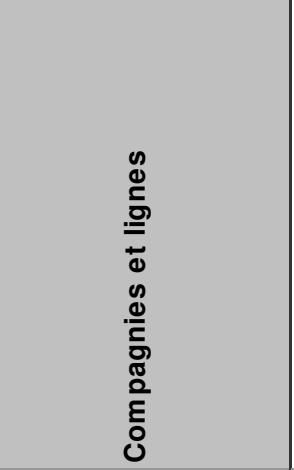 & & 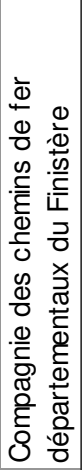 & 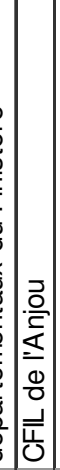 & 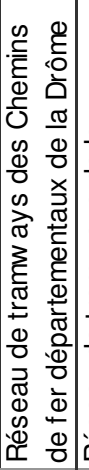 & 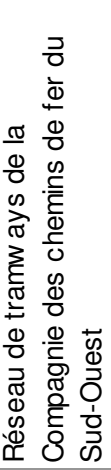 & 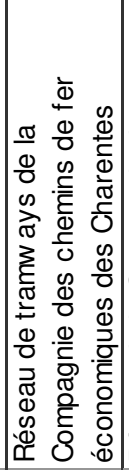 & 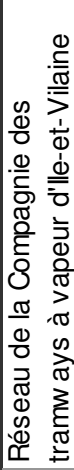 & 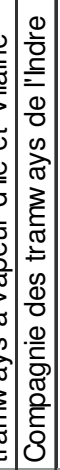 & 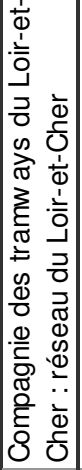 & 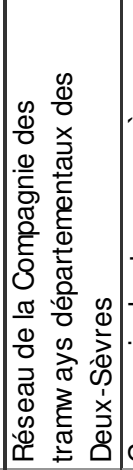 & 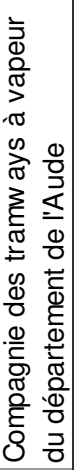 \\
\hline
\end{tabular}




\begin{tabular}{|c|c|c|c|c|c|c|c|c|c|c|c|c|c|c|c|c|c|c|}
\hline 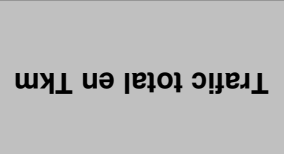 & \multirow{6}{*}{ 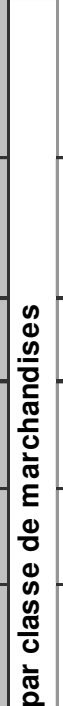 } & 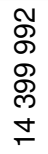 & 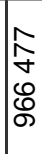 & 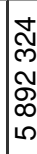 & $\begin{array}{l}10 \\
10 \\
0 \\
10 \\
\infty \\
10 \\
-\end{array}$ & $\mid \begin{array}{l}c \\
\alpha \\
b \\
0 \\
0 \\
0 \\
c \\
c\end{array}$ & b & & & $\begin{array}{l}\infty \\
\infty \\
\infty \\
\frac{\infty}{-}\end{array}$ & 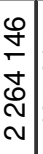 & $\begin{array}{l}\hat{n} \\
0 \\
\vdots \\
o \\
+\end{array}$ & $\begin{array}{l}\mathcal{y} \\
\dot{y} \\
\infty \\
\infty \\
q\end{array}$ & $\begin{array}{l}\mathscr{m} \\
\infty \\
\infty \\
\infty \\
m\end{array}$ & 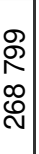 & 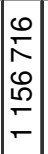 & & $\sum_{\substack{\infty \\
\frac{\infty}{2}}}^{\infty}$ \\
\hline 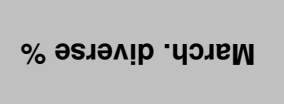 & & 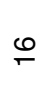 & $\sim$ & $\begin{array}{l}\infty \\
\omega \\
\end{array}$ & $\hat{\circ}$ & $=5$ & كاك & గి & $\begin{array}{l}\infty \\
\vdots \\
0 \\
0 \\
0\end{array}$ & $\begin{array}{c}m \\
0 \\
6\end{array}$ & $F^{-}$ & $\begin{array}{l}\stackrel{N}{m} \\
\stackrel{m}{n}\end{array}$ & $\begin{array}{c}N \\
N \\
\end{array}$ & $\hat{\hat{N}}$ & $\hat{a}$ & $\mid \begin{array}{l}\hat{0} \\
0^{\circ}\end{array}$ & $\stackrel{F}{E}$ & $\begin{array}{l}\frac{\pi}{0} \\
\frac{d}{d} \\
\frac{d}{1}\end{array}$ \\
\hline \% ә૧!!snquoว & & $\stackrel{\sim}{m}$ & $\hat{\stackrel{n}{ }}$ & $\bar{N}$ & $\frac{9}{-}$ & $=\frac{1}{7}$ & 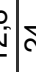 & $\mathrm{v}$ & $\vec{\infty}^{+}$ & $\begin{array}{l}\mathscr{N} \\
N^{\prime}\end{array}$ & $\left|\begin{array}{l}10 \\
10^{\circ}\end{array}\right|$ & $\begin{array}{l}0 \\
0 \\
0\end{array}$ & $\mid \begin{array}{c}\hat{m} \\
\bar{m}\end{array}$ & $\begin{array}{l}\infty \\
\stackrel{0}{\simeq}\end{array}$ & & $\infty$ & $\overline{\underline{m}}$ & एँ \\
\hline 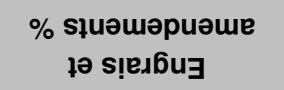 & & $\stackrel{m}{=}$ & $\stackrel{0}{\sim}$ & $\stackrel{n}{\infty}$ & $\stackrel{\infty}{i}$ & ì & 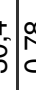 & & $\begin{array}{l}\infty \\
0 \\
0 \\
0\end{array}$ & $\stackrel{m}{\sim}$ & $\begin{array}{l}\stackrel{0}{\sim} \\
\sim\end{array}$ & $\begin{array}{l}m \\
m\end{array}$ & $\widehat{\hat{m}}$ & $\begin{array}{l}10 \\
\infty \\
\infty\end{array}$ & $\begin{array}{l}\stackrel{9}{\tilde{N}} \\
\tilde{N}\end{array}$ & $\mid \begin{array}{l}n \\
\sigma \\
\sigma\end{array}$ & $\underset{\mathscr{C}}{=}$ & $\frac{\overline{2}}{\frac{0}{\bar{N}}}$ \\
\hline 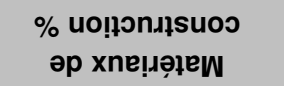 & & $\stackrel{\infty}{-}$ & $\hat{\sim}$ & 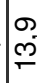 & s. & 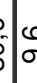 & $i^{2}$ & 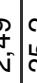 & 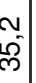 & $\begin{array}{l}m \\
\sigma^{\circ}\end{array}$ & $\bar{m}$ & 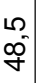 & $\begin{array}{l}\dot{\sigma}_{-} \\
\bar{\sigma}\end{array}$ & $\begin{array}{c}\sim \\
\sim \\
N^{\prime}\end{array}$ & $\begin{array}{l}\dot{\sigma} \\
\dot{\theta}\end{array}$ & ㅇ & $\begin{array}{l}\hat{N} \\
\underline{\underline{\theta}}\end{array}$ & $\mid \begin{array}{c}\sigma \\
\sigma \\
0 \\
0\end{array}$ \\
\hline 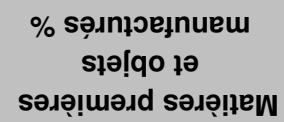 & & $\overline{\tilde{n}}$ & Ñ & it & $\dot{\sigma}$ & 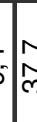 & $=17$ & & $\begin{array}{c}m \\
\tilde{n} \\
\tilde{n}\end{array}$ & $\begin{array}{l}\infty \\
\tilde{n}^{-}\end{array}$ & $\begin{array}{l}\infty \\
\tilde{N}^{-}\end{array}$ & $\begin{array}{l}\hat{m} \\
\tilde{m}^{\circ}\end{array}$ & $\begin{array}{l}\tilde{N} \\
\text { Ñ }\end{array}$ & $\begin{array}{l}0 \\
0 \\
\dot{y}\end{array}$ & $\begin{array}{l}\infty \\
15\end{array}$ & $\begin{array}{l}\nabla_{-} \\
m \\
m\end{array}$ & ले & 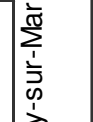 \\
\hline 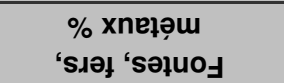 & 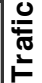 & $\underset{\sigma}{\tilde{O}}$ & 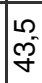 & - & 0 & $=c$ & $\frac{1}{2}$ & 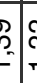 & $\begin{array}{l}m \\
m \\
-\end{array}$ & $\begin{array}{l}\bar{\sigma} \\
\dot{\sigma} \\
0\end{array}$ & $\begin{array}{l}\mathscr{8} \\
\stackrel{2}{0} \\
0\end{array}$ & $\dot{\sigma}_{0}$ & $\mathscr{O}_{0}^{\circ}$ & & $\begin{array}{l}\infty \\
0 \\
0\end{array}$ & $\begin{array}{l}0 \\
0\end{array}$ & $\begin{array}{l}\bar{n} \\
\text { n. }\end{array}$ & $\begin{array}{l}\frac{\pi}{0} \\
\frac{\pi}{0}\end{array}$ \\
\hline 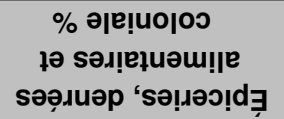 & 岌 & $\underset{\sim}{\sim}$ & O & o & $=$ & $=c$ & 5 & f. & $\begin{array}{l}2 \\
\delta \\
\delta \\
\end{array}$ & $\begin{array}{l}\infty \\
\stackrel{\infty}{0} \\
0\end{array}$ & 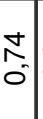 & $\begin{array}{l}\simeq \\
-\end{array}$ & $\hat{o}^{\prime}$ & & $\begin{array}{l}0 \\
0\end{array}$ & - & $\begin{array}{l}\bar{\sigma} \\
0\end{array}$ & 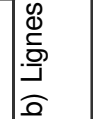 \\
\hline \% səג6!eu!n 'su!n & & $\underset{⿱ 宀}{\dot{\sigma}}$ & $\begin{array}{l}\dot{\sigma} \\
0\end{array}$ & $\mid \begin{array}{l}n \\
10 \\
10\end{array}$ & $\frac{m}{r}$ & $=c$ & $\begin{array}{l}0 \\
0 \\
0\end{array}$ & $\begin{array}{l}0 \\
0 \\
5\end{array}$ & $\begin{array}{l}8 \\
0 \\
0\end{array}$ & $\begin{array}{l}0 \\
0 \\
0 \\
0\end{array}$ & $\overline{6}$ & $\begin{array}{l}\dot{\forall} \\
\mathbf{L}^{\circ}\end{array}$ & $\begin{array}{l}0 \\
0^{-}\end{array}$ & & 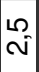 & $\mid \begin{array}{l}\bar{\alpha} \\
\text { s. }\end{array}$ & $\begin{array}{l}\text { 心 } \\
\text { m. }\end{array}$ & ¿े \\
\hline \% səu!ıe ‘'sә|еәдә઼ & סु & $\stackrel{+}{\sim}$ & $\mathbb{O}_{0}^{\infty}$ & N & $\underset{\nabla}{\mid}$ & $=$ & $\begin{array}{l}f \\
v \\
v\end{array}$ & $\overbrace{}^{\infty}$ & 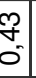 & 0 & 으 & $\begin{array}{l}0 \\
2 \\
0\end{array}$ & $\stackrel{\mathscr{O}}{F}$ & $\begin{array}{l}\stackrel{N}{0} \\
\stackrel{0}{O}\end{array}$ & $\stackrel{1}{\circ}$ & $\left|\begin{array}{l}0 \\
\stackrel{m}{m}\end{array}\right|$ & $\begin{array}{l}\infty \\
0 \\
0\end{array}$ & $\mid$ \\
\hline 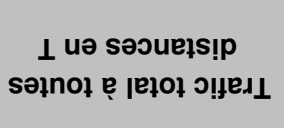 & = & $\begin{array}{l}\text { م } \\
\text { م } \\
\frac{1}{5}\end{array}$ & $\mid \begin{array}{l}\widetilde{O} \\
0 \\
0 \\
0 \\
0\end{array}$ & $\begin{array}{l}N \\
i \\
\mathscr{N} \\
\stackrel{N}{~}\end{array}$ & $\underset{N}{N}$ & $\mid \begin{array}{ll}5 \\
5 \\
15 \\
1 \\
1\end{array}$ & 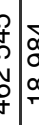 & 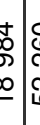 & 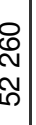 & $\begin{array}{l}\bar{\emptyset} \\
0 \\
\pm\end{array}$ & $\begin{array}{l}\text { N } \\
\text { N } \\
2 \\
N\end{array}$ & 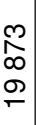 & $\begin{array}{l}\mathcal{N} \\
\text { f } \\
\text { f }\end{array}$ & $\begin{array}{l}\hat{\Omega} \\
6 \\
10\end{array}$ & 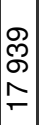 & $\mid \begin{array}{c}\stackrel{1}{N} \\
\frac{N}{N}\end{array}$ & $\frac{0}{0}$ & $\begin{array}{l}\frac{1}{0} \\
\frac{1}{\Phi} \\
\frac{0}{0} \\
\Phi\end{array}$ \\
\hline шપ્ર & & $\frac{\omega}{m}$ & $\bar{N}$ & 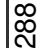 & ని & 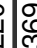 & b & 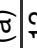 & $m$ & N & $\frac{m}{N}$ & $\stackrel{q}{q}$ & 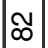 & $ㅇ$ & $\stackrel{0}{\circ}$ & $\bar{m}$ & $\begin{array}{l}0 \\
0 \\
0\end{array}$ & $\frac{\pi}{0}$ \\
\hline łnłeis & $\stackrel{2}{0}$ & $\begin{array}{l}\infty \\
\infty \\
\sum \\
\sum\end{array}$ & $\mid \begin{array}{l}8 \\
\infty \\
\frac{\infty}{z} \\
\sum\end{array}$ & $\begin{array}{l}2 \\
\infty \\
\infty \\
w \\
w\end{array}$ & $\begin{array}{l}8 \\
\infty \\
\infty \\
w \\
\end{array}$ & 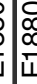 & 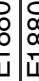 & & $\begin{array}{c}\infty \\
\infty \\
\infty \\
\end{array}$ & $\begin{array}{c}8 \\
\infty \\
\infty \\
\end{array}$ & $\begin{array}{c}8 \\
\infty \\
\infty \\
\end{array}$ & $\begin{array}{l}0 \\
\infty \\
\infty \\
\frac{w}{w}\end{array}$ & $\begin{array}{l}\infty \\
\infty \\
\infty \\
\amalg \\
\end{array}$ & $\begin{array}{l}\infty \\
\infty \\
\infty \\
\frac{\omega}{\omega}\end{array}$ & $\sum$ & $\sum$ & & $\begin{array}{l}\bar{\partial} \\
\frac{\Phi}{\omega}\end{array}$ \\
\hline 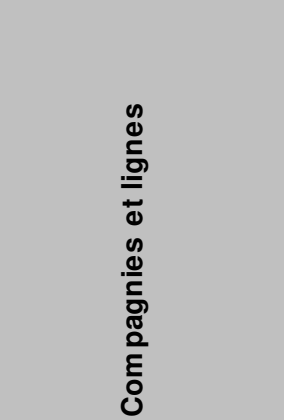 & 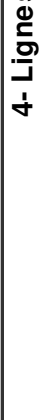 & 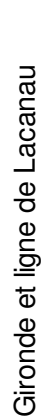 & 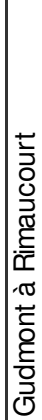 & $\frac{\overline{\underline{\underline{d}}}}{\overline{\underline{\alpha}}}$ & $\frac{\bar{\Phi}}{\bar{U}}$ & $=\begin{array}{l}\varepsilon \\
\varepsilon \\
\varepsilon \\
\varepsilon \\
c\end{array}$ & 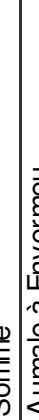 & 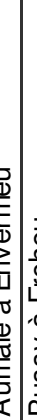 & 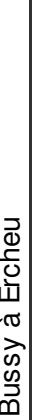 & 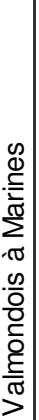 & $\sum_{\frac{0}{2}}^{\frac{0}{2}}$ & 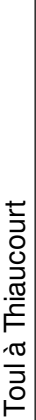 & 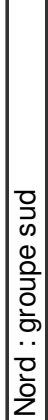 & 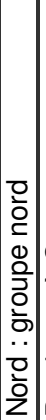 & 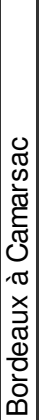 & 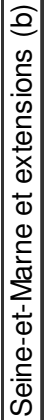 & 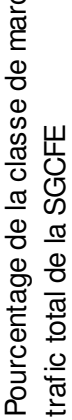 & 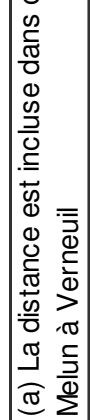 \\
\hline
\end{tabular}

